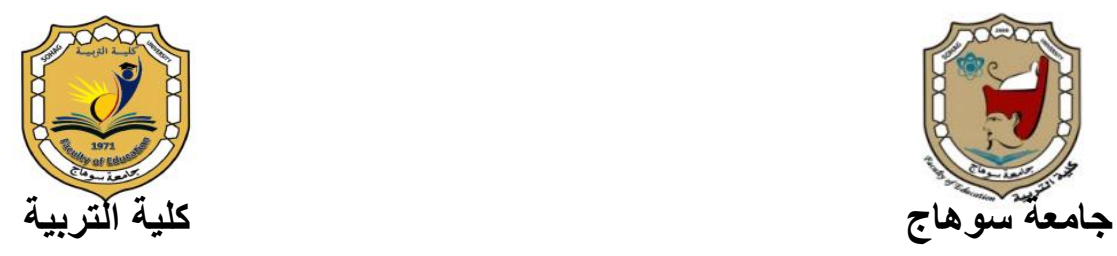

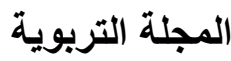

فعالية استخدام مدخل التعلم القائم على التكاهل بين

المتوى واللغة (CLIL) في تنميسة بعض كفايات تدريس العلوم بالاغة الإنمليزية وخفض قلق التدريس لدى الطلاب المعلمين

\title{
| (اعداد
}

$$
\begin{aligned}
& \text { د/ وفاء محمد معوض عبد العال } \\
& \text { مدرس المناهج وطرق تدريس العلوم } \\
& \text { كلية التربية- جامعة بني سويف }
\end{aligned}
$$

$$
\text { تاريخ الاستلام : rا يونيو اץ+rم }
$$

DOI: 10.12816/EDUSOHAG.2021. 


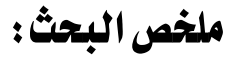

يمثل مدخل التعلم القائم على التكامل بين المحتوى واللغة (CLIL) أحد أكثر الطرق شيوعًا لإعداد الخريجين لمواجهة الحياة العملية، وسوق العمل فى المستقبل. ولقد انتثر استخدام هذا

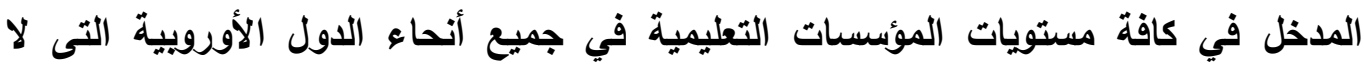
تتحدث الإنجليزية، وكنلك فى دول شرق أسيا، ويعض البلان العبان العربية؛ بغية تحقيق الأهداف

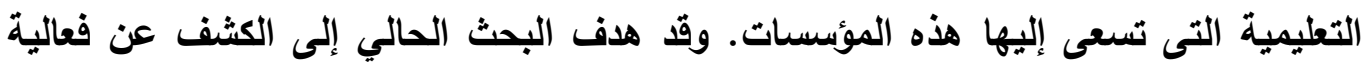

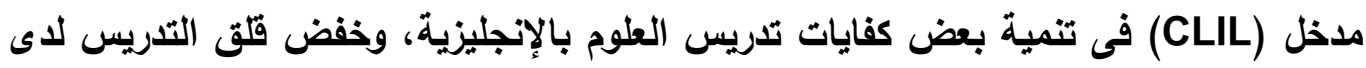

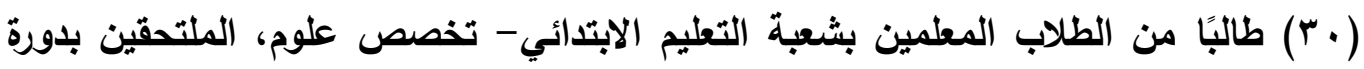
تدريس العلوم بالإنجليزية، والتى تعقد بكلية التربية جامعة بني سويف. وشملت أدوات الطيات البحث

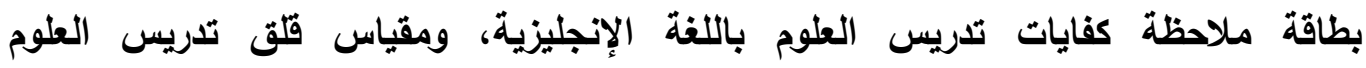

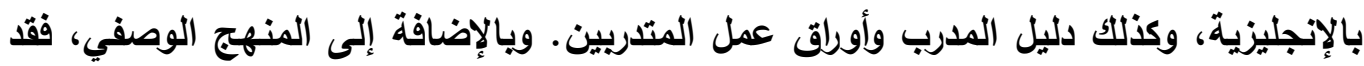
اتبع البحث الحالي المنهج شبه التجريبي، والتصميم التجريبي ذى المجموعة الواحدة. وقد أوضحت المعالجة الإحصائية التى شملت المتوسطات الحسابية، والنسب المئوية، والانحراف المعياري، واختبار قيمة (ت)، توافر كفايات تدريس الطوم باللغة الإنجليزية بدرجة

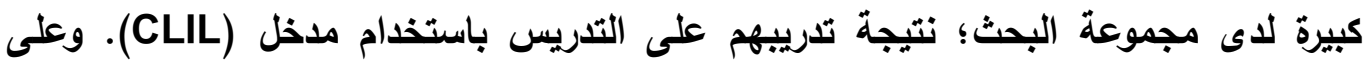

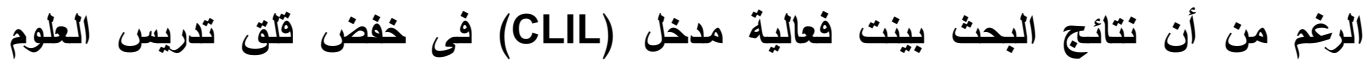
بالإنجليزية لاى مجموعة البحث، فقد كثفت المعالجة الإحصائية باستخام معامل الارتباط لبيرسون، عن وجود علاقة ارتباط موجبة ضعيفة بين كفايات تدريس العوم بالإنجليزية وقلق الإنق

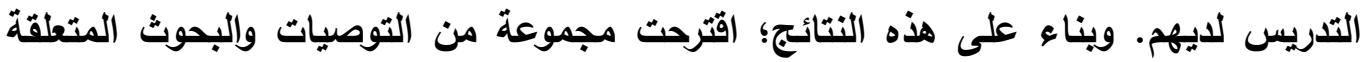
بتدريس العلوم بالإنجليزية، وإعداد مطلمي العلوم لهذا الغرض.

الكلمات المفتاحية: مدخل التطلم القائم على التكامل بين المحتوى واللغة (CLIL)، إعداد

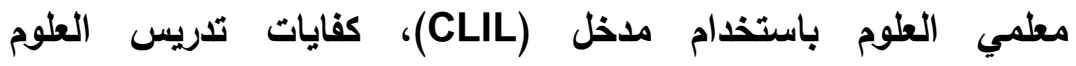
بالإنجليزية، قلق التدريس، قلق تدريس العوم بالإنجليزية. 


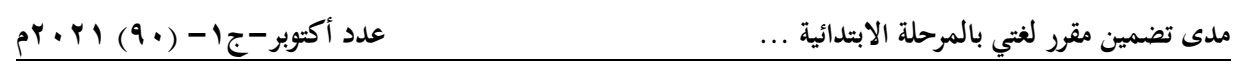

\title{
The Effectiveness of Using Content and Language Integrated
}

Learning (CLIL) Approach in Developing Student Teachers'

Competencies of Teaching Science in English and Reducing their Teaching Anxiety

\begin{abstract}
:
Content and Language Integrated Learning (CLIL) represents one of the most common ways of preparing graduates for future practical life and the labour market. CLIL has spread in all levels of educational institutions throughout European countries that do not speak English, as well as in East Asian countries, and some Arab countries in order to achieve the educational goals pursued by these institutions. The current research aimed at revealing the effectiveness of CLIL approach in developing student teachers' competencies of teaching science in English, and reducing their teaching anxiety. The research group consisted of (30) student teachers in the primary education division, who enrolled in a training course called "teaching science in English" run at the Faculty of Education, Beni-Suef University. The research used the descriptive and quasi experimental methodology with a pre- and post-test treatment group. Data were collected using an observation schedule of teaching science in English and a teaching anxiety scale. The statistical treatment, which included measuring mean, standard deviation, percentage, and T- test, showed development of student teachers' competencies of teaching science in English. Although the research results showed the effectiveness of (CLIL) approach in reducing the student teachers' anxiety about teaching science in English, the statistical treatment using Pearson correlation coefficient revealed a weak positive correlation between their competencies of teaching science in English and teaching anxiety. Based on the research findings some recommendations related to preparing science teachers for teaching in English were suggested.
\end{abstract}

Keywords: CLIL, CLIL teacher education, teaching science in English, competencies of teaching science in English, teaching anxiety, anxiety about teaching science in English. 


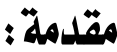

أصبحت الحاجة إلى استخدام اللغة الإنجليزية فى المقررات غير اللغوية، وإتقانها أمرًا لا

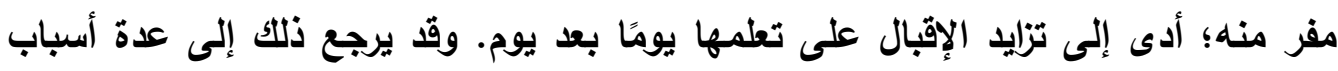

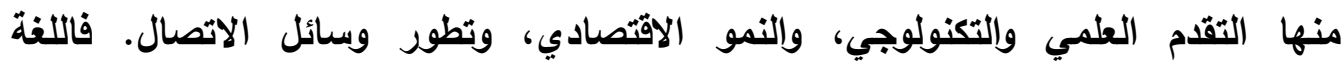
الإنجليزية هى لغة المجتمع العلمي الاولي، وكذلك لغة التكنولوجيا والوسائط الفائقة،

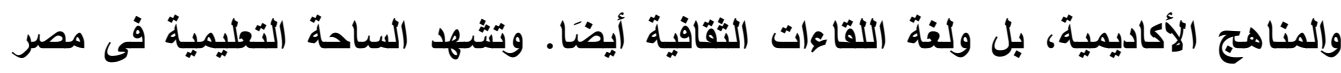

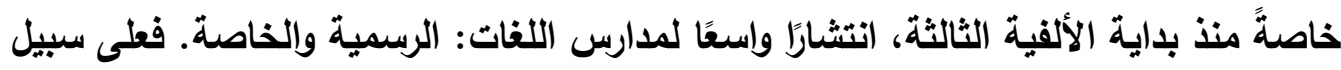

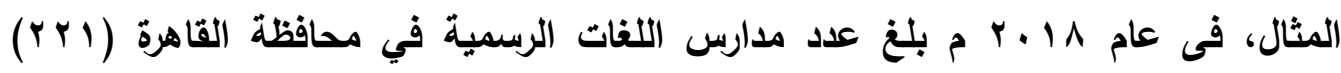

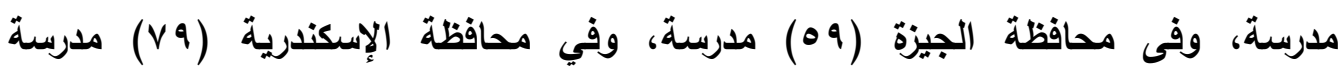
(Samir, 2018). هذا ويبلغ عدد مدارس المستقبل التجريبية وحدها في محافظة القاهرة

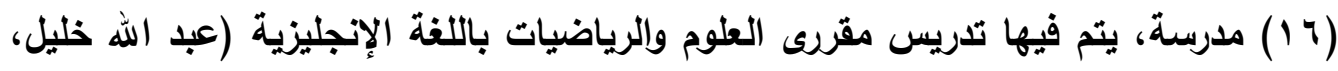

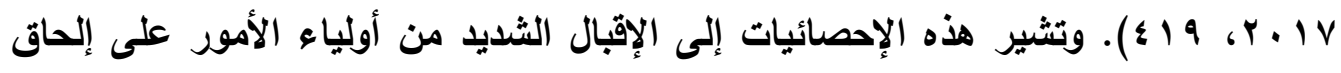

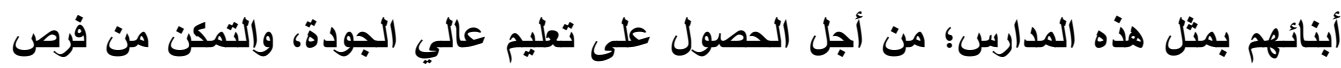
عمل أفضل فى المستقبل. وقد أصبح استخدام اللغة الإنجليزية فى تدريس وتعلم المواد الدراسية كالطوم والرياضيات

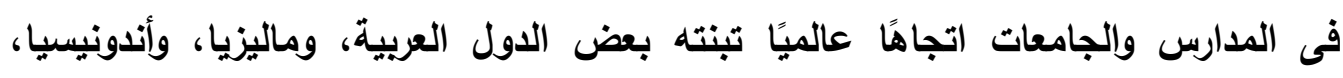

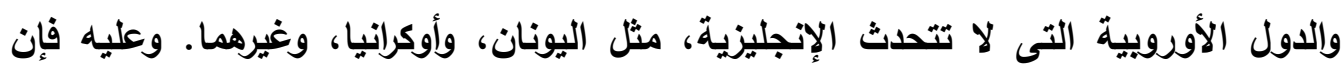

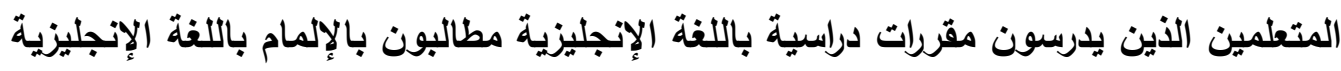

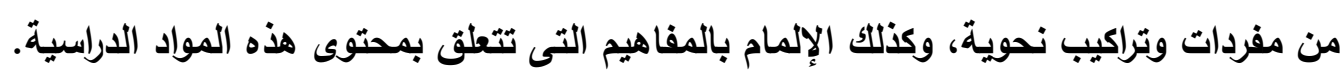

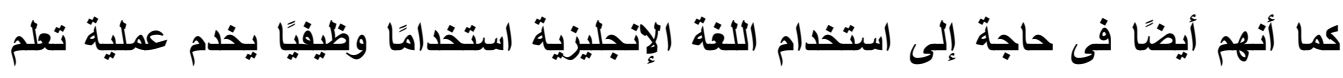

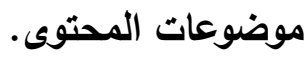

وتتضمن مناهج العلوم العديد من المصطلحات والمفاهيم العلمية التى قد تعنى للتلاميذ

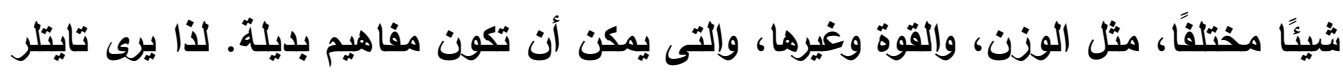

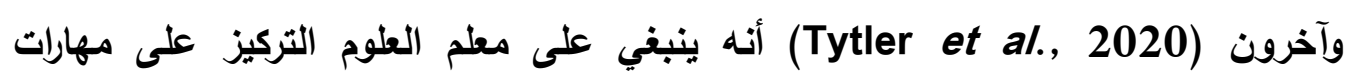

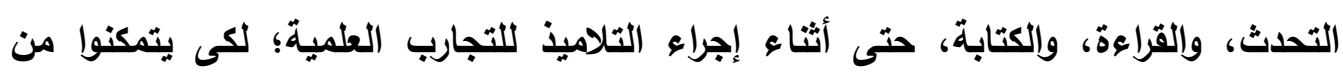


استخدام لغة العلم بطريقة صحيحة، وتنمو لايهم أيضًا القدرة على تذوق جمال لغة العلم ودقته.

فعلى سبيل المثال يحتاج التلميذ فى المرحلة الابتدائية بمدارس اللغات أن يتعرف مفهوم البناء الضوئي باللفة الإنجليزية، والعناصر التى يحتاج إليها النبات لكي يقوم بهذه العملية.

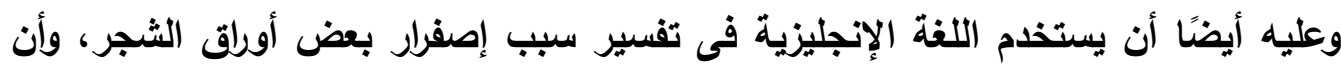
يستنتج أهمية عملية البناء الضوئي. ويالتالي فإن معلم العلوم الذي يقوم بالتدريس فى هذانه المدارس ينبغي أن تتوافر لايه المهارات اللغوية التى تمكنه من ريط اللغة الإنجليزية بالمحتوى العلمي، وتوظيفها بطريقة فعالة فى فصول العلوم. وفى بعض الجامعات يارس الطلاب المعلمون تخصص علوم المقررات العلمية باللغة الإنجليزية؛ مما قد يدعم لايهم تعلم هذه اللغة، ويعزز لديهم المفاهيم العلمية باللغة

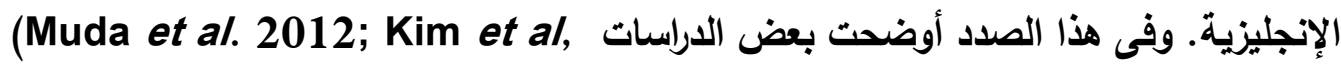
(2018 أن تدريس العلوم والرياضيات باللغة الإنجليزية للطلاب المعلمين ساعد فى إتقانهم أساسيات اللغة الإنجليزية، وتنمية مهارات التواصل بها، كما حسن لايهم مهارات شرح المفاهيم العلمية باللغة الإنجليزية.

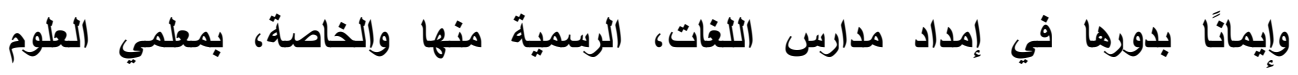
والرياضيات الذين يمتلكون كفايات تدريس مواد التخصص باللغة الإنجليزية؛ عمدت كليات التربية فى مصر إلى تقديم برامج خاصة، ودورات تدريبية تهدف إلى تحقيق هذا الغرض.

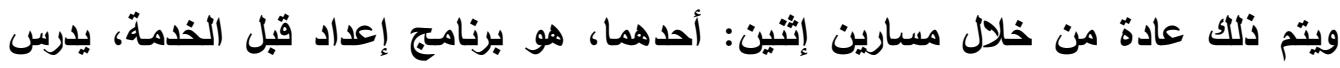
الطالب خلاله أثناء مرحلة البكالوريوس مقررات تربوية، مثل طرق تدريس العلوم أو الرياضيات باللغة الإنجليزية، كما يتم تدريبه على تدريس مواد التخصص فى مدارس اللغات

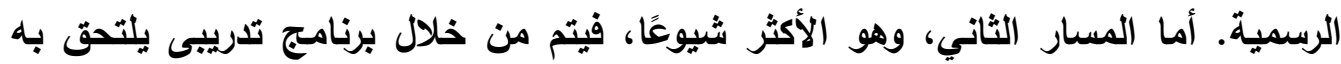
الطلاب المعلمون، والمعلمون قبل الخدمة وأثنائها. وتختلف هذه البرامج التدريبية من جامعة إلى أخرى، من حيث المحتوى، الفترة الزمنية، وآلية التنفيذ، بل والقائمين على التدريب فيها

ولا شك أن المعلمين فى الدول التى لا تتحدث الإنجليزية، يواجهون تحديات عند تدريس مواد تخصصهم باللغة الإنجليزية؛ لأنها تمثل لغة أجنبية لهم. ومن أهم هذه التحديات قدرة 
المعلمين على عرض الدروس داخل فصولهم باللغة الإنجليزية، والتفاعل مع الطلاب مستخدمين هذه اللغة، بل ودعم استخدام اللغة الإنجليزية فى تفاعل الطلاب مع بعضهم.

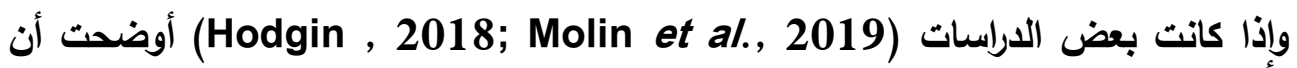
معلمي العلوم الذين يستخدمون لغتهم الأصلية فى التدريس يعانون من درجات مرتفعة من

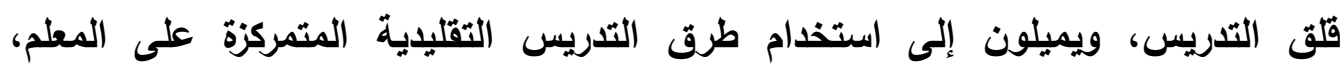
ويتجنبون استخدام طرق التدريس التى تدعم التعلم النشط، بل ويتسببون فى رفع القلق لاى طلابهم أيضًا، فما حال معلى العلوم الذين سيقومون بالتدريس باللغة الإنجليزية التى تمثل

لغة أجنبية لهم ولطلابهم؟ لا شك أن معلمى العلوم المقبلين على التدريس باللغة الإنجليزية، يواجهوا تحديات كبيرة إذا كانت الإنجليزية ليست لغتهم الأم. وتزداد هذه التحديات كلما ضعفت مهارات اللغة

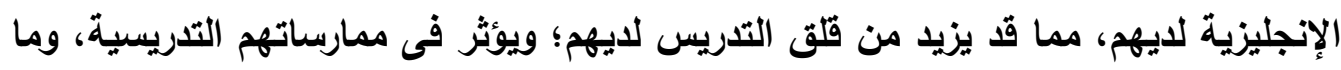
يرتبط بها من إعداد الاروس، وإدراة الصف، وطريقة تدريسهم، والمحتوى العلمى الأى يقدموه للتلاميذ، وكذلك طرق التقويم؛ فينجم عن ذلك عدم تحقيق كافة الأهداف التعليمية المرجوة. فقد أوضحت بعض الدراسات (Palmer et al., 2014; Othman et al., 2020) أن العديد من معلمي العلوم الذين استخدموا الإنجليزية فى التريس بدلاً من لغتهم الأصلية، لجأوا إلى استخدام لغتهم الأم في عرض المحتوى الاراسي، وإلى تقليل استخدام اللغة الإنجليزية، بسبب قلقهم من التدريس بها. وفى هذا الصدد يؤكد كوستاليدو وجريفا (Chostelidou \& Griva, 2014) أن برامج إعداد معلمى العلوم والرياضيات باللغة الإنجليزية يجب أن تركز على احتياجات المعلمين المرتبطة بما سيقومون به بعد تخرجهم، بحيث يقوم بتدريبهم متخصصون في العلوم

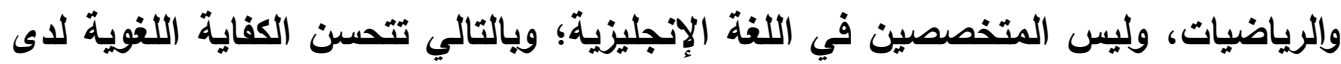

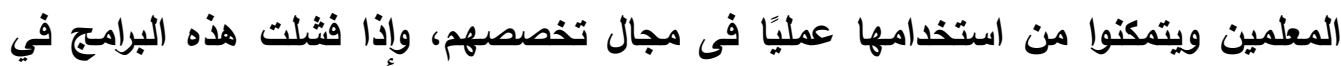
ذلك، فينبغي العودة إلى تدريس العلوم والرياضيات باللغة الأم. ونظرًا لأن المحتوى يرتبط باللفة ارتباطًا وثيقًا، فإن إتقان محتوى المادة الدراسية يتطلب الامدي

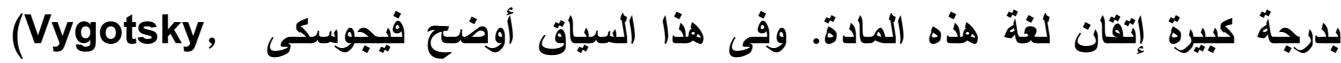
(1987 أن التفكير يتضمن استخدام الكلمات والمفاهيم، وأن الكلام هو أداة لتنمية التفكير. 
ويالتالي، فإن تعلم العلوم يتضمن أيضًا تخصيص طرق للتحدث بطريقة علمية، أى تعلم لغة العلماء، والتى تنطوى على استخدام الحقائق، والمفاهيم العلمية، والدقة فى التعبير، على

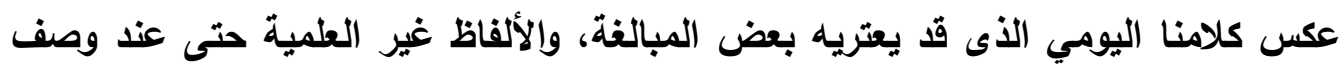
ظاهرة كونية تحدث من حولنا. ويالتالي لا بد لمعلمي العلوم المقبلين على التدريس باللغة الإنجليزية أن يكتسبوا فى هن

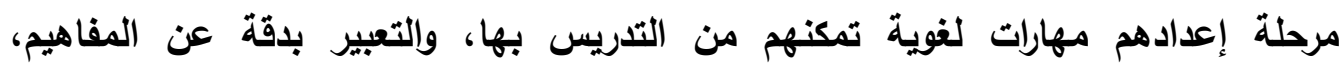
والعلاقات، والمبادئ العلمية التى يشملها كل درس. إنهم فى حاجة إلى الوعى بإمكانيات اللغة الإنجليزية لايهم، وطرق تنميها، ومداخل تكييف كل من المحتوى، وطرق التدريس مع اللغة الإنجليزية؛ لكي يساعدوا الطلاب على تعلم هذا المحتوى دون شعورهم بالقلق من دراسة لهنة العلوم باللغة الإنجليزية. إن هؤلاء المعلمين يحتاجوا إلى التدريب على تدريس العلوم

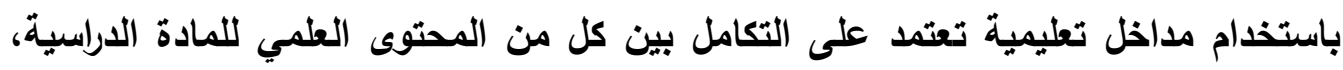
واللغة الإنجليزية، بحيث تتيح لهم فرصًا للتعلم النشط، يتم من خلالها تنمية الأفكار وتبادلها؛ والتعبير عنها بطرق تسهم فى إتقان كل من اللغة الإنجليزية، والمحتوى العلمي على حد سواء، وتقلل من قلق التدريس لديهم، وتمنحهم الثقة فى قدرتهم على التدريس باللغة الإنجليزية.

هذا وتسهم استراتيجيات التعلم الاجتماعية، وما وراء المعرفة فى زيادة ثقة المعلم فى

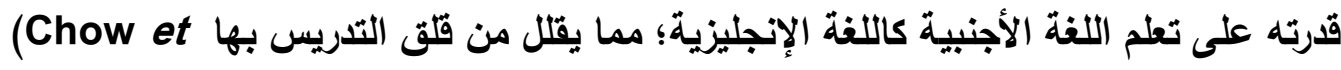
(al., 2018. ومن هنا جاهت فكرة مدخل التعلم القائم على التكامل بين المحتوى واللغة الإنجليزية (CLIL)، الذى يهدف إلى تنمية كل من المحتوى العلمي، ومهارات اللغة الإنجليزية لاى المعلم. وخلال مدخل (CLIL)، يتم عرض موضوعات المادة الاراسية المقررة باستخدام اللغة

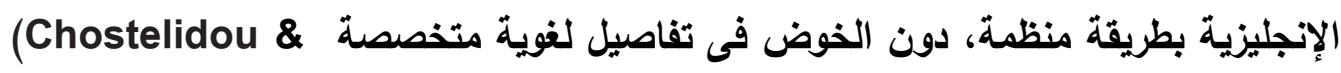
Griva, 2014; Lo et al., 2018). لمحتوى الموضوع الاراسي، وذلك من خلال توفير فرص لنمو وتطوير المهارات اللغوية أثناء

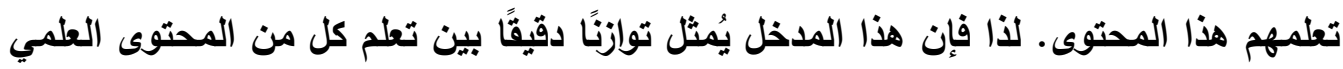
واللغة الإنجليزية؛ حيث تؤدي أنشطة القراعة والكتابة باللغة الإنجليزية إلى نمو المعرفة 
Satılmış et العلمية، كما أنها تحسن أيضًا مهارات اللغة مثل: القراعة والفهم القرائي لديهم .(al., 2015; Jameau \& Henaff, 2018)

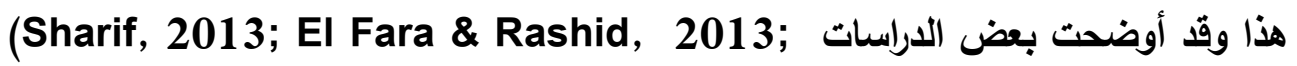
Alcaraz-Mármol, 2018) معلى العلوم أثناء الخدمة، أن المعلمين الذين لم يتم تدريبهم على مدخل (CLIL) لايهم قصور فى استخدام اللغة الإنجليزية داخل الفصول، ويعتمدوا بلرجة كبيرة على لغتهم الأم

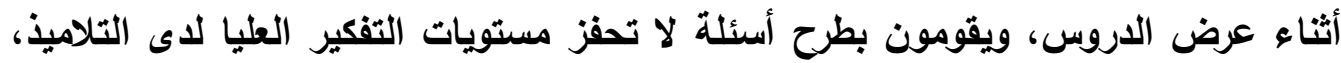
بينما يقوم معلمو العلوم الأين تم تدريبهم على تدريس العلوم بهذا المدخل، يقوموا باستخدام

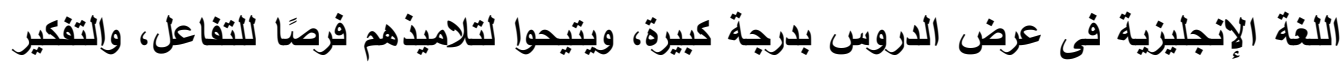
فيما يتعلموه. ويينت دراسة لو (Lo, 2020) فى هونج كونج أن ورش العمل التدريبية القائمة على مدخل (CLIL)، والتى عقدت لتريب معلمى المرحلة الثانوية ذوى تخصصات متباينة، ويعملون بمدارس مختلفة، أسهمت فى تنمية الوعى اللغوى لايهرم، وساعدتهم فى تطبيقه بنجاح داخل فصولهم. كما أشارت نتائج الدراسات أن استخدام المعلمين لهذا المدائل قد ساعد فى رفع مستوى التحصيل فى مادتى العلوم والرياضيات فى المدارس الابتائية العليا فى بولندا (Agnieszka \& Foryś, 2017)، وزاد من دافعية الطلاب نحو التعلم بالمدارس في مئس الابتدائية والثانوية فى إسبانيا (Navarro-Pablo \& Garcia-Jimenez, 2018)، كما أسهم فى خفض درجة القلق من دراسة مقرر البيولوجي باللغة الإنجليزية كلغة أجنبية،

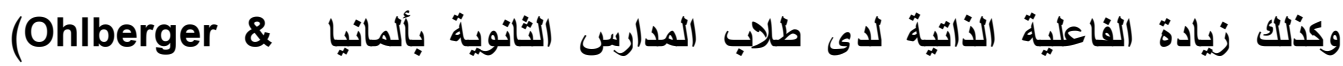

Wegner, 2019

ويعد أن بينت الاراسات (Fitzpatrick, 2018; Huang, 2020) فعالية مدخل (CLIL)

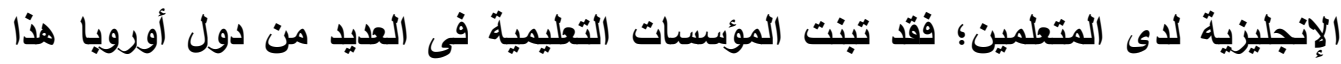
المدخل التعليمى بصورة أساسية من مرحلة ما قبل المدرسة إلى المستوى الجامعي؛ من أجل

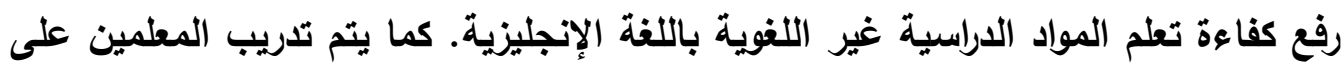

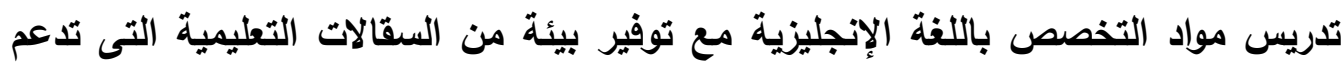

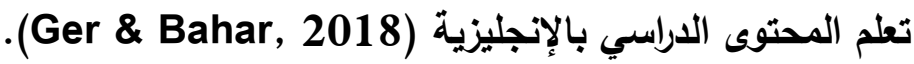


ونظرًا للاور الذي يلعبه تعلم اللغة الإنجليزية في بناء الهوية الأورويبة، والتكامل

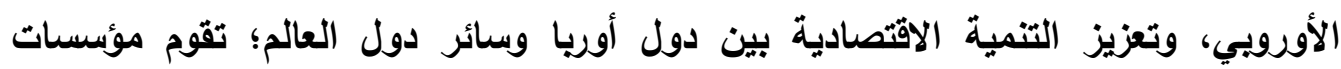

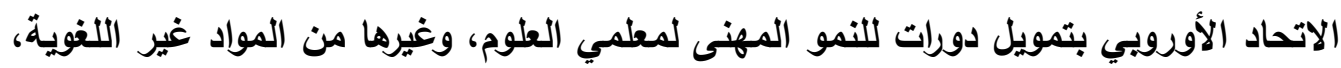
تعقدها مؤسسات تعليمية متخصصة، تنتشر فى دول أورويا مثل المملكة المتحدة وأيرلندا؛ والدانمارك، وغيرها؛ بهدف تدريب هؤلاء المعلمين باستخدام مدخل (CLIL)؛ لتنمية كفايات

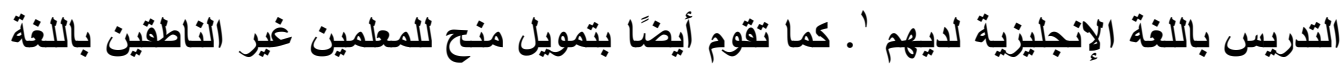

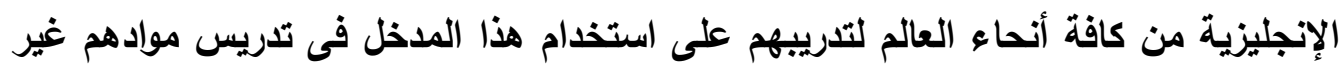

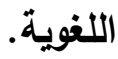
وعلى الصعيد العربي، فإن برامج إعداد المعلمين قبل الخدمة فى جامعات الإمارات العربية

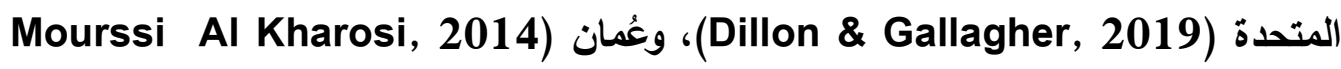
\&)، وغيرها، من دول الشرق الأوسط، وإفريقيا قد تبنت مدخل (CLIL) في تدريب معلمي العلوم والرياضيات قبل الخدمة، كما تم توظيفه بمراحل التعليم قبل الجامعى بهذه الدول أيضًا

(Nikolić, 2017)

وتقام كلية التربية بجامعة بنى سويف برنامجًا تدريبيًا لمدة ثلاثة شهور يهاف إلى إعداد معلمى العلوم قبّل الخدمة للتدريس بمدارس اللغات. ويتم تقديمه في ثلاثة أطوار: الطور الأول ويختص بإدارة الفصل باللغة الإنجليزية، ويقدم فى أريع جلسات، حيث يقوم أحدات

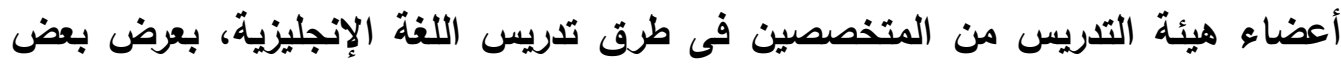

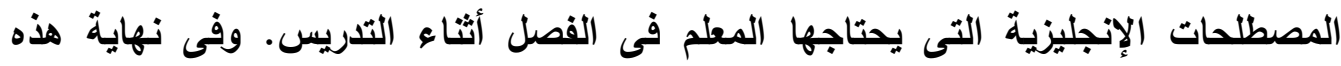

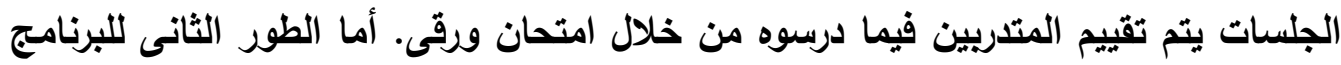

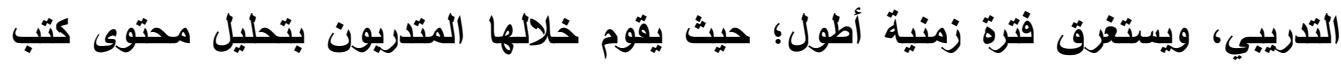
العلوم للفصل الداسي الثانى والمقررة على تلاميذ كل من المرحلة الابتدائية والإعدادية فى فئي مدارس اللغات الرسمية، ويستخرجون ما تحويه من مفاهيم علمية، ومبادئ، وقوانين،

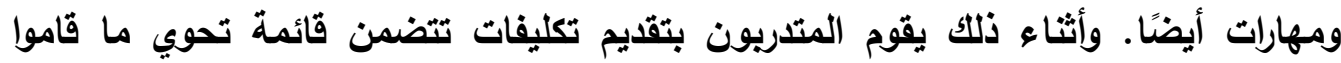

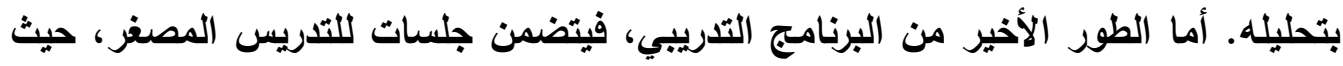

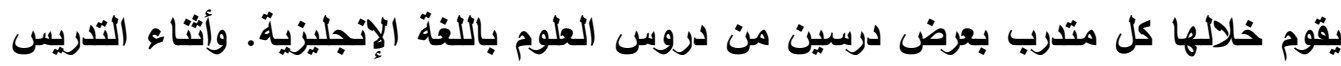


المصغر يقوم المدرب والمتدريون بتقييم من يقوم بعرض الدرس، وعمل تغذية راجعة له. وتتم

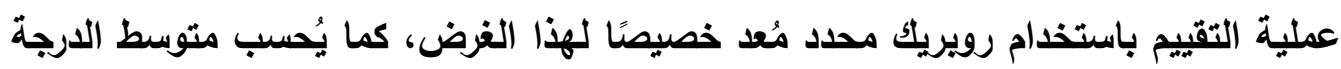
التى يحصل عليها فى المرتين اللتين قام خلالها بالتدريس. أما التقييم النهائي للمتدربين، فيتم من خلال امتحان ورقى، يتضمن أسئلة تتعلق بالمحتوى العلمي، ومهارات تدريس العلوم، وكذلك تصميم خطة لأحد دروس العلوم بالإنجليزية. وفى ضوء أهداف هذا البرنامج التدريبي؛ يتوقع أن يمتلك المتدريون العديد من كفايات

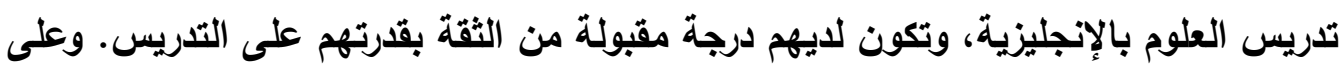
الجانب الآخر، فإن قصور هذا البرنامج؛ قد يتسبب فى تلني كفايات تدريس العلوم بالإنجليزية لدى المتدربين الذين يتم إعدادهم لهذا الغرض، وكذلك ضعف ثقتهم فى قدرتهم

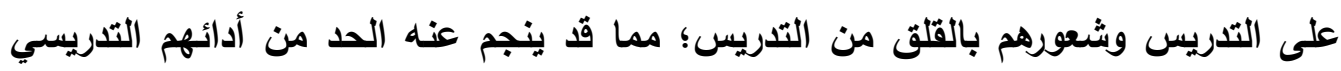
عند التحاقهم بمدارس اللغات. فقد خلصت بعض الدراسات (مثل: Ekşi \&Yakışık, 2016; Ohlberger \& Wegner, 2019 بلغة أجنبية، أدى إلى شعور الطلاب المعلمين بقلق التدريس، وشعورهم بالإحباط، وفشلهم

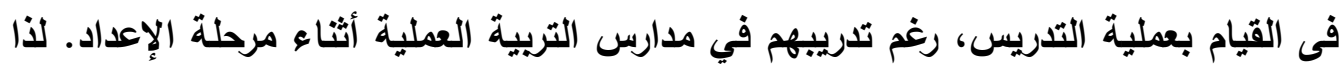
فمن المهم تقييم الوضع الحالى لبرامج إعداد معلمي العلوم باللغة الإنجليزية، وتبني مداخل تعليمية تركز على تنمية كفايات تدريس العلوم بالإنجليزية لاى الملتحقين بهذه البرامج، وهو العهو ما يسعى إليه البحث الحالي.

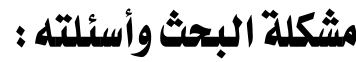

من خلال عمل الباحثة فى تدريب معلمي العلوم على التدريس باللغة الإنجليزية؛ لاحظت ضعف قدرتهم على عرض دروس العلوم أثناء جلسات التدريس المصغر الأى يجب أن يقوم به المتدريون فى نهاية البرنامج. فعلى سبيل المثال عندما يُكلف المتدريون بعرض درس علوم باللغة الإنجليزية أمام زملائهم، كثيرًا ما يظهر لايهم أخطاء لغوية فى عناصر الارس لفرل

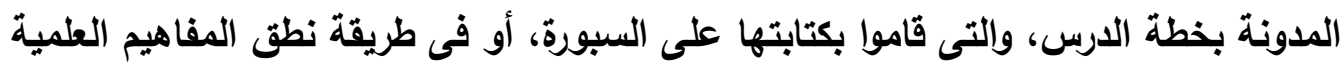
بالإنجليزية. هذا بالإضافة إلى ما يُظهره المتدريون من قلق واضح بثأن حضورهم التدريس المصغر، حيث يعتذر بعضهم عن الشرح، ويتغيب البعض الآخر عن الحضور. كما تبدو بعض علامات القلق أيضًا على من يقوم منهم بعرض دروس العلوم باللغة الإنجليزية؛ حيث 
ترتعش أيديهم، وترتجف أصواتهم، ويتلعثم بعضهم أثناء الكلام، ويتوقف آخرون لبعض الوقت أثناء عرض الدرس عن الثرح بطريقة ملحوظة. وأحيانًا ما يغمض المتدرب عينيه لفترات

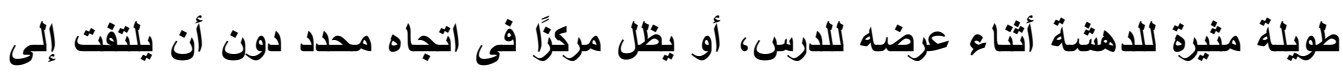
بقية زملائه؛ مما ينتج عنه ضعف واضح فى التواصل، والتفاعل اللفظى بينه وبينهم. كما

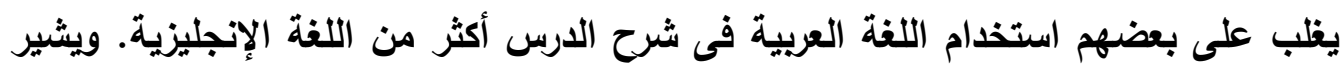

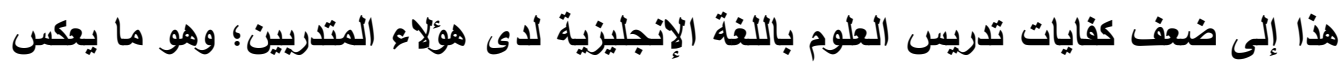
قصورًا واضحًا فى البرنامج التدريبي المقدم لهم. ونظرًا لتكرار حدوث ذلك مع المتدربين فى هذا البرنامج، قامت الباحثة فى نهاية إحدى

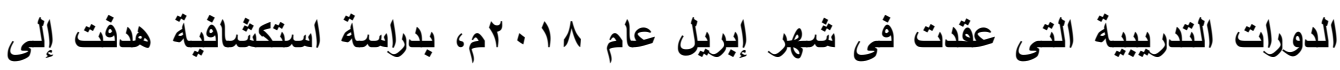
التعرف على تصورات المتدربين لاستعدادهم لتدريس العلوم باللغة الإنجليزية. وشملت الدراسة

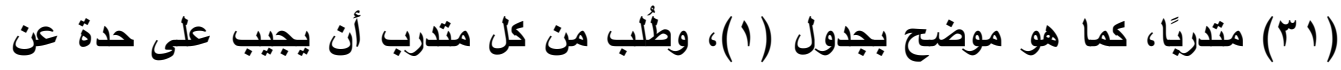

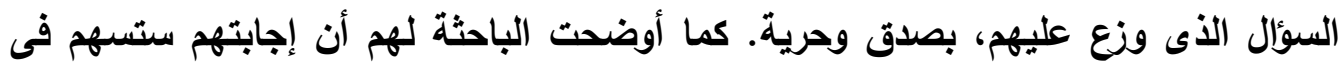
تقييم البرنامج التدريبي الذى يعقد بالكلية.

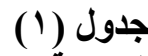

مجموعة الدراسة الاستكشافية (1)

\begin{tabular}{|c|c|c|c|}
\hline العدد الكلي & \multicolumn{2}{|c|}{ الجنس } & \multirow[t]{2}{*}{ الشعبة } \\
\hline \multirow[t]{5}{*}{ rl } & إناث & ذكور & \\
\hline & $r$ & 1 & فيزياء \\
\hline & 7 & ---- & كيمياء \\
\hline & 0 & ---- & بيولوجي \\
\hline & $1 \varepsilon$ & $r$ & تعليم ابتائي- تخصص \\
\hline
\end{tabular}

وقد نص السؤال الاستكشافي على: "هل أنت مستعد لتدريس أحد دروس العلوم باللغة الإنجليزية للتلاميذ فى إحدى المدارس الاس

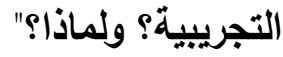

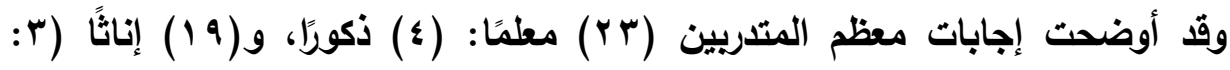
بيولجي، 1: فيزياء، و ؛: كيمياء، و 11: علوم شعبة التعليم الابتدائي) أنهم غير مستعدين

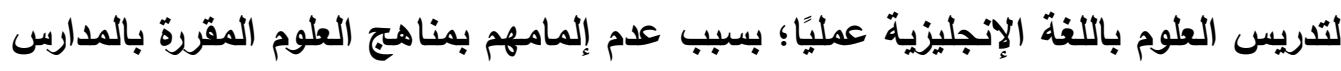

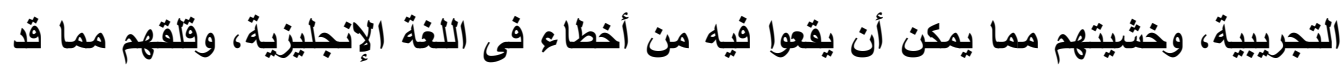


يواجهونه من سخرية التلاميذ، أو زعزعة شخصياتهم أمامهم، وشعورهم بالحاجة إلى مزيد

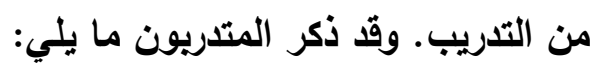

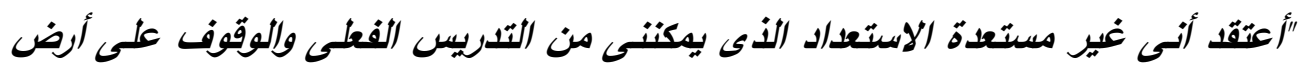

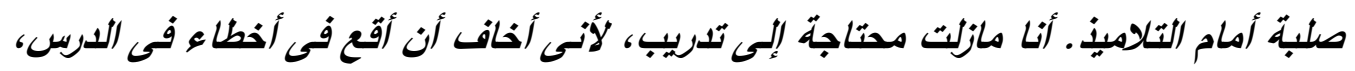

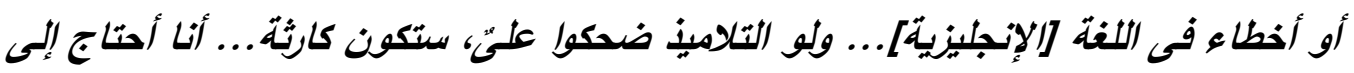

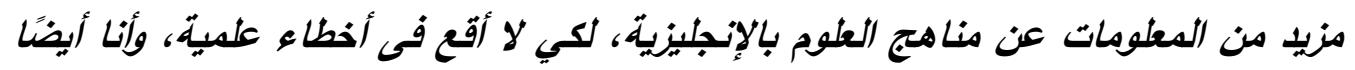

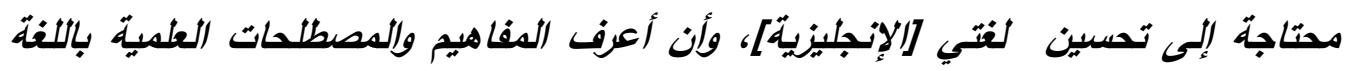

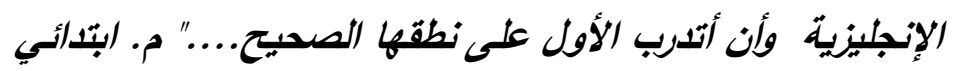

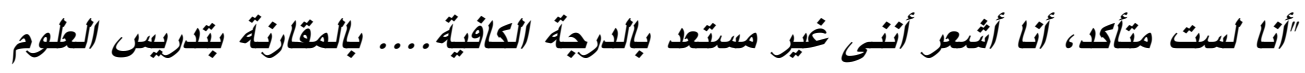

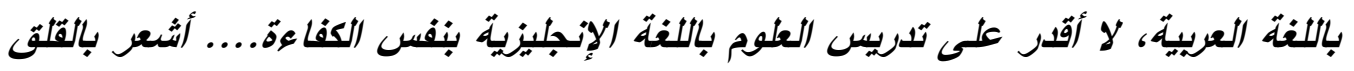

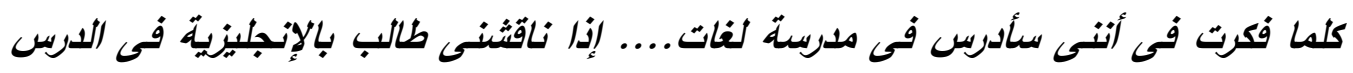

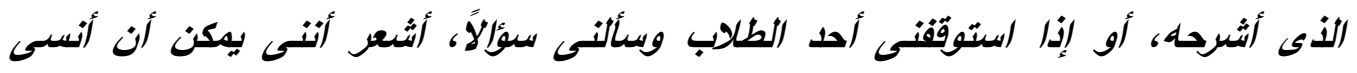

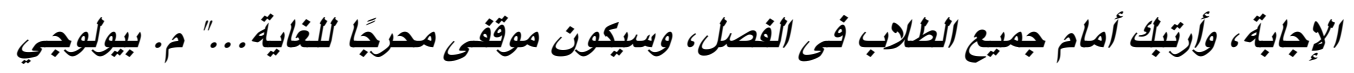
وتوضح نتيجة هذه الدراسة الاستكثافية عدم استعداد المتربين لتدريس العلوم باللغة

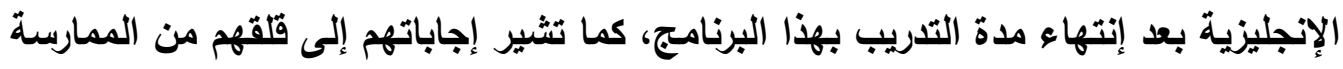
الفعلية للتدريس فى المدارس التجريبية للغات. وعلى الرغم من اهتمام الباحثين بتنمية كفايات التدريس وخفض مستويات قلق التدريس

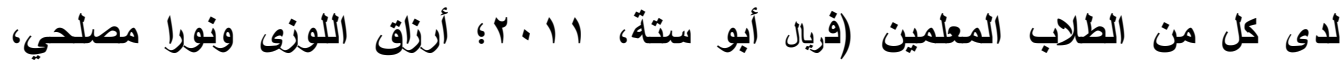

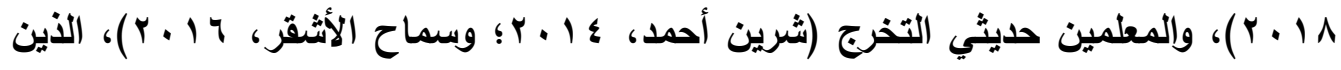
يقومون بتدريس مواد التخصص باللغة العربية، إلا أن معلمي العلوم الذين يتم إعدادهم

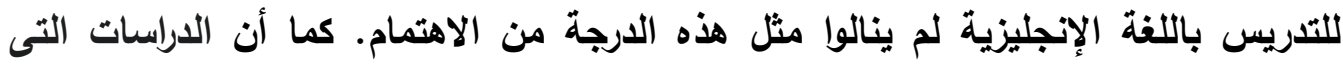

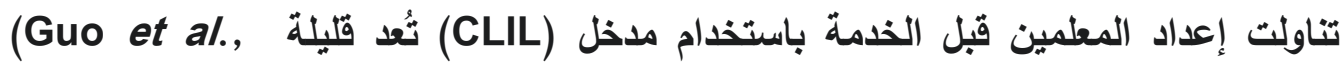

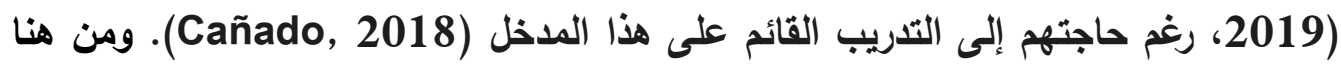
كان اتجاه البحث الحالى إلى استخدام مدخل (CLIL) فى تدريب معلمي العلوم على التدريس باللغة الإنجليزية. ومن ثم يمكن صياغة مشكلة البحث في التساؤل الرئيس التالي: 
ما فعالية استخدام مدخل التعلم القائم على التكامل بين المحتوى واللغة (CLIL) في تنمية بعض كفايات تدريس العلوم باللغة الإنجليزية وخفض قلق التدريس لاى الطلاب المعلمين؟ ويتفرع من هذا السؤال الرئيس أسئلة البحث التالية:

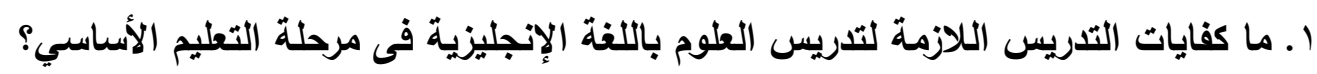
r. ما درجة توافر كفايات تدريس العلوم باللغة الإنجليزية لاى مجموعة البحث قبل تدريبهم

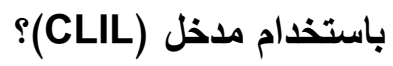
r. ما مستوى قلق تدريس العلوم باللغة الإنجليزية لاى مجموعة البحث قبل تدريبهم

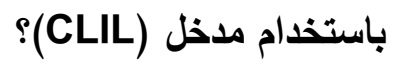
ع. ما درجة توافر كفايات تدريس العلوم باللغة الإنجليزية لدى مجموعة البحث بعد تدريبهم

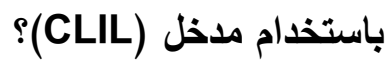
ه. ما فعالية استخدام مدخل (CLIL) فى تنمية بعض كفايات تدريس العلوم باللغة الإنجليزية لاى مجموعة البحث؟ 7. ما مستوى قلق تدريس العلوم باللغة الإنجليزية لدى مجموعة البحث بعد تلريبهم

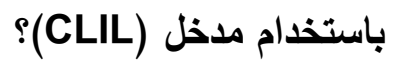
V. ما فعالية استخدام مدخل (CLIL) فى خفض قلق تدريس العلوم باللغة الإنجليزية لاى مجموعة البحث؟ مابه ^. ما العلاقة بين كفايات تدريس العلوم باللغة الإتجليزية ومستوى قلق التدريس لاى مجموعة البحث؟ م المبن

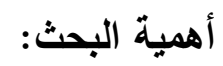

- محاولة مسايرة التوجهات العالمية المعاصرة فى مجال تدريس العلوم باللغة الإنجليزية، والاستفادة من نتائج البحوث وإلدراسات التى حثت على تبنى مدخل (CLIL) فى تعلم مواد غير لغوية باستخدام لغات أجنبية.

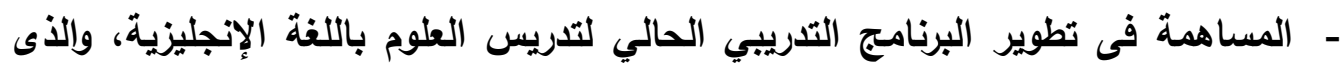
تقدمه إحدى كليات التربية فى مصر. - تكمن أهمية البحث الحالي فيما يمكن أن يسهم به لبرامج إعداد معلمي العلوم باللغة الإنجليزية، سواء البرامج الخاصة التى تقدم لطلاب البكالوريوس، أم التريبية التى تقدم 
للطلاب المعلمين، والمعلمين قبل الخدمة؛ حيث يقدم البحث قائمة كفايات تدريس العلوم بالإنجليزية، ويطاقة ملاحظة بعض هذه الكفايات، يمكن استخدامهما فى تقييم وتطوير هذه البرامج. - يقدم البحث نموذجًا لتدريب معلمي العلوم على التدريس باللغة الإنجليزية باستخدام مدخل (CLIL)، يمكن الرجوع إليه من خلال دليل المدرب، وأورلق عمل المتدربين، الملحقين بالبحث. أهداف البحث: هدف البحث الحالي إلى: - تحديد كفايات تدريس العلوم باللغة الإنجليزية، وعمل قائمة بها.

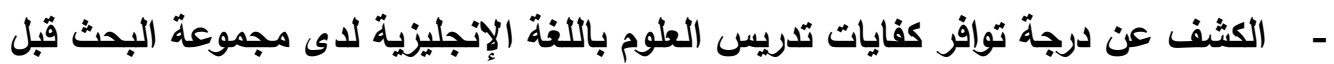
تلديبهم باستخدام مدخل (CLIL). - الكشف عن مستوى قلق تدريس العلوم باللغة الإنجليزية لاى مجموعة البحث قبل تلاريبهم باستخدام مدخل (CLIL). - الكثف عن فعالية استخدام مدخل (CLIL) فى تنمية بعض كفايات تلدريس العلوم باللغة الإنجليزية لاى مجموعة البحث. - الكثف عن فعالية استخدام مدخل (CLIL) فى خفض مستوى قلى تدريس العلوم باللغة الإنجليزية لاى مجموعة البحث. - الكشف عن العلاقة بين درجة توافر كفايات تدريس العلوم باللغة الإنجليزية، ومستوى قلث التريس لاى مجموعة البحث قبل ويعد تدريبهم باستخدام مدخل (CLIL). حلدود البحث: اقتصر البحث الحالي على: - مجموعة من كفايات تدريس العلوم باللغة الإنجليزية، وهى الكفايات المرتبطة بستة مجالات: التخطيط للارس، وإدارة الصف، وعرض الارس، والمعرفة العلمية، واستخدام اللغة الإنجليزية فى تدريس العلوم، والتقويم. - بعض جواتب قلق تدريس العلوم باللغة الإنجليزية، وهى: إدارة الصف، وعرض الارس، واستخدام اللغة الإنجليزية فى تدريس العلوم. 
- الطلاب معلمي العلوم الملتحقين بدورة تدريس العلوم باللغة الإنجليزية في كلية التربية جامعة بني سويف، وقا بلغ عددهم ( • ب) متدريًا من طلاب الفرقة الرابعة شعبة التعليم

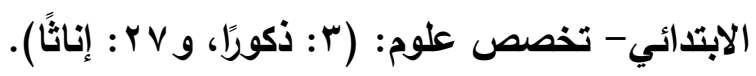

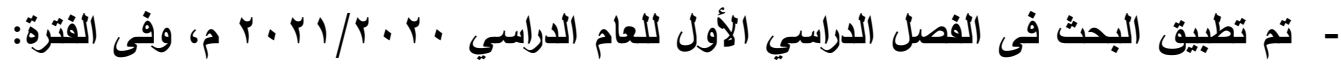

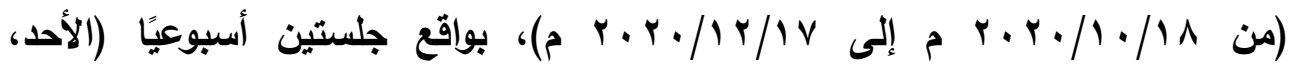
والخميس). وشملت هذه الفترة كل من جلسات التدريب، والجلسات التى تم خلالها تطبيق أدوات البحث قبليًا، ويعديًا على مجموعة البحث. فروض البحث: - مرو 1 - ضعف درجة توافر كفايات تدريس العلوم باللغة الإنجليزية لاى مجموعة البحث قبل تدريبهم باستخدام مدخل (CLIL). ץ - ارتفاع مستوى قلق تدريس العلوم باللغة الإنجليزية لاى مجموعة البحث قبل تدريبهم

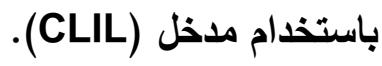
r- زيادة درجة توافر كفايات تدريس العلوم باللغة الإنجليزية لاى مجموعة البحث بعد تدريبهم باستخدام مدخل (CLIL). ع - انخفاض مستوى قلق تدريس العلوم باللغة الإنجليزية لاى مجموعة البحث بعد تدريبهم

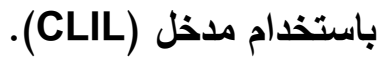
ه- يوجد فرق دال إحصائيًا عند مستوى دلالة (ه . . ) بين متوسطى درجات مجموعة البحث فى القياس القبلى (قبل التدريب باستخدام مدخل (CLIL) والقياس البعدى (بعد التدريب باستخدام مدخل (CLIL) لكفايات تدريس العلوم باللغة الإنجليزية لصالح

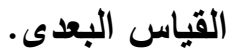
צ- يوجد فرق دال إحصائيًا عند مستوى دلالة (ه...) بين متوسطى درجات مجموعة البحث فى القياس القبلي (قبل التدريب باستخدام مدخل (CLIL) والقياس البعدى (بعد التدريب باستخدام مدخل (CLIL) لمقياس قلق تلريس العلوم باللغة الإنجليزية لصالح القياس البعدي. 
V- توجد علاقة ارتباط سالب/ عكسي دالة إحصائيًا عند مستوى دلالة (ه...) بين

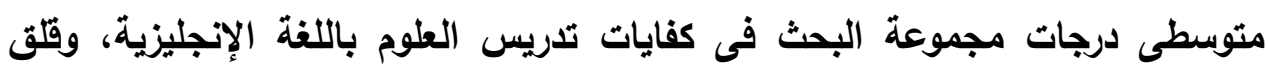

منهج البحث: اتبع البحث الحالي كلاً من: - المنهج الوصفي في تحديد كفايات تدريس العلوم باللغة الإنجليزية، وكذلك فى عمل بطاقة ملاحظة اشتملت على ستة مجالات من هذه الكفايات؛ للكشف عن مدى توافرها فى

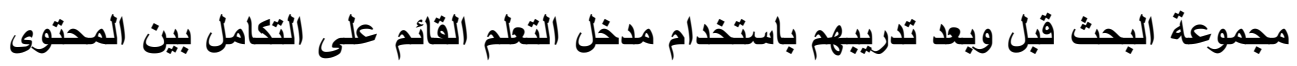
واللغة (CLIL). كما استُخدم المنهج الوصفي لتصميم مقياس قلى تدريس العلوم باللغة الإنجليزية؛ للكثف عن مستوى القلق لاى الطلاب المعلمين مجموعة البحث قبل ويعد

تدريبهم.

- المنهج شبه التجريبي، والتصميم التجريبي ذى المجموعة الواحدة؛ لاختبار فعالية استخدام مدخل (CLIL) فى تنمية بعض كفايات تدريس العلوم باللغة الإنجليزية، وخفض

قلث التدريس لاى مجموعة البحث. أدوات البحث: وشملت ما يلي: - بطاقة ملاحظة كفايات تدريس العلوم باللفة الإنجليزية: تم تصميمها؛ لتحليل الممارسات

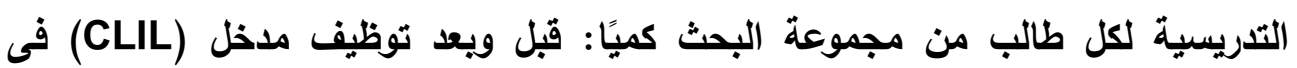
تدريس العلوم باللغة الإنجليزية؛ وذلك للتعرف على درجة توافر بعض كفايات تدريس لته

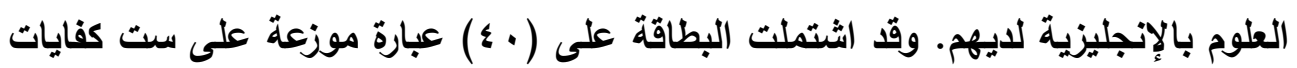
تلريسية، هى: التخطيط للارس، وإدارة الصف، وعرض الإس،، والمعرفة العلمية، واستخدام اللغة الإنجليزية فى تدريس العلوم، والتقويم. - مقياس قلق تدريس العلوم باللغة الإنجليزية: وقد تم بناؤه للكثف عن مستوى قلق تدريس العلوم باللغة الإنجليزية لاى مجموعة البحث، وذلك قبل ويعد توظيف مدخل

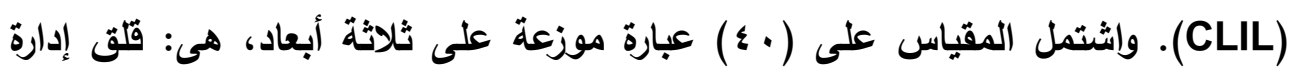
الصف، وقلق عرض الدرس، وقثق استخدام اللغة الإنجليزية فى تدريس العلوم. 
- دليل المدرب، وأولق العمل اللازمة لتدريس وتعلم محتوى كتب العلوم للفصل الدراسي الثانى، المقررة على تلاميذ المرحلة الابتدائية (الصفوف: الرابع، والخامس، والسادس) بمدارس اللغات الرسمية، باستخدام مدخل (CLIL) (ملحق ه). مصاحات البحث:

Content and Language مل - ملت التعلم القائم على التكامل بين المحتوى واللفة Integrated Learning Approach (CLIL) يُعرف مدخل (CLIL) بأنه مدخل تعليمي ثنائي التركيز Dual-focused Approach يهاف إلى تعلم محتوى مادة دراسية ليست من اللغويات (كمادة العلوم على سبيل المثال) باستخدام لغة أجنبية، يتم تعلمها أيضًا (Lo \& Lin, 2019: 151). ويُعرف مدخل (CLIL) فى البحث الحالي بأنه أحد مداخل التعلم، الأى يتم من خلاله استخدام اللغة الإنجليزية لتريس وتعلم كل من المحتوى العلمي لمناهج العلوم المقررة على المرحلة الابتدائية فى الفصل الاراسي الثانى (من الصف الرابع إلى الصف السادس) بمدارس من

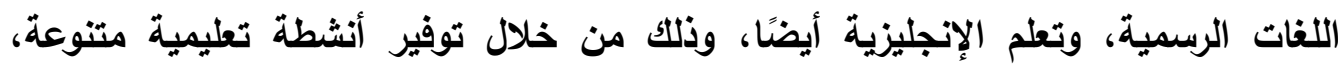
واستخدام مصادر تعليمية مختلفة، وتقليم العديد من السقالات التعليمية فى إطار اجتماعى لإسلى تعاونى، تستخدم خلاله اللغة الإنجليزية استخدامًا وظيفيًا، بهرف تعلم الطلاب المعلمين هذا

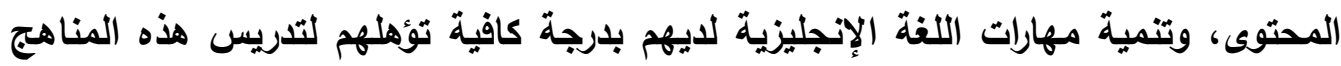
دون توتر أوقلق.

\section{- - كفاىات التلدريس: Teaching Competencies} تُعرف كفايات التدريس بأنها مجموعة من المهارات والمعارف التى يجب أن يمتلكها

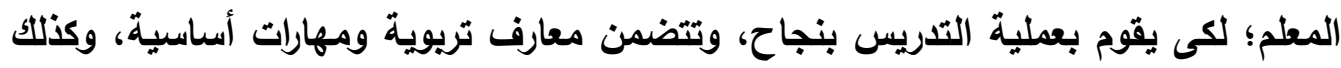
(Gougoulakis, معارف ومهارات محدة تتعلق بفئات عمرية معينة، ومواد دراسية محدة ومئة 2021, 90-91).

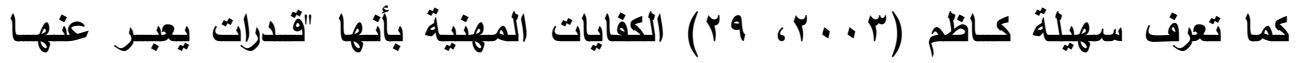
بعبارات سلوكية تثمل مجموعة مهـام معرفية، ومهاريـة، ووجدانيـة، تكون الأداء النهائي المتوقع إنجازه بمستوى مرضي من ناحية الفعالية، والتي يمكن ملاحظتها وتقويمها بوسائل

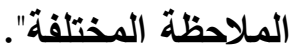


وتُعرف كفايات تدريس العلوم بالإنجليزية فى البحث الحالي بأنها معارف ومهارات يمتلكها الطلاب المعلمون مجموعة البحث، والتى ترتبط بممارساتهم لتدريس مناهج العلوم المقررة بالجية على تلاميذ المرحلة الابتدائية بمدارس اللغات الرسمية (من الصف الرابع إلى الصف بمفيط

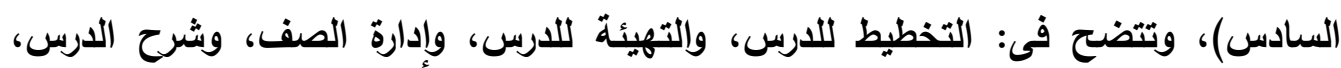

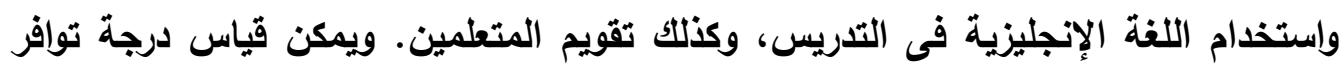
هذه الكفايات لاى مجموعة البحث باستخدام بطاقة ملاحظة تم إعدادها لهذا الغرض، ويمساعدة تسجيلات الفيديو التى أخذت أثناء ممارساتهم للتدريس.

\section{-}

يُعرف قلث التدريس بالمشاعر أو المعتقدات أو السلوكيات التي تؤثر سلبًا فى قرة المعلم على بدء مهام التدريس، أو مواصلتها أو إنهائها (Novak \& Wisdom, 2018, 415).

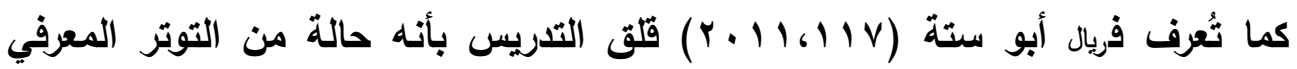
والاضطراب النفسي تنتاب الطالب المعلم وتعوقه عن إعداد وتتفيذ أنشطة التدريس كما ينبفي، مما يؤثر سلبًا على أدائه التدريسي. ويُعرف قلق التدريس إجرائيًا بأنه حالة إنفعالية مؤقتة تسبب شعيلة شعور الطالب المعلم بالتوتر

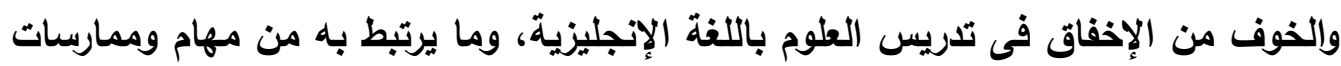

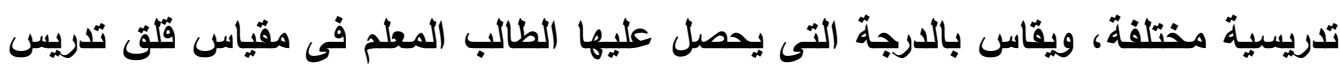

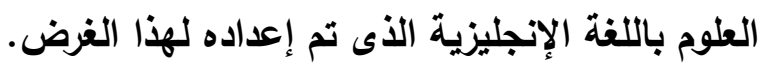

\section{الإطار النظرى:}

تعتبر فعالية المعلم أمرًا فى غاية الأهمية لنجاح العملية التعليمية، والتى يمكن التحقق منها من خلال قياس كفايات التدريس التى يمتلكها، وغيرها من العوامل التى ينبغى مراعاتها

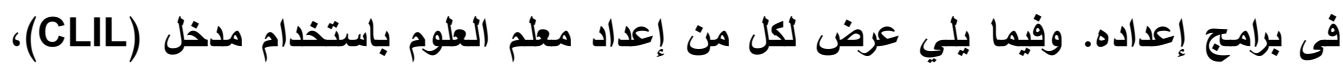
وكفايات تدريس العلوم بالإنجليزية، وقلق تدريس العلوم بالإنجليزية. أولاً - - إعداد معلم العلوم بـاستخدام ملخخل (CLIL) :

- ماهية مدخل التعلم القائم على التكامل بين المحتوى واللغة (CLIL): إن مدخل (CLIL) ليس مدخلاً جديدًا لتعليم اللغة الأجنبية، كما إنه ليس مدخلاً جديدًا لتعليم المواد الدراسية غير اللغوية، ولكنه دمج مبتكر لكليهما (Nikolić, 2017, 120). 
وعندما يتم استخذام اللغة الإنجليزية في التعلم القائم على مدخل (CLIL)، فإن المدخل يسمى Content English Integrated Learning (CEIL) أى التعلم القائم على تكامل المحتوى واللغة الإنجليزية. ومع ذلك فإن الثائع فى الأدبيات، والمواقع الرسمية للمؤسسات التعليمية التى تقدم دورات تدريبية للمعلمين فى استخدام هذا الدذخل، هو

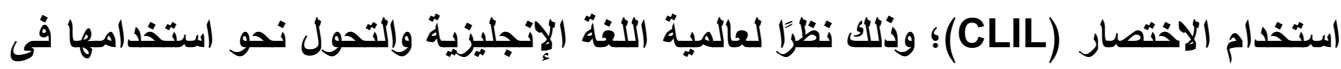
تدريس المناهج التعليمية فى كافة المراحل الدراسية.

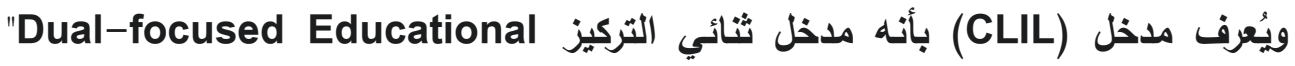
Approach" اللغة الإنجليزية لاى المطلمين، ، وذلك من خلال تنمية مهارات استخام اللغة الإنجليزية (Garzón- تحدثًا، وقراءة، وكتابة، وتوظيفها فى تعلم هذا المحتوى العلمى غير اللغونة Díaz, 2021, 242)

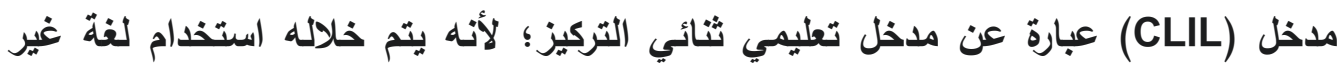
اللغة الأصلية للمتعمين فى تدريس وتعلم كل من المحتوى، وهذه اللغة في آن آن واحد. ويشير وولف (Wolff, 2020) إلى أن مدخل (CLIL) يستتذ إلى نظريات علم النفس المعرفي، والبنائية الاجتماعية، والتى تؤكد على أن تعلم اللغة يحدث عندما ينخرط المتعلمون

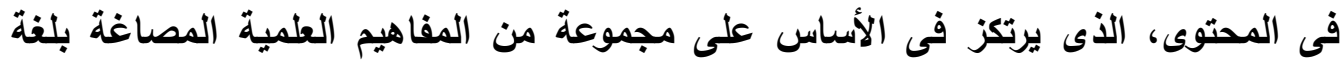

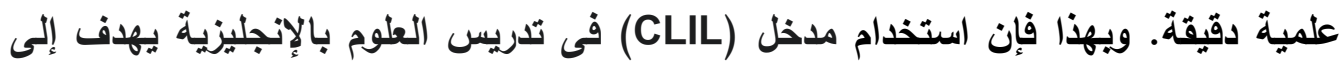

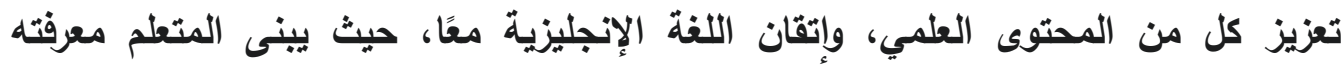

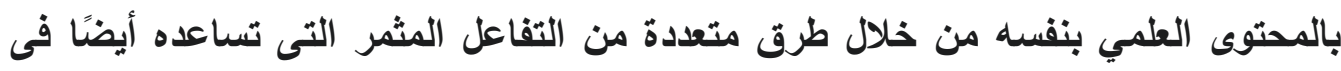

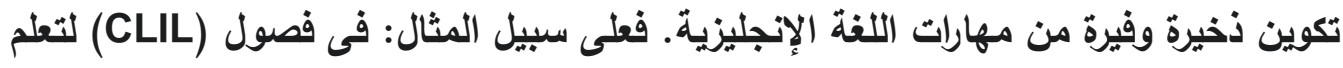

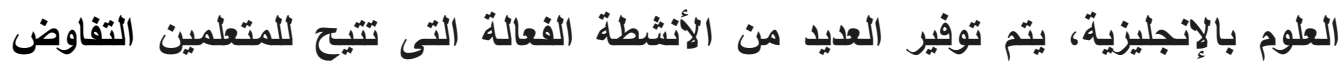
المشترك على مغنى وتطبيقات المفاهيم العلمية المراد تطلمها مستخدمين اللغة الإنجليزية

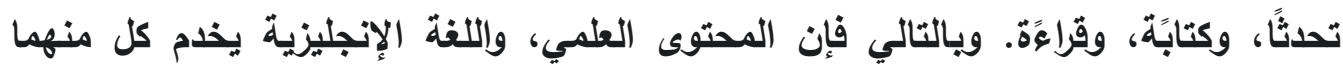

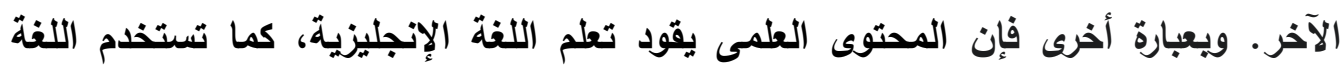
الإنجليزية لتعلم المحتوى العلمي. 
ويرى المتخصصون فى علم النفس، أن مدخل (CLIL) يُعتبر مدخلاً للتحفيز المعرفي، حيث يعزز الحافز والثقة لدى المتعلمين، وينمى لايهم مستويات التفكير العليا والدنيا (Montalto, 2016). ويرتكز مدخل (CLIL) على المبادئ الأساسية الأربعة المعروفة بال (Graham, et al. 2020, 166-169) (4 Cs) ا- المحتوى Content: لا يتضمن المحتوى اكتساب المعرفة والمهارات المرتبطة بمنهج غير لغوى فحسب، بل يتضمن أيضًا طريقة التعلم، حيث يقوم المتعلمون بيناء معرفتهم، وفهمهم، وتطوير مهاراتهم. r- الإدراك Cognition: فتعلم المحتوى مرتبط بالتفكير، ولتمكين المتعلمين من بناء تفسيرهم للمحتوى، يقوموا بممارسة عمليات التفكير العليا مثل التركيب، والتحليل، وحل هرئل المشكلات، والتقويم، وتستخدم اللغة خلال هذه العمليات استخدامًا وظيفيًا. ץ- الاتصال Communication: فالتعلم يتم من خلال التفاعل وليس مجرد الكلام، فاستخدام اللغة الإنجليزية أثناء التعلم يمثل أمرًا أساسيًا؛ لذا يجب أن تكون هذه اللغة واضحة. ويالنسبة لفصول العلوم فيحتاج المتعلمون إلى مهارات الاتصال لبناء المعرفة العلمية لايهم، حيث يستخدموا اللغة الإنجليزية لكى يعبروا عن معرفتهم بالمحتوى العلمى، وما يتضمنه من حقائق، ومفاهيم، وييانات علمية، وكذلك للتعبير عن اتجاهاتهم وأفكارهم وتفسيرها كتابة وشفهيًا. لذا فإن استخدام مدخل (CLIL) يمكن أن يتيح فرصنا عديدة لتنمية

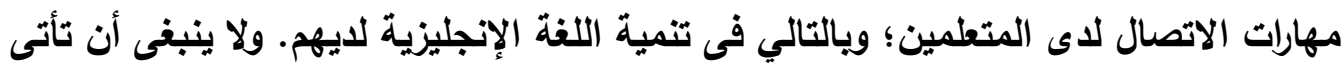
هذه الفرص عرضيًا، وإنما يتم التخطيط والإعداد المسبق لها؛ حتى يكون اتصالاً هادفًا. وهناك طرقًا عدة لتحقيق ذلك، مثل طرح الأسئلة مفتوحة النهاية، نقد مقالة أو موضوع علمي لئي حديث الساعة، وغيرها.

هذا وقد روعى فى أثناء جلسات تدريب مجموعة البحث، تقسيم الطلاب المعلمين إلى

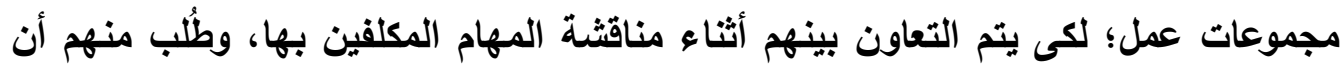
يستخدموا اللغة الإنجليزية فى مشاركة بعضهم البعض أفكارهم، وكذلك إعادة النظر في لغة

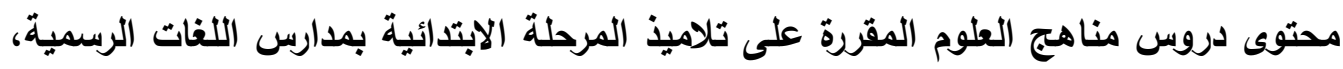
وإعداد ملخص لهذه الدروس أيضًا. ولتنمية مفردات اللغة الإنجليزية؛، طلبت الباحثة من لن 
الطلاب المعلمين وضع بعض المفاهيم العلمية فى جمل جليدة من إنشائهم، وكذلك إعطاء مرادفات ومتضادات لبعض الكلمات. كما عمدت الباحثة إلى تنمية قواعد اللغة الإنجليزية لايهم بطرق عديدة. فعلى سيبيل المثال طُلب منهم فى بعض المواقف مراجعة جمل إنجليزية

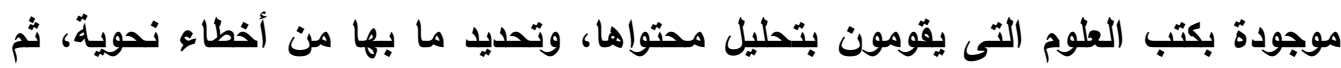

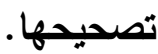

؛ - الثقافة Culture: اللفة عنصر من عناصر الثقافة؛ لذا لا بل من الوعي بكيفية استخدام اللغة الأجنبية فى سياق الثقافات التى تستخدم هذه اللغة.

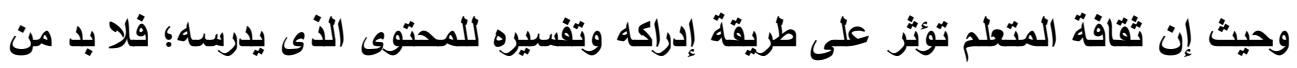
تفسير اللفة الإنجليزية فى إطار ثقافة المجتمع الذى يعيش فيه، وكذلك تنمية وعيه باستخدام هذه اللغة فى إطار مجتمع العلماء. وفى أثناء تدريب مجموعة البحث، عمدت الباحثة إلى البى الإثارة إلى كيفية استخدام اللغة الإنجليزية فى مواقف محددة داخل الفصل الدراسي، وكذلك عدم الترجمة الحرفية للجمل الواردة بكتب العلوم موضع التحليل. ولتتمية وعى الطلاب الإبه

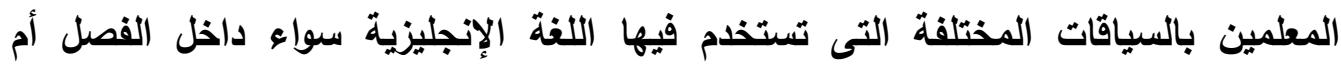
خارجه؛ تم تكليفهم بمشاهدة بعض البرامج العلمية، وغير العلمية، ثم التعليق على بعض التض

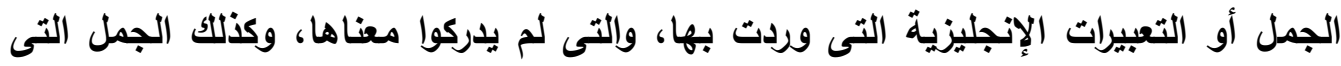
كانوا يستخدموها استخدامًا مختلفًا عن السياق التى وردت فيه. فعلى سبيل المثال، كلمة تستخدم لتثير إلى العلماء الباحثين، كما تثير أيضًا إلى فئة العلميين الذين يدرسون فروع العلم المختلفة كالفيزياء، و الكيمياء، والبيولوجي، ويحصلوا فقط على درجة إدهاء جامعية فيها، دون أن يكونوا باحثين. وفى مواقف أخرى، مثلاًعند دراسة الجهاز الهضمي فى الإنسان، تم حث الطلاب المعلمين على مناقشة أكثر أمراض الجهاز الهضمي شيوعًا في مصر، وفى بعض البلدان الأخرى، وكذلك العادات الغذائية لاى المصريين التي تتؤثر على صحة الجهاز الهضمي. وجدير بالذكر أن المبادئ الأربعة السابقة لمدخل (CLIL) متحدة وتعمل معًا بشكل

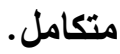


- آلية توظيف مدخل (CLIL) في تعليم المحتوى العلمي واللفة الإنجليزية:

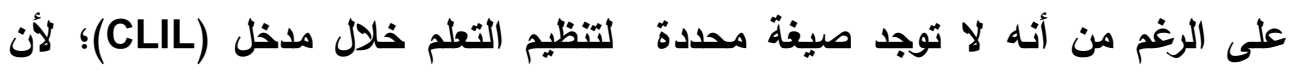

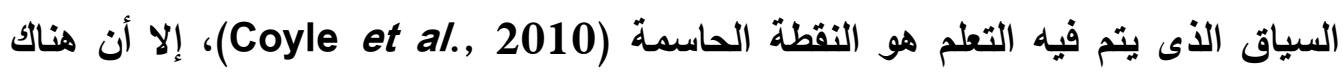

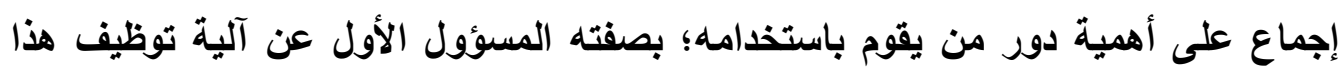
المدخل فى تعليم المحتوى العلمي باستخدام لغة أجنبية. بالإضافة إلى أنه الهنه الأكثر وعيًا بالسياق الذى يوظف فيه هذا المدخل. هذا وتُعد كفايات اللغة الإنجليزية أحد أهم كفايات التدريس المطلوية لتدريس مواد دراسية غير لنوية باللغة الإنجليزية باستخدام مدخل (CLIL)

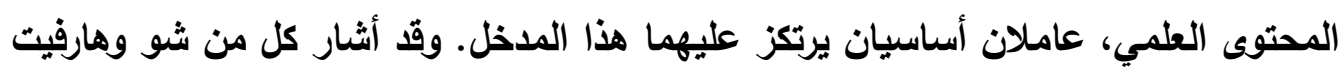
(Xu \& Harfitt, 2019)

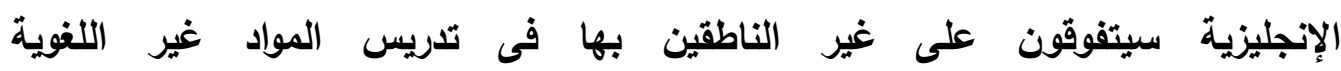

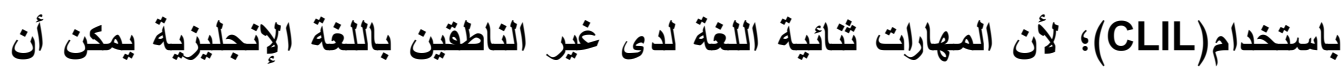
تمكنهم من إدراك الفرق بين اللغتين، ومن تدريس المحتوى العلمى باستخدام اللغة الإنجليزية

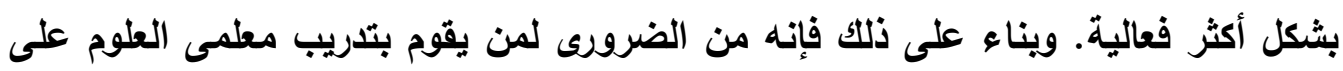

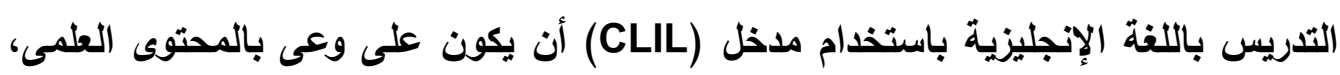
بالإضافة إلى إتقانه اللغة الإنجليزية.

ويرى دالتون-بوفر (Dalton-Puffer, 2013: 219) أن معلمى المطمين الذين يتبنون مدخل (CLIL) فى تدريب معلمي المواد غير اللغوية، يواجهون بعض التحديات تتمثل

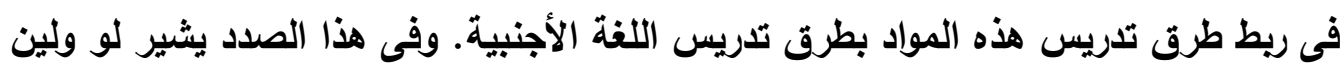
(Lo \& Lin, 2019: 155) وتدريس هذه اللغة بثكل منهجي ضمن دروس هذه المواد دون تحميل الكثير من تدريس

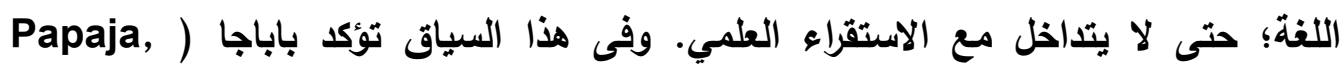

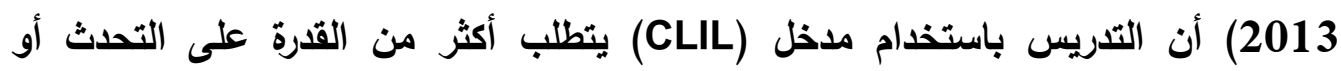

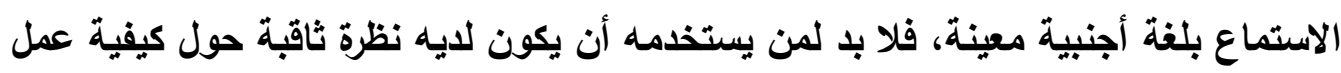

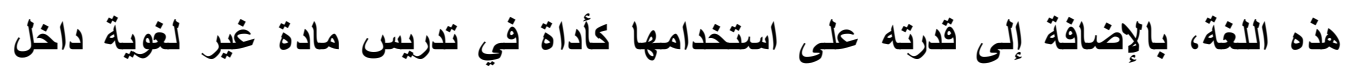
الفصل. كما يشير لى ولى (Lee \& Lee, 2017) إلى أن نجاح مدخل (CLIL) يتطلب 
Language-Specific (LPK) ممن يوظفه المعرفة بطرق تدريس خاصة باللغة Pedagogical Knowledge (An et al., وترى آن وآخرون Language-Specific Content Curricula 2019: 170) أن من يستخدم هذا الدذخل يمكنه أن يدعم اللغة الإنجليزية التى يتم تناول

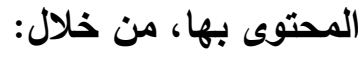
- - تثنجيع المتعلمين على التعرف على التراكيب اللغوية والمغنى العلىى لهذه التراكيب. - مساعدة المتعلمين فى التعرف على ما لايهم من صعويات تتعلق باستخدام اللغة الإنجليزية فى تطلم المحتوى العلىى. - تقلميم أمثلة للمحتوى العلمى باستخدام تراكيب إنجليزية متنوعة. - - تصحيح الاستخدام غير المناسب للغة الإنجليزية فى المحتوى العلمي. ولتنمية مهارات اللغة الإنجليزية لاى مجموعة البحث الحالي، طلبت الباحثة من الطلاب الابل

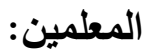
- - وضع خط باللون الأخضر تحت الكلمات التي يعرفونها خاصة فى الجلسات الأولى من التدريب؛ حتى يتم تعزيز معرفتهم بها، ورفع ثقتهم فى قدرتهم اللغوية.

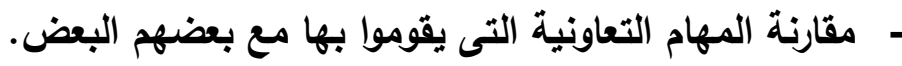

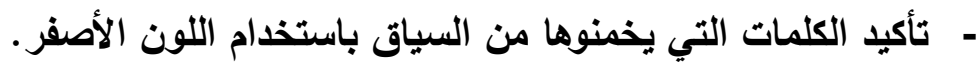

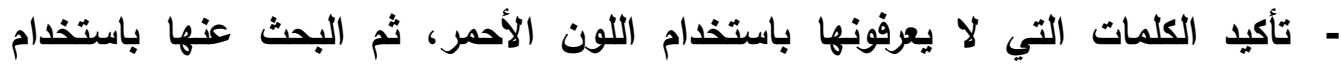
القاموس (English-English dictionary)، ووضعها فى جمل من إنثائهم، وعمل بألمان قائمة بها فى مذكرات مخصصة لذلكت. كما حدد كل من لو ولين (Lo \& Lin, 2019:157) بعض الأدوار المطلوية ممن

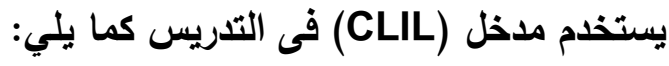
- التعرف على مستوى المعرفة الحالية لدى المتعلمين. - ريط المعرفة الجديدة بما يعرفه المتعلمون بالفعل، أو بما يمكنهم أدائه. - الاستمرار فى تحفيز المتعلمين على الاهتمام بكل مَهمة تُطب منهم.

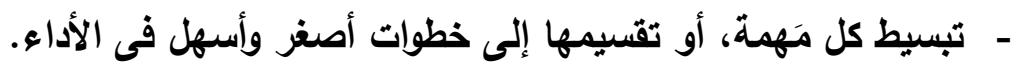
- - نمذجة المهارات المطلوية، أو شرح كيفية القيام بالمهمة. 
- تقديم تلميحات، أو محفزات، أو إثارات لتسهيل عملية التعلم.

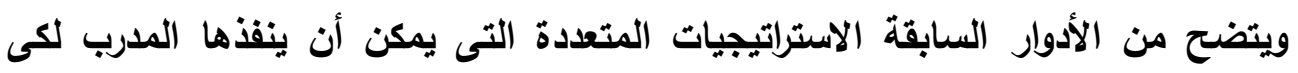

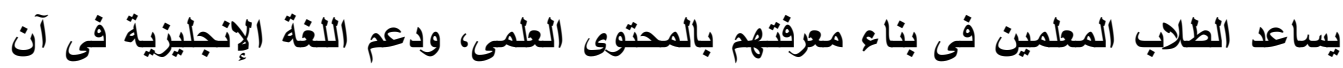
واحد. وتُعد السقالات التعليمية Instructional Scafolldings أبرز هذه الاستراتيجيات. والسقالات التعليمية هي الخطوات التي يتخذها المعلم لدعم تعلم المتعلمين؛ حتى يتمكنوا من فهم المحتوى الجديد وتنمية مهارات جديدة لايهه، ويمرور الوقت يمكن للمتعلمين استخدام وتطبيق ما تعلموه في سياقات مختلفة دون الحاجة إلى هذه السقالات (Fernández)

.Fontecha et al. 2020: 2

وتعتبر السقالات التعليمية من أهم الطرق التى تساعد المتعلمين ذوي المستويات العلمية واللغوية المتنوعة فى تعلم كل من المحتوى العلمى للمنهج، وكذلك تعبيرات اللغة الإنجليزية المرتبطة بهذا المحتوى. ويعتبر التواصل اللغوى بين المعلم والطلاب أحد السبل التى توفر السقالات التعليمية التى تدعم تعلم اللغة والمحتوى معًا من خلال النصوص المكتوية والمنطوقة (Lin, 2016). وقد صنف شو وهارفيت (Xu \& Harfitt, 2019: 224-225) استراتيجيات السقالات التى يمكن أن يدعم بها المعلمون تعلم طلابهم للعلوم باللغة الإنجليزية، إلى ست فئات، هى: 1- التدخل Mediation: يقوم المعلم بإعادة الصياغة اللغوية لبعض الجمل للى

المتعلمين؛ بهدف مساعدتهم فى إجراء تعديل لغتهم إلى اللغة الأكاديمية المتخصصة. r- استخدام أسئلة تتمى مهارات التفكير العليا: حيث يسأل المعلم أسئلة استقصائية Probing for Expansion المتعلمين، وتوسيع نطاق المناقشات، حيث يتاح لهم الفرصة لتوضيح أفكارهم والاستشهاد بأمثلة شخصية أو يومية. ץ- الترجمة Translation: عندما يصعب على المتعلمين فهم مصطلح ما، يقوم المعلم بترجمته إلى اللغة الأم، ويشرحه بشكل أوضح.

ع - إثارة المناقشات بين الطلاب Evoking Discussions among Students: ينظم المعلم المناقشات الجماعية بين الطلاب، لتحقيق هدف محدد، أو إكمال مهمة 
ه- تثجيع الطلاب على البناء الأتي من خلال العرض والتمثيل Encouraging Students' Self-Scaffolding through Presenting and Representing لهم الفرصة لكى يقوموا بذلك بأنفسهم. צ- حجب السقالات Withholding the Scaffolding: يقوم المعلم بتحفيز الاهتمامات العلمية لاى المتعلمين. وعندما يبدى المتعلمون هذه الاهتمامات؛ يحفز المعلم السقالات الأتية لايهم عن طريق حجب السقالات التى يقدمها. كما اقترحت فريدة باوان (Pawan, 2008: 1454-1455) نموذجًا لأنواع السقالات التعليمية التى يمكن أن تُقدم للمتعلمين، عند استخدام مدخل (CLIL)، وهذه السقالات هیى: ا. السقالات اللغوية Linguistic Scaffolding: وتهدف إلى تبسيط اللغة الإنجليزية، وجعلها أكثر سهولة للمتعلمين، من خلال اختصار الاختيارات، والتحدث في زمن المضارع، وتجنب استخدام المصطلحات اللغوية (idioms)، واستخدام التعليمات المباشرة للكتابة، والمفردات.

r. السقالات المفاهيمية Conceptual Scaffolding : وتهذف إلى تزويد المتعلمين بأطر داعمة لمعنى المفهوم من خلال توفير محطات تنظيمية، واستعارات، ومرئيات، ونماذج، وتجارب عملية. أى أن السقالات المفاهيمية تثنمل على الوسائط المتعددة. r. السقالات الاجتماعية Social Scaffolding: وتركز على استخدام التفاعل الاجتماعي لاعم "التعلم بالتدخل"، مثل عمل المتعلمين فى مجموعات، تدريب الأقران بعضهم لبعض،

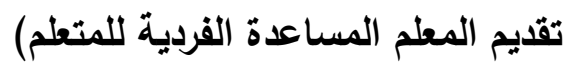
ع. السقالات الثقافية Cultural Scaffolding: ويتم خلالها استخدام مواد مصنعة من البيئة المحيطة بالمتعلمين، وكذلك استخدام أدوات ومصادر للمعرفة تكون مألوفة لايهر.

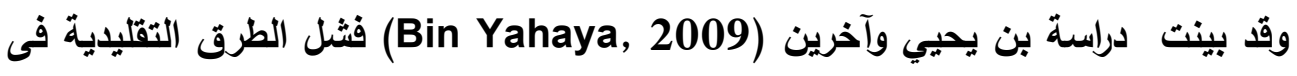
تدريب معلمي العلوم والرياضيات فى ماليزيا على تدريس مواد التخصص باللغة الإنجليزية، وضرورة استخدام استراتيجيات السقالات التعليمية التى تحفز المعلمين على تعلم الإنجليزية. كما أوضحت دراسة فان كامبين وآخرين (Kampen et al., 2018) التى أجريت على لكئل 


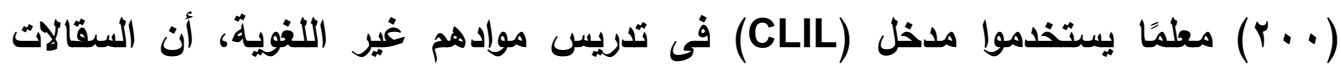

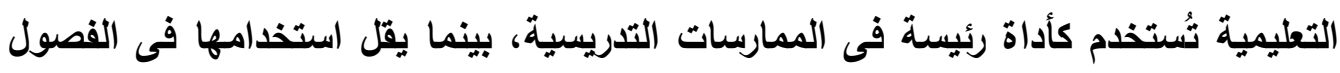

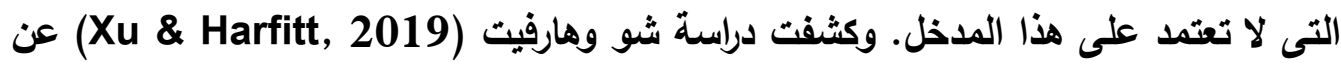
وجود علاقة طردية بين الوعى بالتدريس باستخدام الإنجليزية كلغة أجنبية لاى معلمى العلوم

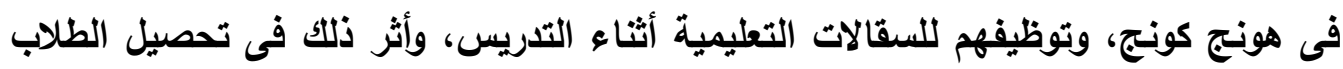
للعلوم، ودافعيتهم للتعلم. كما أوضحت دراسة هو وآخرين (Ho et al., 2019) أن استخدام المعلمين للسقالات المرئية المتمثلة فى الرسومات التوضيحية فى دروس الإسموزية الكيميائية فى النبات، والتى

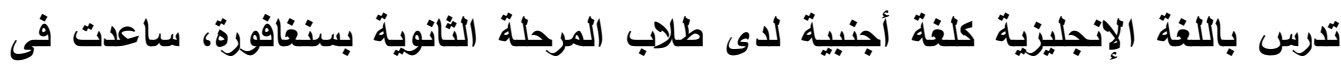

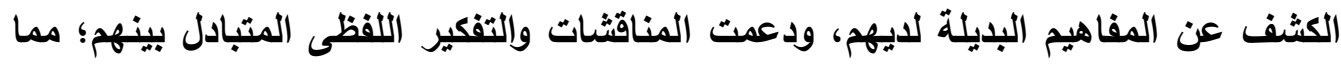
يسر تعديل المفاهيم البيويوجية لديهم، كما ساعدهم فى تعلم لغة المحتوى العلمى بصورة دقيقة أيضًا. كما بينت دراسة هى ولين (He \& Lin, 2019) أن استخدام خرائط المفاهيم فى فصول البيولوجي بالمرطة الثانوية فى هونج كونج والتى يوظف فيها مدخل (CLIL)، ساعد فى توفير فرص لكتابة وقراءة مفاهيم الوراثة باللغة الإنجليزية، وتبادل الطلاب لها؛ مما فيأي كان له أثثرًا فى نمو التنور البيولوجي واللغة الإنجليزية لديهم. وتثثير هذه الدارات وغيرها إلى تعدد صور السقالات التعليمية بين المرئية والنصية والثفهية، والتي يمكن أن تستخدم فى تدريس العلوم باستخدام مدخل (CLIL)؛ لاعم تعلم كل

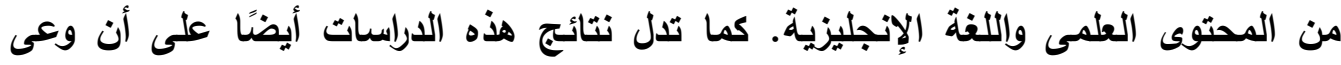

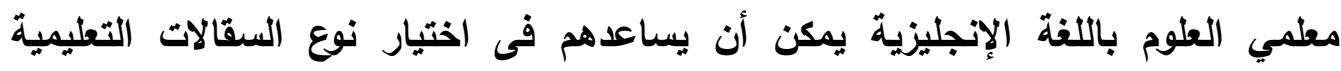
المناسبة للمتعلمين، وكذلك اختيار الوقت المناسب لتقليمها؛ لكى تنجح عملية التكامل بين

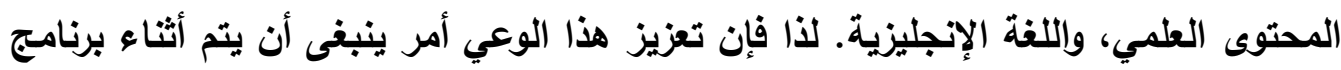
إعدادهم، وهو ما سعت إليه الدراسة الحالية من خلال استخدام مدخل (CLIL). وجدير بالذكر أنه تم توظيف العلد من السقالات التعليمية الاجتماعية، والمرئية والثشفهية أثناء تدريب مجموعة البحث الحالي، مما أسهم فى تفاعل الطلاب المعلمين وانخراطهم فى بلى عملية التطلم. وقد استخدمت العليد من الوسائط التعليمية مثل الملصقات، والمجسمات، ومواد

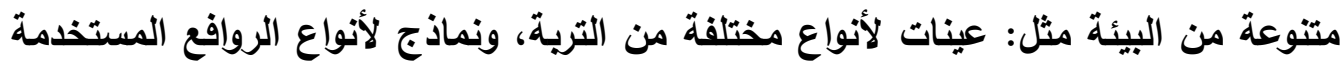


فى المنزل، كما استخدم جهاز عرض البيانات فى عرض مقاطع فيديو عن أجهزة جسم

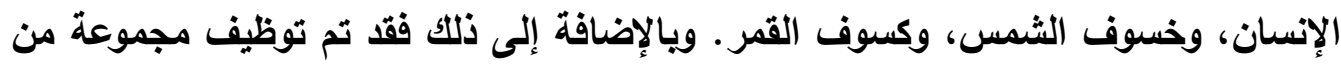

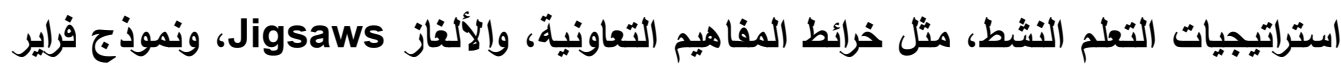
Educational Frayer's Model Games و Cover-Copy-Compare strategy؛ وذللك لاعم التفاعل بين مجموعة البحث، وتعزيز تعلمهم المحتوى العلمي لمقررات العلوم موضع الدراسة، وتنمية مهارات اللغة الإنجليزية شفهيًا وكتابة فى بيئة تعليمية يسودها جو من المرح. ومما سبق عرضه، يمكن إيجاز أهم خصائص مدخل (CLIL): - التركيز المزدوج على كل من المحتوى العلمي للمادة الدراسية غير اللغوية، واللغة الإنجليزية التى تمثل لغة أجنبية للمتعلمين. - توفير العديد من الوسائل والأنشطة التعليمية؛ لاعم تعلم المحتوى واللغة. - يعمل المتعلمون معًا فى مجموعات تعاونية صغيرة، ويتم توزيع المهام عليهم، حيث يتبادلوا

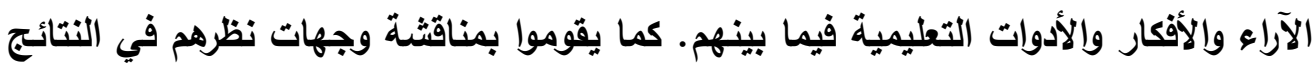
التى حصلوا عليها، وكذلك فى معانى الكلمات وطريقة نطقها، وتراكيب الجمل؛ مما يكون له أثر فى تعلمهم المحتوى العلمي، ومهارات اللغة الإنجليزية. - يقوم المعلم بتوجيه المتعلمين وتيسير تعلمهم من خلال تقبيم المهام التعليمية إلى مراحل صغيرة؛ لاعم ويناء السقالات التعليمية لديهم. ثانياً - كفايات تدريس العلوم بـالإنجليزية: تُعرف الكفاية فى معجم المعاني الجامعَ بأنها "ما يلزم بالضَّبط على قدر الحاجة، إلى حدّ

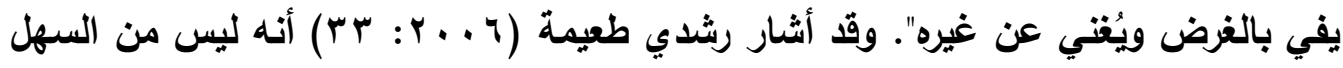
تقديم تعريف دقيق لكلمة كفايات، كما أوضح أنها تثمل مختلف أثكال الأداء التي تمثل الحد

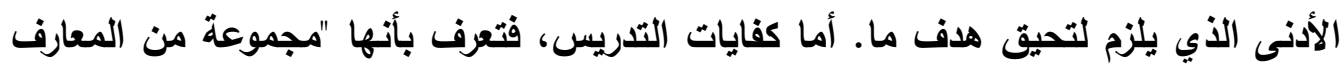

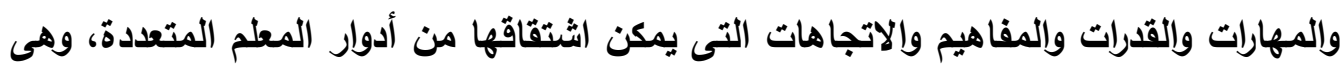

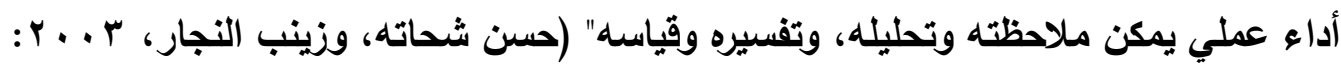

${ }^{2}$ https://www.almaany.com/ar/dict/ar-ar/\%D9\%83\%D9\%81\%D8\%A7\%D9\%8A\%D8\%A9/ 


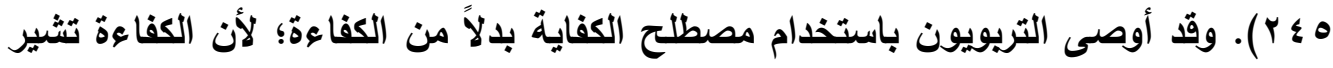
إلى بلوغ مستوى حد أعلى من مستوى الكفاية؛ أى أن الكفاءة درجة أعلى من الكفاية. ويشير ذو الكفل (Zulkifli, 2016) إلى أن كفايات التدريس هى مزيج معقد من المهارات والمعرفة والمواقف والقيم المتكاملة التى تظهر فى سلوك المعلم وممارساته التدريسية، ويمكن قياسها بطرق مختلفة، مثل: تخطيط المعلمين للاروس، وتطويرهم للمواد التعليمية، وإدارتهم لعملية التدريس، وطرق التقويم التى يستخدموها، وغيرها. وإذا كان المعلم هو أهم عناصر العملية التعليمية؛ فإن التحقق من كفايات التدريس لديه يُعد أمرًا بالغ الأهمية. لذا فقد أصبح مدخل التعليم القائم على الكفايات - Competence based Education

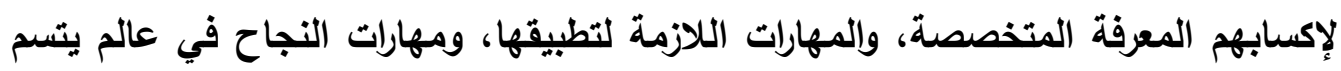
بالتغير المستمر(Villalba-Condori et al., 2020).

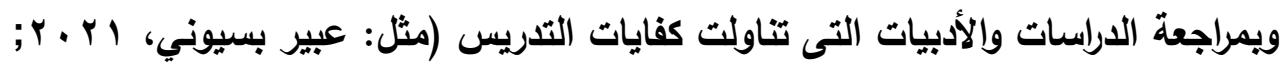
(Werven et al., 2021 ; Ramlawati \& Yunus, 2018 على مجموعة من المجالات التى تنتمى لها هذه الكفايات. وهذه المجالات هى نفس المعايير التى المتضمنة بوثيقة المستويات المعيارية للمعلم قبل الجامعى (الهيئة القومية لضمان جودة

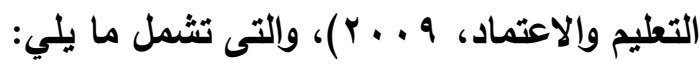
- التخطيط: ويشمل عدة كفايات منها: تحديد الاحتياجات التعليمية للتلاميذ، والتخطيط للأهداف التعليمية، وتصميم أنشطة تعليمية ملائمة.

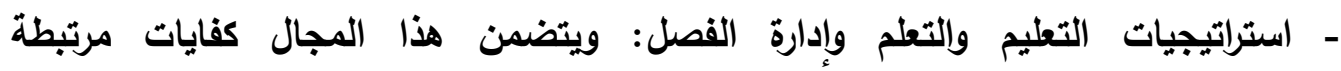
بالممارسات التدريسية للمعلم، مثل استخدام استراتيجيات تدريس تناسب حاجات التلاميذ، وتتمية أنواع مختلفة من التفكير لاى التلاميذ، وإدارة وقت التعلم بكفاءة.

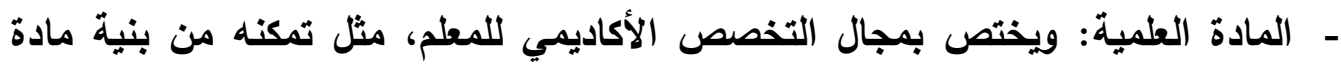
تخصصه، وطرق البحث فيها، وتكاملها مع التخصصات العلمية الأخرى. - تكنولوجيا التعليم: ويشمل هذا المجال كفايات ترتبط بممارسة المعلم لمهارات الاتصال، وتوظيف تكنولوجيا التعليم. 
- السياق المجتمعي: ويشمل إلمام المعلم بثقاقة المجتمع المحيط بالمدرسة، وعلاقته بأعضائه، والمشاركه فى تطويره تربويًا.

- - التقويم: ويضم هذا المجال كفايات تتعلق بالتقويم الثامل، والتغذية الراجعة. - - أخلاقيات المهنة: ويركز هذا المجال على علاقة المعلم بالمتعلمين وزملائه، وأخلاقيات المهنة. - المبات

- التنمية المهنية المستمرة: ويضم تنمية مهنية ذاتية، وتنمية مهنية جماعية. وتعتبر هذه المعايير بمثابة المحك المرجعي للتقييم المستمر لجودة برامج إعداد المعلمين فى في

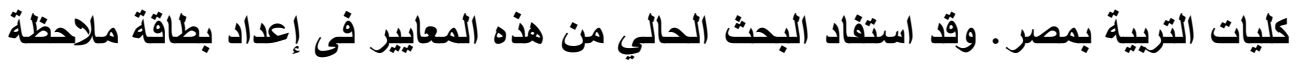
كفايات تدريس العلوم باللغة الإنجليزية، ويناء مقياس قلث تدريس العلوم باللغة الإنجليزية.

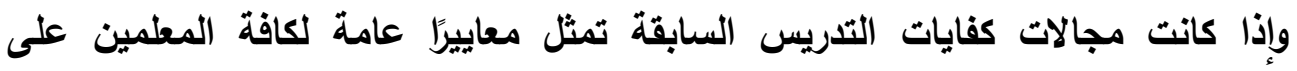

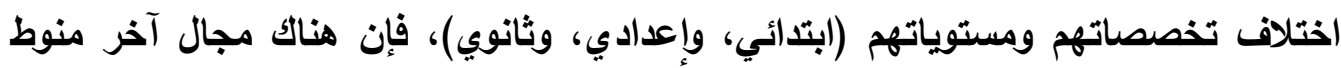

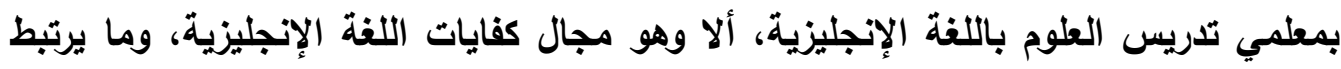

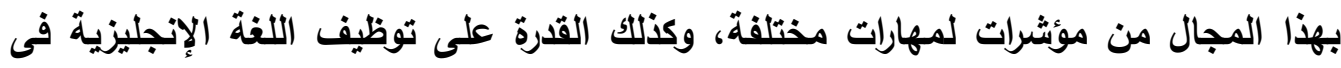
تنفيذ مناهج العلوم دون توتر أو قلق، وهو ما هدف البحث الحالى إلى تحليدها والتحقى منها لاى مجموعة البحث قبل ويعد تبني مدخل (CLIL). - الكفايات اللفوية لتدريس العلوم بالإنجليزية: Qizi et al., ) رغم اهتمام البحث التريوى بكفايات تدريس اللغة الإنجليزية كلغة أجنبية 2020) لاى المعلمين، وفى حدود ما تم مراجعته من دراسات ويحوث مرتبطة بمجال تدريس

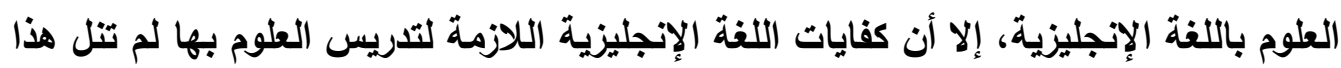

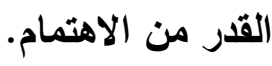
وهناك خطأ شائع لاى بعض العامة، بل ولدى الكثير من الطلاب المعلمين بكلية التربية محل عمل الباحثة، وهو أن اللغة الإنجليزية تمثل لغة ثانية لهم. والحقيقة هى أن اللغة الإنجليزية هى لغة أجنبية لهم؛ لأنها ليست لغة رسمية للاولة. ويالتالي فإن كفايات اللغة الإنة الإنجليزية المطالب بها معلو العوم الذين سيدرسون بالإنجليزية تمثل كفايات لغة أجنبية.

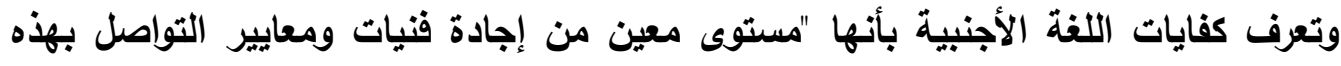


Valeeva, ) "اللغة، والتى تظهر فى قدرة الفرد على العمل في مواقف اجتماعية متنوعة

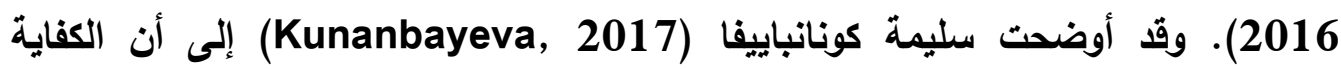
اللغوية التدريسية تمثل المكون الرئيس للكفايات المهنية لمعلى العلوم الذين يدرسون باللغة

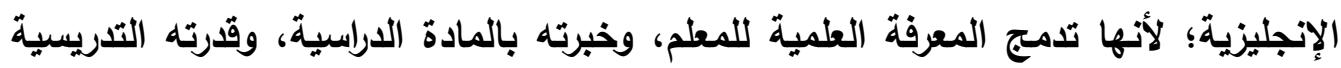
بكفايات التواصل باللفة الإنجليزية مع الطلاب بالمدرسة. لذا فإن تحديد الكفايات اللغوية

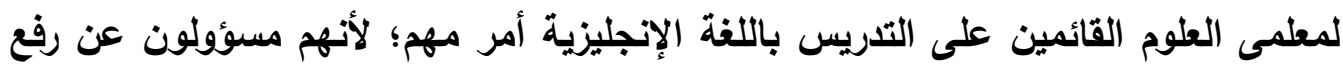

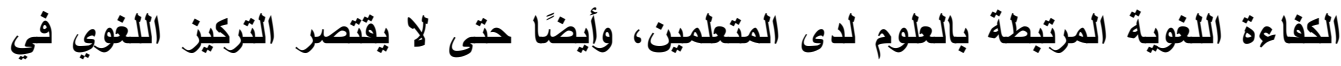

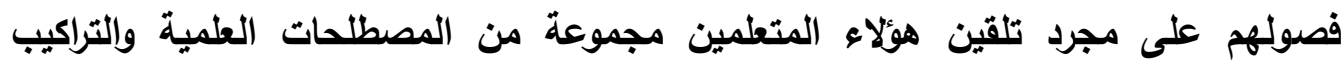
اللغوية بطريقة مجزأة، لا تؤدى إلى تنمية مهاراتهم اللغوية بشكل وظيفي.

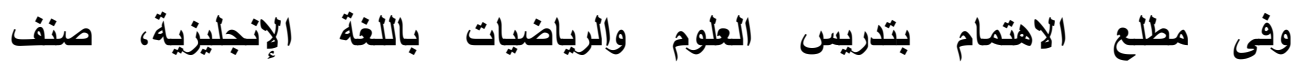
كومينز (Cummins, 1986) مستويات إتقان اللغة الإنجليزية للتدريس بها إلى لئي

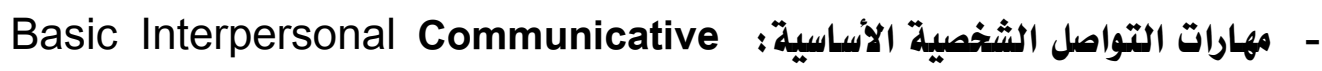
Skills (BICS) باللغة، ومهارات استخدامها في مواقف الحياة الحقيقية؛ لتلبية احتياجات التواصل لايه،

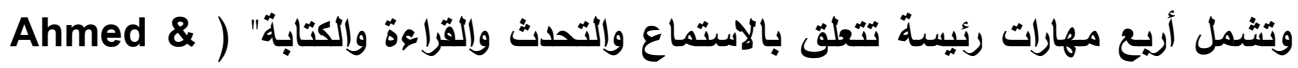

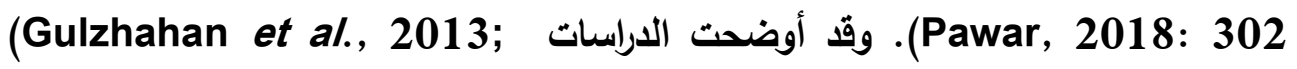
Sharif, 2013; Smakova \& Paulsrud, 2020) التدريب لتنمية الكفاية التواصلية؛ لكى يدرسوا باللغة الإنجليزية، وأنها أساس رئيس للكفايات المهنية اللازمة لإعداده. Cognitive/Academic Language Proficiency إجـادة اللفة الأكاديميـة إن الأداء الفعال في العلوم باللغة الإنجليزية يتطلب تنمية اللغة الأكاديمية لاى (CALP)

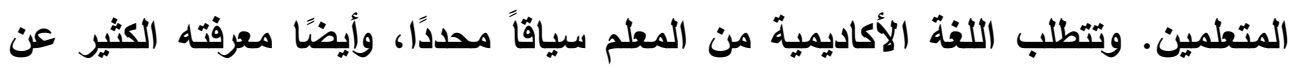
المادة الاراسبة. كما حددت أبدونازاروفنا (Abdunazarovna, 2021) مجالات الكفايات التواصلية لتدريس العلوم باستخدام اللغة الإنجليزية كلغة أجنبية، كما يلي: 
1- الكفاية النحوية: وتثمل القدرة على تطبيق قواعد النحو لتكوين أو تفسير رسالة بشكل

صحيح.

ץ - كفاية الخطاب: وهى القدرة على ريط العديد من الأفكار معًا بثكل مناسب، وعلى تبادل

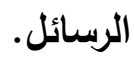

r- الكفاية اللغوية الاجتماعية: وتثير إلى القدرة على استخدام اللغة فى المواقق الاجتماعية المختلفة.

؛ - الكفاية الاستراتيجية: ويقصد بها القدرة على فهم المعنى الأساسي، حتى في حالة عدم

$$
\text { وجود مفردات مناسبة. }
$$

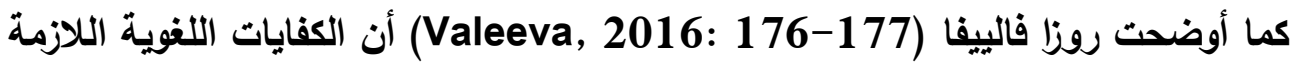

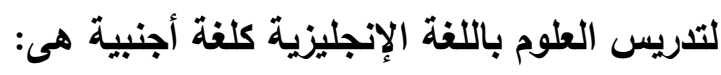

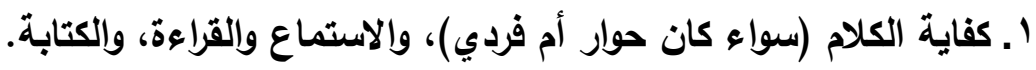

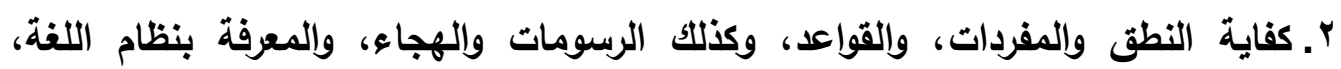

والقدرة على ممارستها.

r.كفاية اجتماعية وثقافية: وتثتمل مهارات التواصل باللغة الإنجليزية والقدرة على استخذامها بثكل فعال في مواقف اجتماعية وثڤقافية، بالإضافة إلى معايير وآداب السلوك

أثناء استخدامها.

؛ ـ كفاية الخطاب: وهى الكفاية التواصلية باللغة الإنجليزية، أى القدرة على بناء الخطاب، أي استخام وتفسير أثنكال ومعاني الكلمات وتنظيمها لبناء نص متماسك، حيث يتم استخدام وسائل الريط بفعالية (الضمائر والاقتران، والظروف، والوسائل النحوية الأخرى).

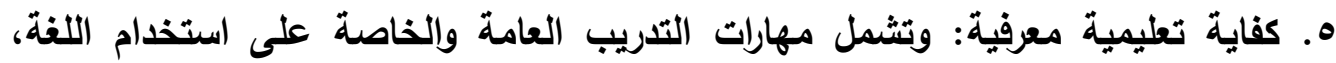
وأساليب وتقتيات التعلم المستقل للفات، مثل القواميس المختلفة (الإنجليزية-العربية،

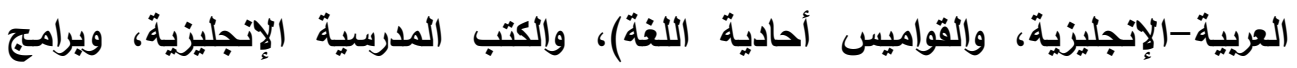

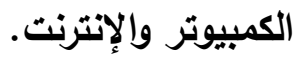

4. كفاية استراتيجية: تعنى القدرة على استخدام تقنيات التواصل اللفظية وغير اللفظية لتعويض النقص في المعرفة بقواعد النحو، لتعزيز التأثير الخطابي لرسالة الكلام أو الو التئية 
لإيقاف عملية الاتصال. ويمكن استخدام مجموعة متنوعة من المواد الصوتية والمرئية لتطوير الكفاية الاستراتيجية. ومما سبق تتضح أهمية امتلاك مطلم العلوم الذى سيدرس باللغة الإنجليزية الكفايات

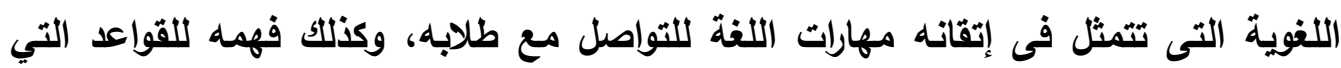

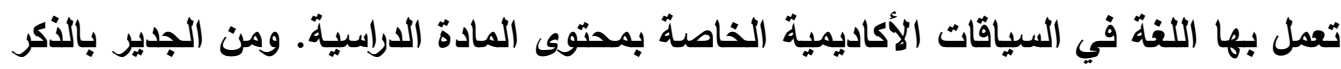

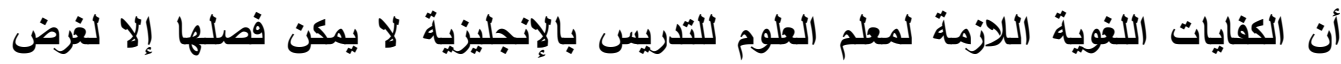

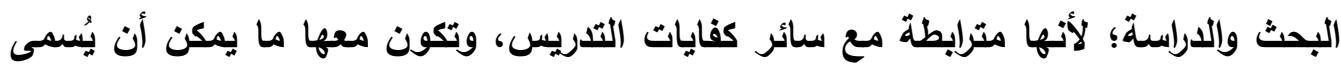
"مملغم كفايات التدريس"؛ لأن كفايات التدريس متضمنة في كافة الممارسات التدريسية للمعلم

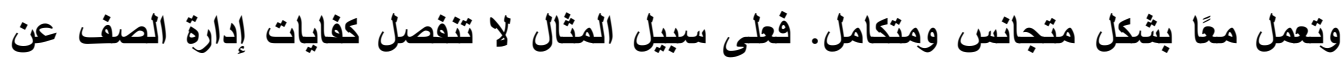

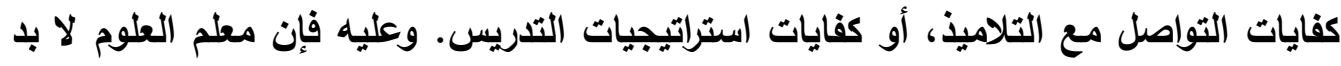
وأن يمتلك جميع الكفايات السابق عرضها؛ حتى يتمكن من التدريس باللغة التهات الإنجليزية.

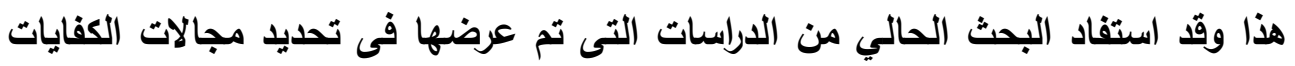

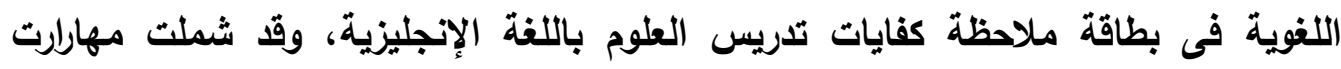

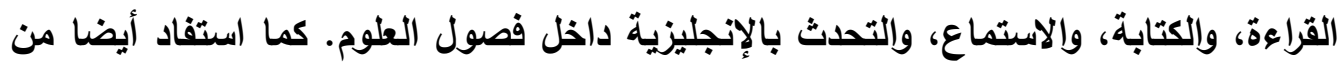

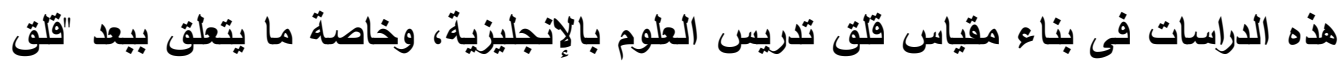
استخدام اللغة الإنجليزية فى التدريس". ونظرًا لأن مدخل (CLIL) يعتمد على التواصل اللغوى، ومشاركة الطلاب فى عملية التعلم، من خلال توفير مدخلات لغوية غنية ومتنوعة بين اللغة الأكاديمية، واللغة الصفية، كما لألاكية يتميز (CLIL) أيضًا بالاهتمام المتزيد بتتمية المتطمين للاستراتيجيات المعرفية لايهم،

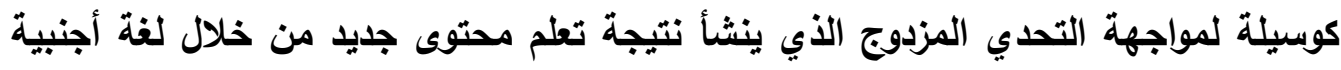

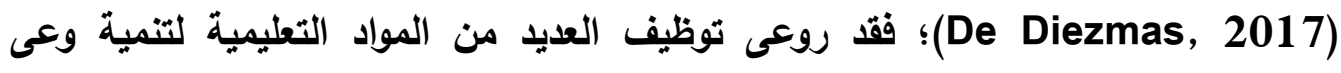
مجموعة البحث الحالي بالمحتوى العلمى لمناهج العلوم المقررة على تلاميذ المرحلة الابتدائية بدارس اللغات الرسمية، بالإضافة إلى تنمية كفايات اللغة الإنجليزية لايهم. فعلى سبيل المثال استخدمت القواميس الورقية والإلكترونية الناطقة. كما تم تصميم العديد من الأدوات

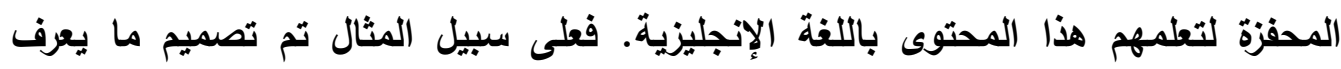

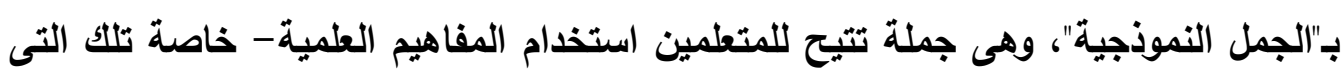


يصعب نطقها أو كتابتها. والثكل التالي يوضح مثالين للجمل النموذجية التى صممها الطلاب المعلمين بأنفسهم وقاموا بتعليقها على حائط قاعة التدريب، وذلك بعد وضعها فى إطر ملونة

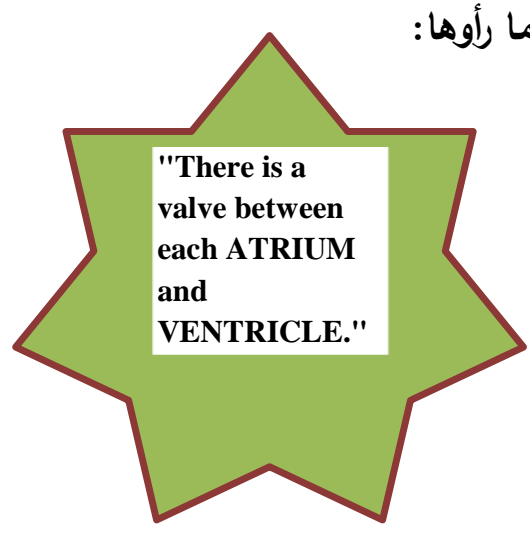

ومزخرفة؛ لتكون أمامهم، فيقرأوها ويكرروا نطقها كلما رأوها:

شكل ( 1) : أمثلة للجمل النموذجية التى صممها الطلاب المعلمون أثناء التدريب

كما استخدمت الرسوم البيانية والنماذج العلمية مثل الجهاز الهضيمي والجهاز التنفسي، وقام الطلاب ببعض التجارب العملية، مثل فحص تركيب الزهرة؛ وذلك لتنمية مهارات اللغة الإنجليزية، ومساعدتهم فى تكوين مفاهيم علمية صحيحة وإلتحدث بلغة علمية دقيقة، وكسر حاجز القلث من التحدث بها. وفى أحيان أخرى طُب منهم مشاهدة بعض الأبه الأفلام ويرامتج الأطفال العلمية وغير العلمية، والتى تقدم باللغة الإنجليزية؛ لتحسين النطق من ناحية اهية، والتعرف على السياقات المختلفة للتعبيرات الإنجليزية. بالإضافة إلى ذلك، فقد استعين ببعض الأنثطة المحفزة لتمية الكفايات اللغوية لاى

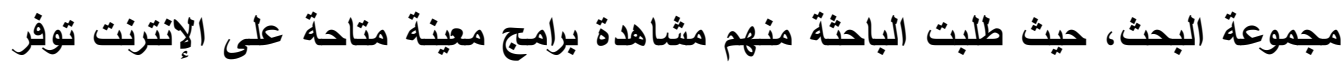

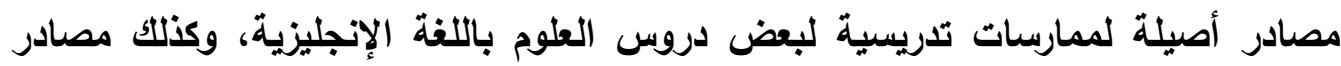

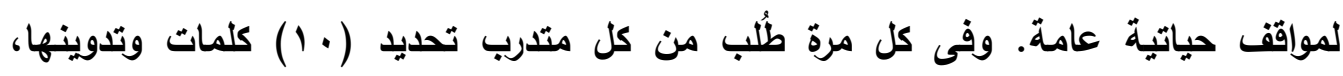
والتعليق أثناء جلسات التدريب على طريقة نطقه لهذه الكلمات قبل ويعد مشاهده هذه هره الاروس والمواقف. كما استعين أيضًا بموقع متخصص على الإنترنت، يدعمه الاتحاد الأورويى"؛ يهذف إلى التنمية المهنية للمعلمين غير الناطقين بالإنجليزية فى كافة الإنية 
التخصصات والمراحل الدراسية. ومن الجدير بالذكر أن هذا الموقع يقدم دليلاً استرشاديًا لتنمية مختلف مهارات التدريس باستخدام مدخل (CLIL).

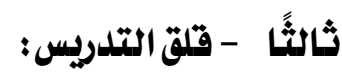
يُعرف القلق بصفة عامة بأنه إحساس غير طبيعي بالخوف، والذي غالبًا ما يُصاحَب بأعراض جسدية مثل التوتر، والتعرق، وزيادة معدل النبض، والثكك الذاتي للفرد في قدرته على التأقلم ؛ (Webster, 2021). والقلق نوعان مختلفان: قلق السمة، وقثلق الحالة. ففي النوع الأول، يكون القلق سمة

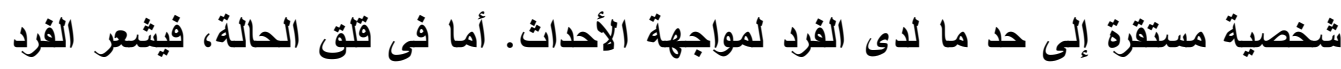
بالقلق بصفة مؤقتة فى مجموعة معينة من المواقف، وقد تظهر علامات جسدية معينة في

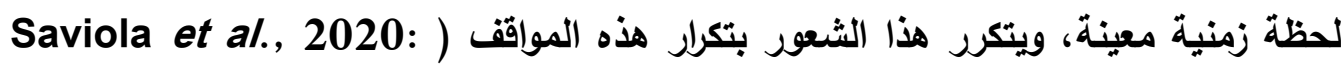

ويشير قلق التدريس إلى "المشاعر أو المعتقدات أو السلوكيات التي تتداخل مع قدرة

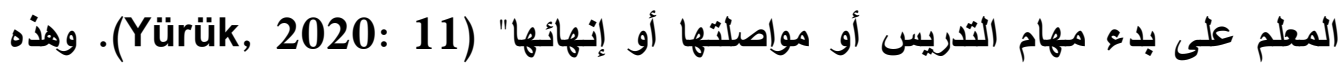

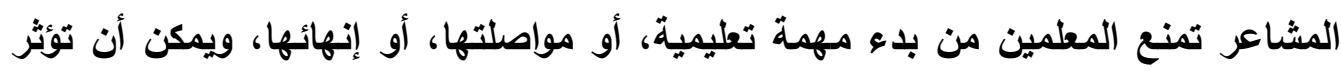

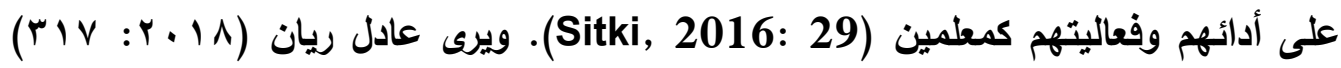
أن قلق التدريس عبارة عن مشاعر مختلطة من الإحساس بالرغبة فى الانخراط فى مهمات

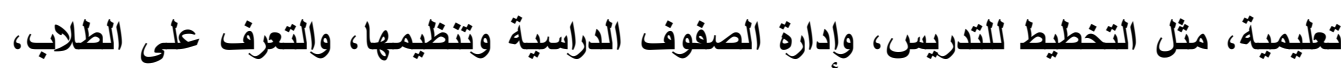
ويبين شكوك الطلاب المعلمين بعدم قدرتهم على التعامل ميع المواقف غير المألوفة في أثناء

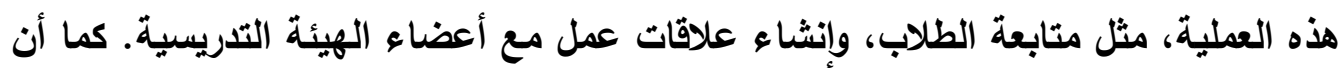
قلق التدريس لدى الطلاب المعلمين هو قلق يرتبط بموقف محدد بالتدريس، وممارساتهم

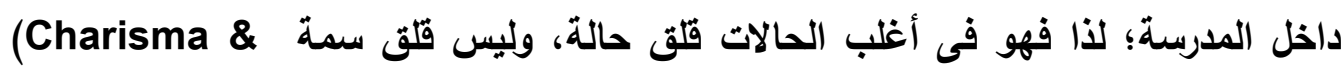
Nurmalasari, 2020; Fernández-Batanero, 2021). ولقد أصبح قلق التدريس بؤرة اهتمام العديد من التريويين؛ بعد أن بين كيفني وسنكلير (Keavney \& Sinclair, 1978) ضرورة قياس قلث المعلم، ودراسة مصادره، وعواقبه. ونظرًا لما تتمتع به مناهج العلوم من طبيعة خاصة تتطلب معلمًا لديه كفايات التدريس التى ودريه 
تؤهله لتنمية العديد من أنماط التفكير والمهارات الحياتية لاى التلاميذ، وليس مجرد نقل

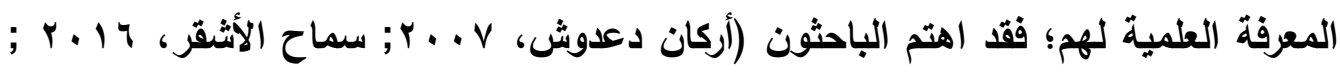
(Novak \& Wisdom, 2018 (Alshammari, 2015; Senler, 2019; Yürük, 2020) لادى الطلاب المعلمين رغم أنه قد يكون عرضيًا، إلا أنه يؤثر سلبًا على اتجاهاتهم نحو مهنة التدريس، والفاعلية للتدريس لايهم. مصادرقاتق التلدريس: تعتبر التربية العملية عامل مهم لإعداد اللطلاب المعلمين؛ حيث تمثل مختبرًا لتطبيق المعرفة النظرية عن التدريس واستراتيجياته، ونظريات علم النفس، وغيرها في أرض التهابه الواقع.

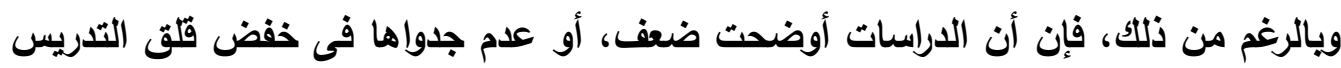

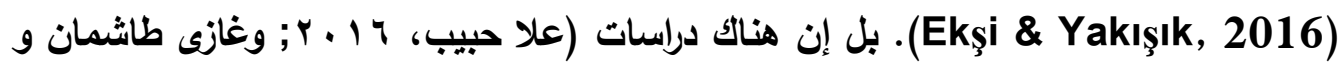

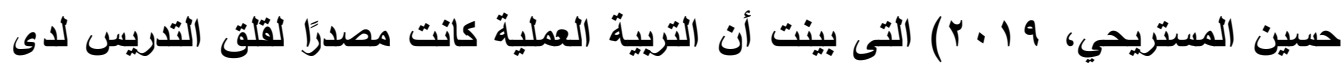
(Mosaddaq \& Barahmeh, الطلاب المعلمين. فقد كشفت دراسة مصدق ويرهمه (2016أن الطلاب المعلمين يعانون من قلث التدريس، والذى تسبيت فيه مصادر مختلفة كاتت أهمها إدارة الفصل الدراسي، وإدارة الوقت، وتخطيط الدروس، وملاحظة المشرف، وطلاقة التحدث باللغة الإنجليزية التى تمثل لغة أجنبية لهم. القلق المرتبط بحالة معينة ينعكس ويتكرر في مواقف معينة. (Kralova \&Tirpakova, 2019; Charisma \& كما أكدات الاراسات Nurmalasari, 2020) المصادر المسببة للقلق، والمؤئرة سلبًا على آداء المعلمين فى الفصل، ويظهر هذا القلق فى الآنى

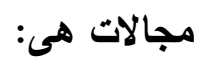

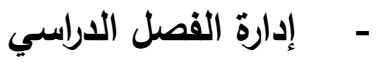
- ملاحظة المشرف لهم أثناء تدريسهم فى الفصل.

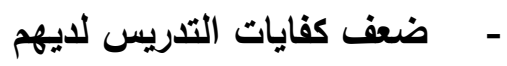
- - تلنى الكفاعة في اللغة الإنجليزية 
ويسمى قلى استخدام لغة أجنبية (تحدثًا، وكتابة، وقراءة، واستماعًا) بقلث اللغة الأجنبيةForeign Language Anxiety. وهذا النوع من القلق يظهر عند أولئك الذين يستخدمن لغة أجنبية غير اللغة الأم. ويُعرف قلق اللغة الأجنبية بأنه "مشاعر فريدة من التوتز والخوف تتعلق باستخدام الفرد لغة أجنبية، وتظهر في سياق الفصل الدراسي، وتنشأ

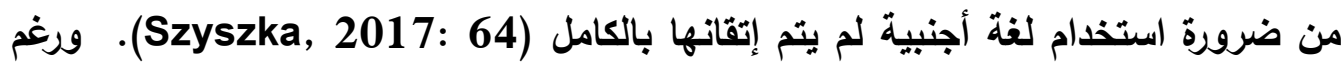
أن قلق اللغة الأجنبية يشمل القلق تجاه كافة مهارات اللغة من تحدث، وقراءة، وكتابة، واستماع، إلا أن قلث التحدث بلغة أجنبية يُعد أحد أهم المتغيرات الوجدانية التي تؤثثر على فئى

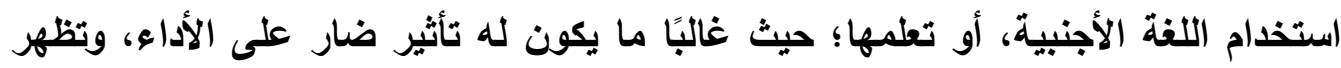
أعراضه فى ارتعاش اليدين والرعشة والتعرق والخوف، والنسيان، وجفاف الفم والحلق، وسرعة ضريات القلب وصرير الصوت (Rajitha \& Alamelue, 2020). وهناك من يرى آنس أن قلث اللغة الأجنبية يمكن أن تسبيه عوامل نفسية أكثر من العوامل المتعلقة بالكفايات اللغوية لاى الفرد، كما أنه قلق عرضي أو موقفي؛ حيث يزول بزوال العوامل المسبية له له .(Alrabai, 2015; Kralova et al., 2017) وقد تناولت الدراسات قلق التدريس لاى معلمى اللغة الإنجليزية كلغة أجنبية، أما قلى التدريس بالإنجليزية كلغة أجنبية لادى معلمى المواد الأخرى مثل العلوم، فتندر الدراسات التى التى تناولته. ومن هذه الدرسات دراسة عزيزة رجب بماليزيا (Rajab, 2007)، التى أوضحت أن النه

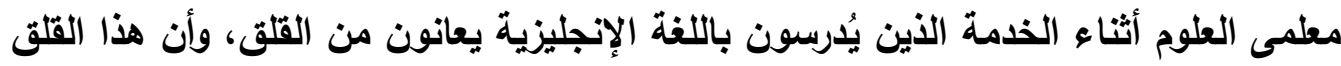
يرتبط بمجالات ثلاثة هى: التواصل مع الطلاب باللغة الإنجليزية، والتقييم السلبي بواسطة

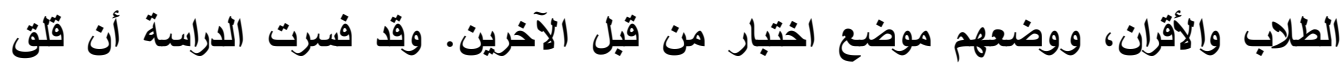

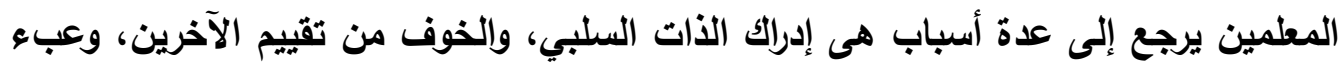
الاضطرار إلى القيام بالمزيد من الإعداد لتدريس العلوم باللغة الإنجليزية مقارنة باللغة الأم.

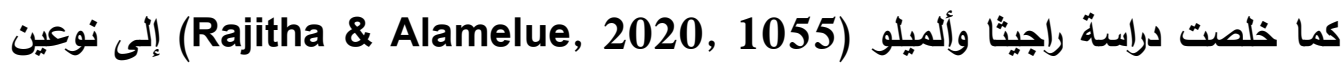
من العوامل التى تسبب قلق تدريس العلوم باللغة الإنجليزية كلغة أجنبية، وهذه العوامل هى:

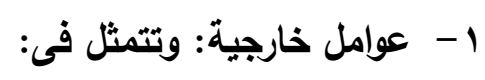

- ضعف المعرفة باللغة الإنجليزية، ويشمل ضعف المفردات، والنحو، وخاصة النطق لدى 
- تقييم الأقران والآخرين، ويقصد به شعور وتفكير الطلاب المعلمين فى تقييم الآخرين

لبفة التى يتحدثون بها.

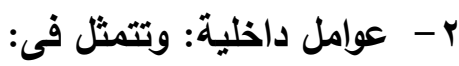

- خوف وقلق الطلاب المعلمين من الموقف والأداء التدريسي، ومواجهة الآخرين سواء

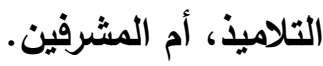
- ضعف الثقة بالنفس، وتثبر إلى ضعف ثقة الطالب المعلم فى قدرته على استخدام اللغة الإنجليزية فى تدريس العلوم. - الخجل، ويشير إلى شعور الطالب المعلم بالخجل من التواصل باللغة الإنجليزية مع الإنع الآخرين من التلاميذ، أو المشرفين، أو حتى الأقران. ومما سبق يتضح أن الاراسات بينت أن الطلاب المعلمين يمكن أن يعانوا من القلق الأى الى الى يرتبط بمجالات متعددة من كفايات التريس. وعليه فإن ما يمكن أن يعانيه الطلاب المعلمون الذين سيقومون بتدريس العلوم بالإنجليزية من قلق التدريس، يمكن أن يكون مزيجًا من القلق الأى يعانيه معلمو العلوم الذين سيدرسون باللغة الأم بالإضافة إلى قلق استخدام اللغة الإنجليزية. وحيث إن كفايات التريس متكاملة، تؤثر فى بعضها البعض، وتثأثر بها؛ فإن بان

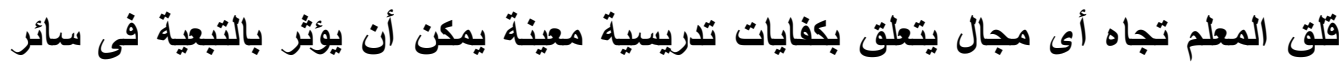

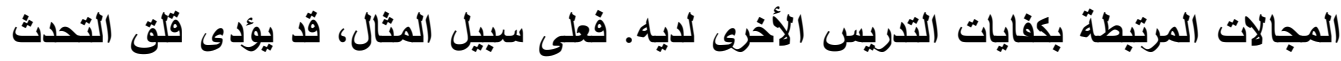

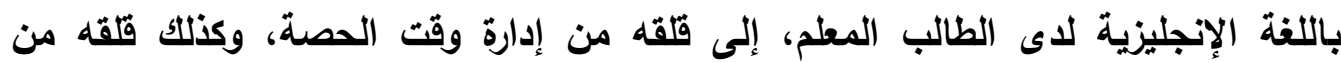
مناقثة طلابه فى محتوى الارس، ومن كم ونوع الأسئلة التى يمكن أن يطرحها عليهم، وهكذا، ومن هنا تتبع أهمية التحقى من مستوى قلق التدريس لاى الطلاب المعلمين، والمعلمين حديثي التخرج، وعلاقته بكفايات تدريس العلوم بالإنجليزية لديهم، ومحاولة خفضه منه

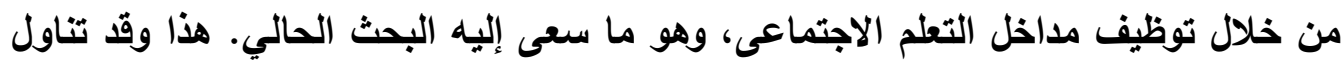

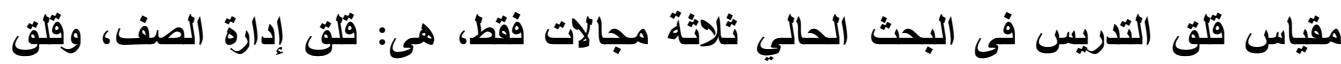
الأداء التذريسي، وقلق استخدام اللغة الإنجليزية فى تدريس العلوم: تحدثًا، وقراءة، وكتابةً،

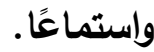


- آليات ومداخل التخلص من قلق التدريس : نظرًا للآثار السالبة التى قد تتجم عن قلق التدريس لدى الطلاب المعلمين، فقد سعت بعض الاراسات للحد منه من خلال عدة ميكانيزمات. فعلى سبيل المثال حددث كاريسما ونورمالاساري (Charisma \& Nurmalasari, 2020) ست آليات لعلاج قلى التدريس، وهى: التكيف، والإعداد الجيد للتدريس، ويناء علاقة جيدة مع المشرف، والتتلاميذ، وتعزيز الثقة بالنفس، وتتمية التفكير الإيجابي، والحفاظ على الهـوء ضد العوامل المثيرة للقلق. وجلير بالذكر أن هذه الآليات تسلط الضوء على دور برنامج التربية العملية، وما يمكن أن أن يقوم به مشرف الجامعة من علاج قلق التدريس لاى الطلاب المعلمين من خلال توظيفه آليات ومداخل مختلفة، وهو ما أكدته دراسة مينون (Menon, 2020) التى أوضحت أن استخدام التحفيز والدعم من قبل مشرف الكلية ساعد الطلاب المعلمين فى التظلب على الشعور بالقلق تجاه مشرف المدرسة، وحفزهم على استخدام أساليب الاستقصاء فى فصول الفيزياء، رغم رفض هذا المشرف لها. كما سعى بعض الباحثين إلى خفض قلق تدريس العلوم من خلال تبنى استراتيجيات

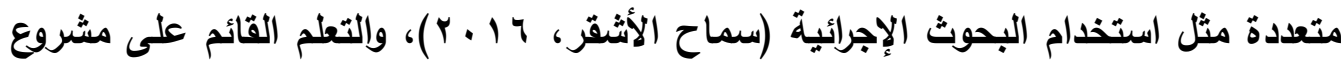
الطباعة ثلاثية الأبعاد (Novak \& Wisdom, 2018). ويينت الاراسات أن استخدام خرائط المفاهيم المفاهيم التعاونية (Czerniak \& Haney, 1998)، وأساليب التفاعل الاجتماعى (بتول زبيري، وآسيا عبد الغني، IV V. V مع الطلاب المعلمين، والبنائية الاجتماعية (Ali, 2015) مع المعلمين حديثى التخرج، لها أثر إيجابى فى خفض فلى التدريس لديهم. كما كثفت دراسة بيلتون (Pelton, 2014) أن استخدام ندوات التدريس ف قد أسهمت فى تخلص الطلاب المعلمين من قلقهم، وزادتهم ثقة

فى مهاراتهم التدريسية. أما بالنسبة للطلاب المعلمين الذين يتم إعدادهم للتدريس بلغة أجنبية، فقد استخدم كرالوفا Psycho- برنامج التدريب النفسي الاجتماعي (Kralova et al., 2017) Social Training

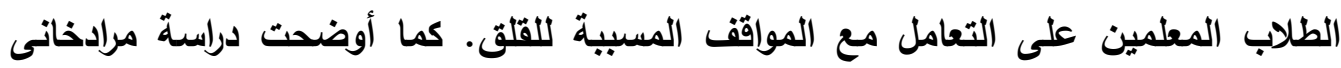
وآخرين (Moradkhani et al., 2017) أن الممارسات التأملية التعاونية للطلاب 
المعلمين تعالج قلق التدريس لايهم، وتحسن من أدائهم التدريسي باللغة الإنجليزية كلغة

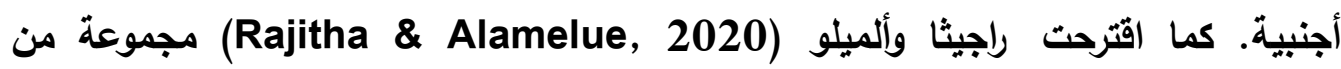
الاستراتيجيات التى يمكن أن تسهم فى خفض قلى تدريس العلوم باللغة الإنجليزية لاى الطلاب المعلمين، مثل: قراءة الصحف والكتب، واستخدام القواميس، ومشاهدة الأخبار التليفزيونية، والأفلام، والتحدث إلى بعضهم البعض باللغة الإنجليزية. وجدير بالذكر أن معظم الاستراتيجيات التى استخدمت لخفض قلث تدريس العلوم باللغة

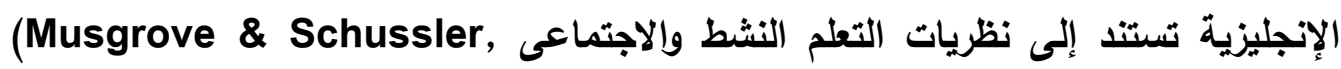
(2020. ومن ثم فقد تبنت برامج إعداد معلمي المواد غير اللفوية فى الدول غير الناطقة بالإنجليزية مدخل التعلم القائم على التكامل بين المحتوى واللغة (CLIL) كأحد مداخل التعلم الاجتماعي؛ بغية إكسابهم كفايات التدريس بالإنجليزية دون توتر أو قلث. لذا فقد عمد البحث الحالي إلى تبني مدخل (CLIL) لتدريب الطلاب المعلمين على تدريس العلوم بالإنجليزية. وقد استفاد البحث الحالي من نتائج هذه الدراسات فى توظيف العديد من الآليات والتكليفات لطلاب مجموعة البحث؛ بغية اختزال قلق تدريس العلوم بالإنجليزية لايهم تدريجيًا. فعلى فئ

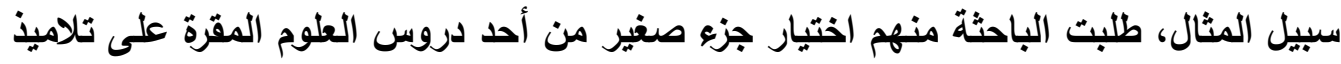
المرحلة الابتدائية، وإلقيام بتدريسه مرة أمام المرآة، ومرة أخرى تسجيله بالفيديو وإعادة مشاهدته، وتأمل أدائهم، وتقييمه. وكذلك قراءة وترجمة أى إعلانات تصادفهم، وقراءة المكتوب على أى زجاجات وأغلقة العلاج بالمنزل، وترجمة بعض الحكم والأمثال الثعبية المصرية إلى الإنجليزية، ومناقشة بعضهم البعض فيها، وغيرها من الأنشطة التى أضفت جوًا من المرح أثناء التدريب.

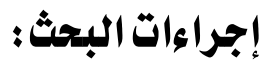
ا ـ الاطلاع على الأدبيات ذات الصاء الصلة بكل من:

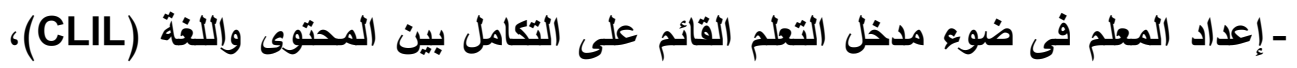
(Hernández, 2017; Stoddart et al., 2017; ) وتدريس العلوم باللغة الإنجليزية Turner, 2019 وكفايات التدريس (مثل: وثيقة المستويات المعيارية للمعلم قبل الجامعى،

$$
\cdot(r \cdot . q
$$


ـ قلث التدريس، وقلث تدريس العلوم، وقلث تدريس العلوم باللغة الإنجليزية (مثل:

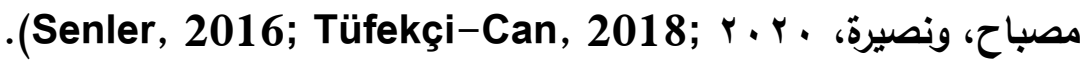

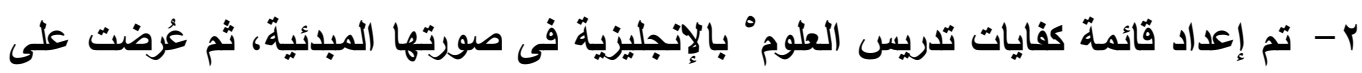
السادة المحكمين (ملحق ا )، وتم تعديلها فى ضوء آرائهم؛ لتصبح فى صورتها النهائية

$$
\text { (ملحق r). }
$$

r- صُممت بطاقة ملاحظة كفايات تدريس العلوم باللغة الإنجليزية لدى الطلاب المعلمين، وتم ضبطهما ومراجعتهما، والتأكد من صدقهما من خلال عرضهما على مجموعة من السادة

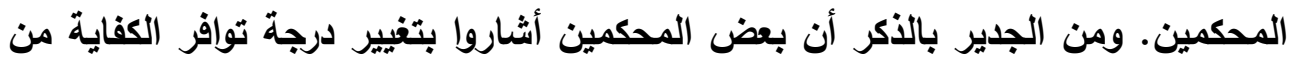
(متوسطة- ضعيفة- كبيرة) إلى: (غير موجودة- ضعيفة- متوسطة- كبيرة- كبيرة جدًا).

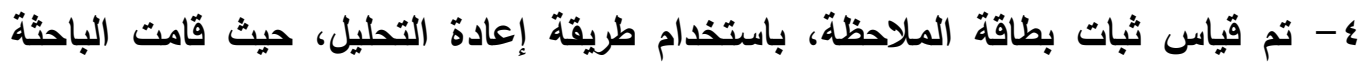
بتحليل الممارسات التدريسية التى تم تسجيلها بالفيديو لتسعة من الطلاب المعلمين خارج

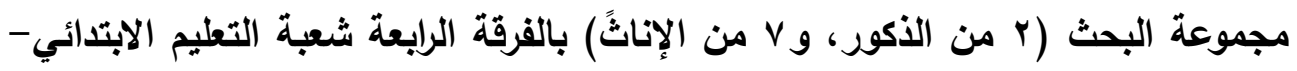
تخصص علوم، وذلك فى بداية التحاقهم بدورة تدريس العلوم بالإنجليزية فى أكتوير عام

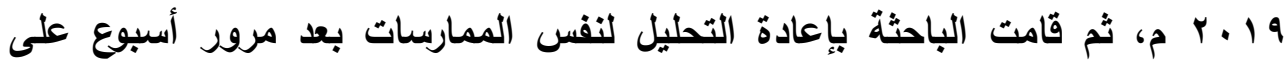
عملية التحليل الأول. وياستخدام معادلة كوير، تم حساب نسبة الاتفاق لجميع كفايات التدريس التى شملتها بطاقة الملاحظة. وجدير بالذكر أنه تم حذف بعض كفايات التدريس ذات الصلة بمجال "استخدام الوسائل التعليمية وتوظيف التكنولوجيا فى التدريس"؛ حيث لم تصل النسبة المئوية للاتفاق بينها إلى قيم مقبولة، بينما تم قبول كفايات التدريس الأخرى؛ حيث حصلت هذه الكفايات على نسبة مئوية للاتفاق ذات قيم مقبولة تراوحت بين

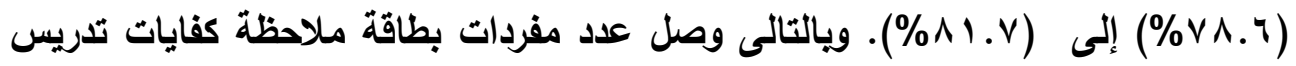

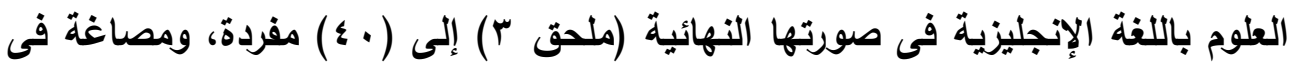


صورة سلوكيات تدريسية قابلة للملاحظة والقياس، وقسمت درجة توافرها إلى خمس .

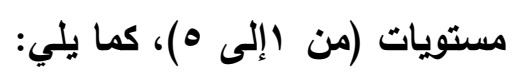

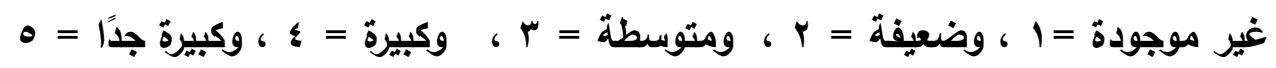

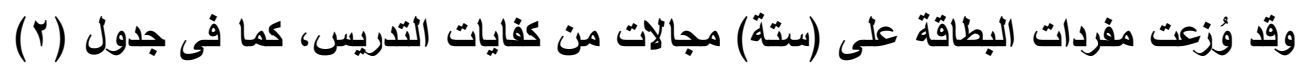
التالي: - n

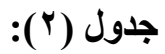

توزيع عبارات بطاقة الملاحظة على مجالات كفايات تدريس العلوم بالإنجليزية

\begin{tabular}{|c|c|}
\hline عدد العبارات & المجال \\
\hline $\mathrm{v}$ & - - التخطيط \\
\hline 7 & - إدارة الصف \\
\hline 9 & - عرض الدرس \\
\hline$\varepsilon$ & ـ المعرفة العلمية \\
\hline$\Lambda$ & الإنجليزية في تدريس العلوم \\
\hline 7 & - - التقويم \\
\hline$\varepsilon$ & العدد الكلى للعبارات \\
\hline
\end{tabular}

ه- تم تصميم مقياس قلق تدريس العلوم باللفة الإنجليزية لاى الطلاب المعلمين. وقد تم

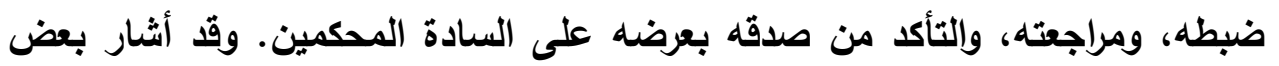

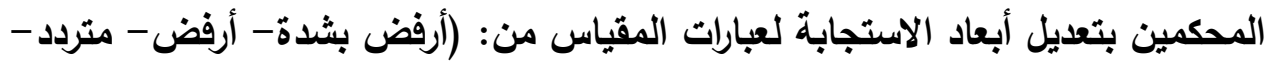

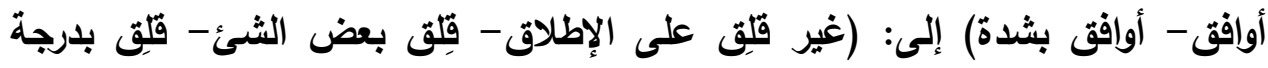

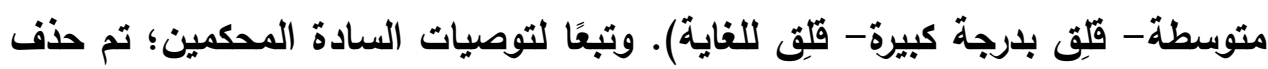
بعض العبارات نتيجة تكرار معناها، كما تم إعادة صياغة العبارات السالبة إلى عبارات موجبة، وكذلك إعادة صياغة البعض الآخر؛ لضبطها لغويًا. فعلى سبيل المثال، تم إعادة صياغة العبارة: أثناء قيامى بتدريس العلوم بالإنجليزية، أشعر بالقلق من قدرتى لعنى

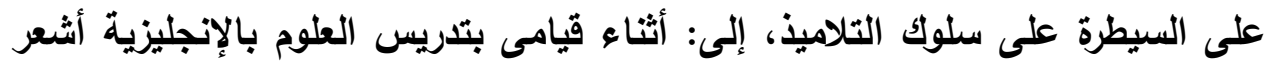

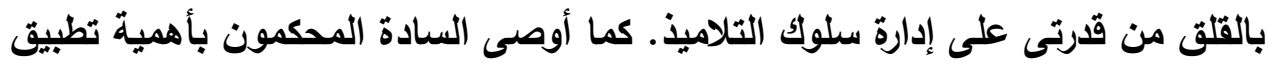

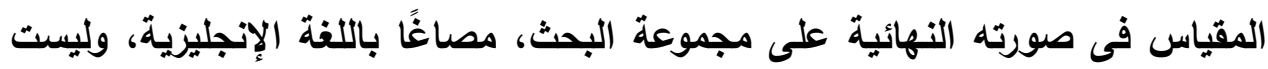
العربية. ד- تم تطبيق مقياس قلق تدريس العلوم باللغة الإنجليزية، المصاغ بالإنجليزية على

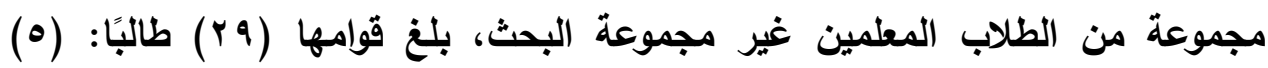


ذكورًا، و (؟Y) إناثًا، وهم الطلاب الأين التحقوا بدورة تدريس العلوم باللغة الإنجليزية بالكلية فى أكتوير 9 أب م. وقت تم حساب ثبات المقياس باستخدام طريقة "التجزئة

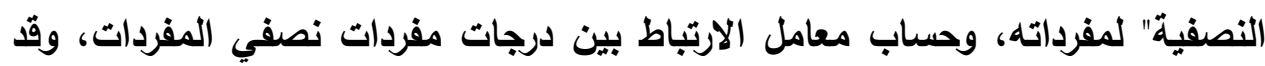

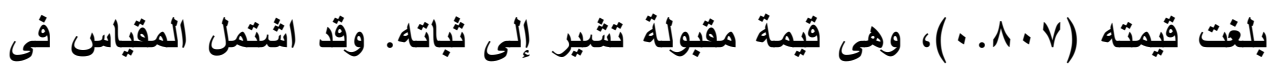

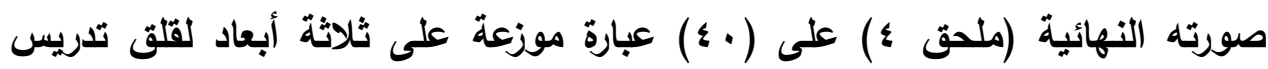

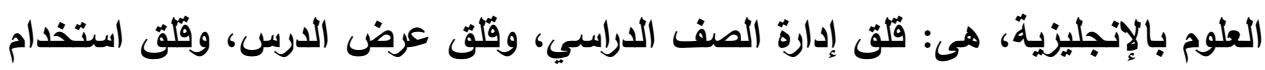
اللغة الإنجليزية فى تدريس العلوم. وقد وزعت العبارات على هذه الأبعاد كما فى جدول

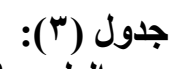

توزيع عبارات مقياس قلق تدريس العلوم بالإنجليزية على أبعاد المقياس

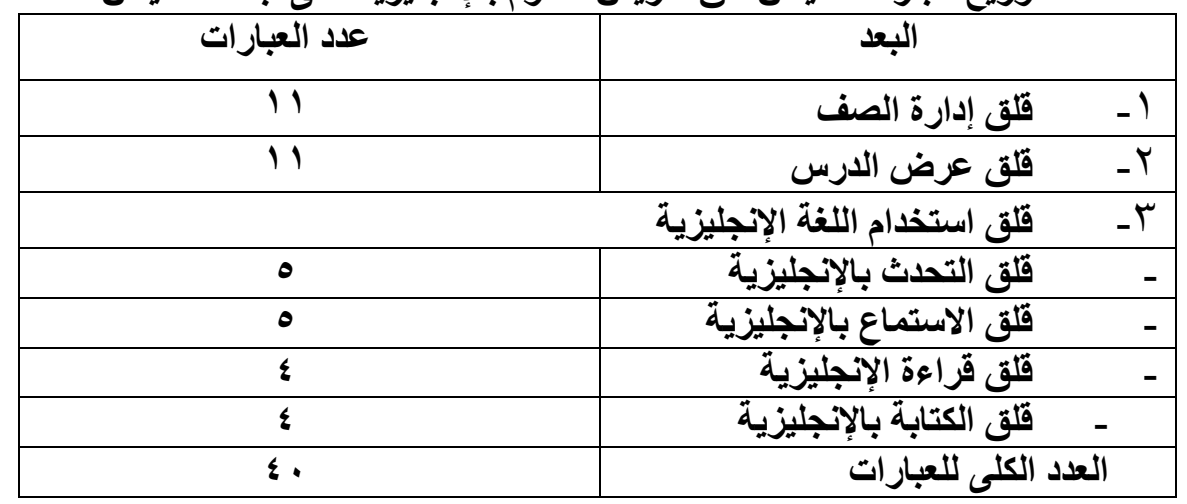

V - فى أول لقاء بين الباحثة ومجموعة البحث، ويعد أن أنهوا دراسـة الجزء الأول من الدورة التدريبية، والمعروف باسم "إدارة الصف الدراسي Classroom Management"، تم تمدئ

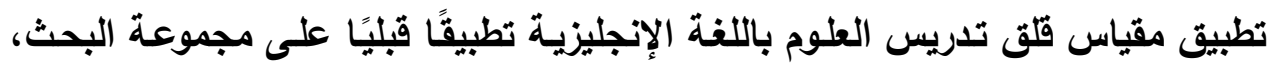

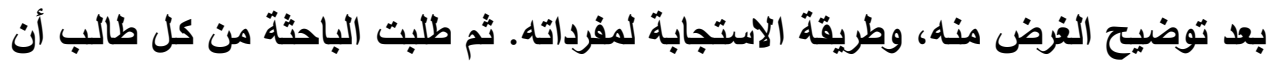

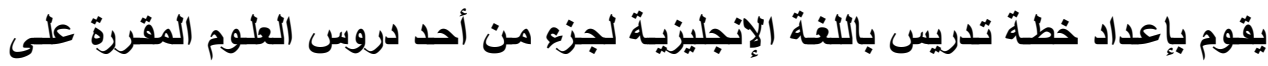

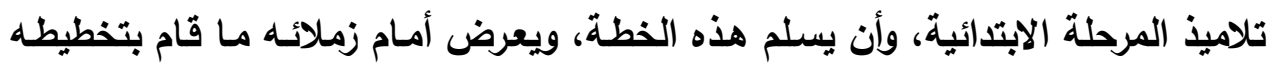

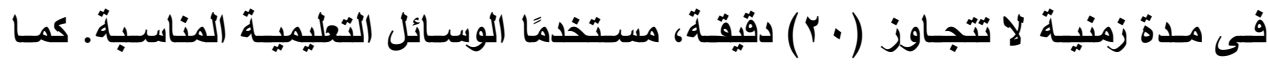

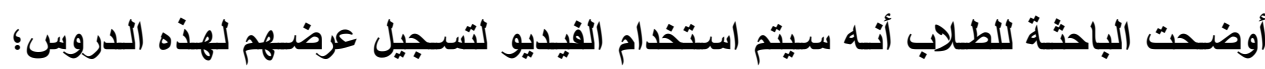
وذلك لغرض البحث الحالي فقط، مع الحفاظ على خصوصيتهم وهويتهم. كما طلبت عدم 
التعليق على الطريقـة التـى يعرض بهـا أى طالب درسـه، وإنمـا يكون سـائر الطـلاب

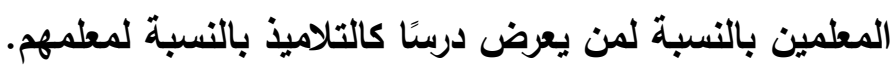

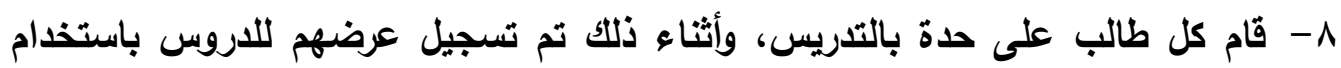
كاميرة القيديو. 9- تم إعداد دليل المدرب، وأولق العمل اللازمة لتدريس وتعلم محتوى كتب العلوم للفصل الدراسي الثانى، المقررة على تلاميذ المرحلة الابتائية (الصفوف: الرابع، والخامس، والسادس) بمدارس اللغات الرسمية، باستخدام مدخل (CLIL) (ملحق •). واشتتمل دليل المدرب على الأهداف الإجرائية لكل جلسة، ومخطط التدريس، واستراتيجيات التعلم

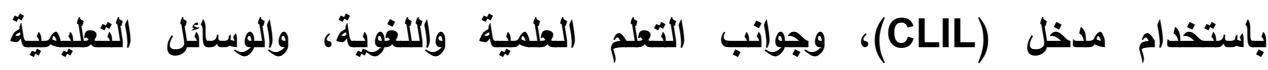
المستخدمة (مثل القواميس، وجهاز العرض، والفيديوهات، والنماذج العلمية، وغيرها)، وروابط المواقع التعليمية المناسبة لمحتوى كل جلسة. واشتملت أولق العمل على ولى الأنشطة والتدريبات المصاحبة لكل جلسة، وكذلك أساليب التقويم، والتكليفات التى طلب جلب الته من مجموعة البحث القيام بها فى المنزل. • 1 - قامت الباحثة بتدريس المحتوى المحدد وفقًا لمدخل (CLIL)، واستغرق ذلك ( • ( ) جلسات، بواقع جلستين: يومي الأحد والخميس من كل أسبوع، موزعة كما بجدول ( ؛ ) التالي: - n

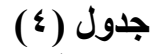

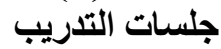

\begin{tabular}{|c|c|c|c|}
\hline مدة كل جلسة & عدد الجلسات & اللارحتوى الفيل & على العلوم المقرى كتاب \\
\hline \multirow{3}{*}{ 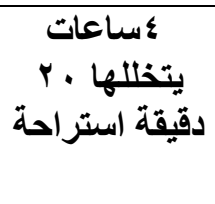 } & $r$ & \multirow[t]{3}{*}{ الثاني } & الرابع \\
\hline & $r$ & & الخامس \\
\hline & $\varepsilon$ & & السادس \\
\hline • • سـاعة & 1. & & العدد الكلي \\
\hline
\end{tabular}

1 - ا فى نهاية الجلسة العاشرة، تم تطبيق مقياس قلق التدريس تطبيقًا بعديًا على مجموعة البحث، وطلب من كل منهم تخطيط أحد دروس العلوم بالإنجليزية وإعداد الوسائل التعليمية اللازمة؛ وذلك لعرضه خلال (0 1 - ب ) دقيقة فى الجلسات التالية. وأثناء 
هذه الجلسات تم تجميع خطط الاروس، كما تم تسجيل الأداء التدريسي لكل متدرب باستخدام كاميرة الفيديو. r ا - تم تفريغ نتائج التطبيق القبلي والبعدي لمقياس قلق تدريس العلوم باللغة الإنجليزية، ومعالجتها إحصائيًا، حيث حسبت المتوسطات الحسابية، والانحرافات المعيارية، والنسب المئوية لارجات الطلاب. rا - قامت الباحثة بمشاهدة تسجيلات الفيديو التى تحوى الأداء التدريسي (القبلي، والبعدى) لكل طالب؛ لتحليل ما تضمنته من كفايات التدريس، باستخدام بطاقة ملاحظة كفايات تدريس العلوم باللغة الإنجليزية، وتم رصد الارجات. ع ا- لاختبار صحة فروض البحث؛ عُولجت النتائج إحصائيًا باستخدام البرنامج الإحصائي (SPSS)

$$
\text { المئوية، وقيمة (ت)، ومعامل الارتباط لبيرسون. }
$$

ه 1 - تم تفسير النتائج، وتقديم التوصيات، والبحوث المقترحة.

نتائج البحث:

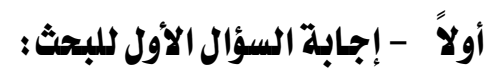

تبعًا لإجراءات وخطوات البحث السابق ذكرها، وللإجابة عن السؤال الأول للبحث، الذى ينص على "ما كفايات التدريس اللازمة لتدريس العلوم باللغة الإنجليزية فى مرحلة التعليم

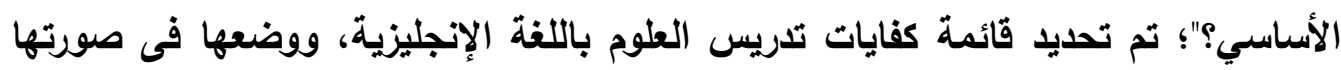
النهائية (ملحق r) التى اشتملت عشر مجالات لكفايات التدريس تم صياغتهم فى صورة لإنى

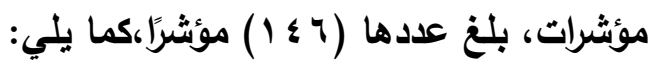


جلول (•):

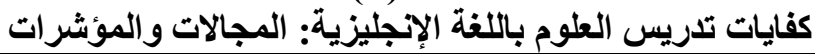

\begin{tabular}{|c|c|c|}
\hline العدد الكلي للمؤشرات فى & علدايات هذا المجال الدالة على & في القائمة كفايات التّريس \\
\hline \multirow{10}{*}{$1 \leqslant 7$} & Yr & 1 - التخطيط \\
\hline & 11 & r- إدارة الصف \\
\hline & 17 & rـ تنفيذ الارس \\
\hline & 11 & ــ المادة العلمية \\
\hline & $\Lambda$ & •ـ الاتصليم ال وتكنولوجيا \\
\hline & rr & דـ اللغة الإنجليزية \\
\hline & Ir & V- التقويم \\
\hline & 9 & ^ــ السياق المجتمعي \\
\hline & $1 \varepsilon$ & 9 - مهنية المعلم \\
\hline & 14 & • 1- التنمية المهنية \\
\hline
\end{tabular}

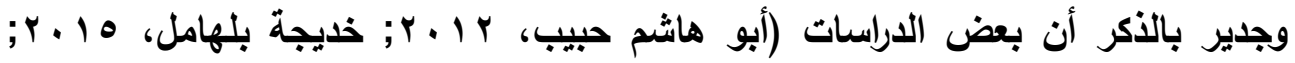
Amalia \& Saraswati, 2018) مجالات محددة، هى: التخطيط، والتنفيذ، والتقويم، بينما أكلات دراسات أخرى وهيئات

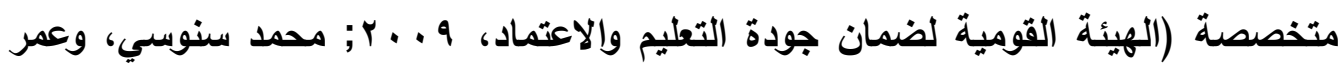

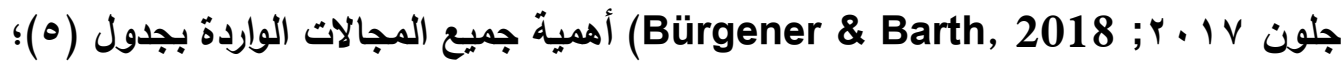
لأنها جميعًا مترابطة وتصب فى بوتقة العملية التعليمية، وهو ما تم التحقق منه من خلال تحكيم قائمة كفايات تدريس العلوم بالإنجليزية. ثانيًا - إجابة السؤال الثاني للبحث: للإجابة عن السؤال الثاني للبحث، الأى ينص على: "ما درجة توافر كفايات تدريس العلوم باللغة الإنجليزية لاى مجموعة البحث قبل تدريبهم باستخدام مدخل (CLIL)؟"، تم التحقق

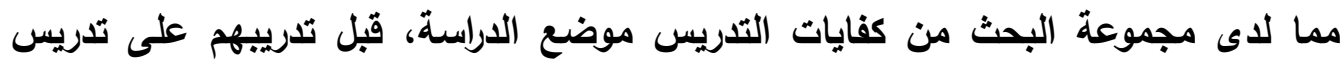
العلوم بالإنجليزية باستخدام مدخل (CLIL). وتمثل هذه الكفايات مجموعة الممارسات

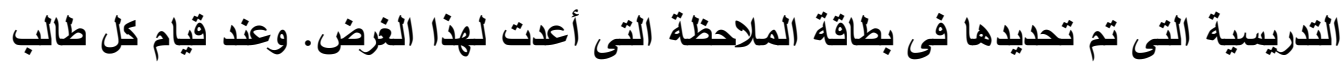
منهم بعرض أحد دروس العلوم، كان من الضرورى جعل هذه المواقف قريبة إلى حـ ما لما يمكن أن يحدث فى الفصول العادية بالمدرسة، بأن يعرضها على سائر زملائه من مجموعة جله 
البحث؛ فيقوموا بدور التلاميذ، ويكون لهم حرية مناقشة زميلهم فيما يعرضه، والاستفسار

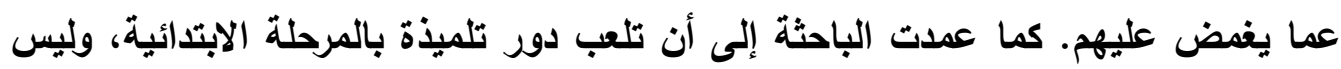

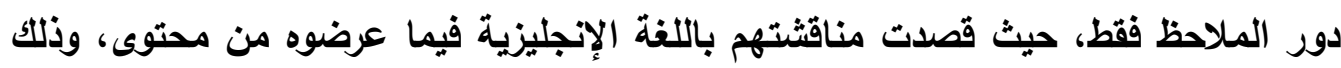
من خلال طرح بعض الأسئلة للاستفسار عما قاموا بشرحه. وفى بعض الأحيان تظاهرت

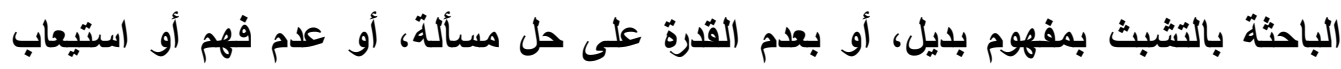

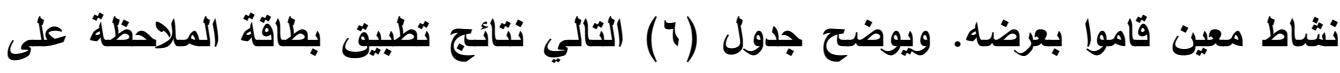

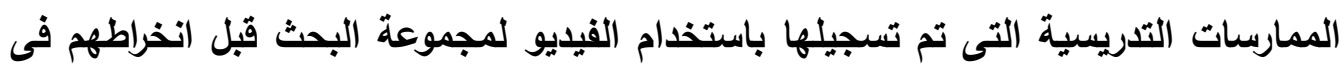

التدريب القائم على مدخل (CLIL):

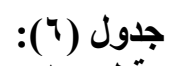

المتوسطات الحسابية والانحرافات المعيارية لدرجات مجموعة البحث في كفايات تدريس العلوم

\begin{tabular}{|c|c|c|c|c|c|c|}
\hline أفراد & الكفاية & $\begin{array}{l}\text { المئوية } \\
\text { \% }\end{array}$ & الالحياري & الحسابي & الكفاية لكل & 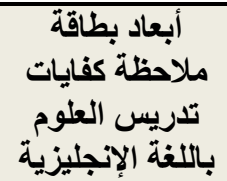 \\
\hline \multirow[t]{6}{*}{$r \cdot$} & كبيرة & $\Lambda 0.1 \leqslant \mu$ & $1 . r v 0$ & rq.^. & ro & - للادرسطيط \\
\hline & ضعيفة & $0 . . V V$ & $1 . K Y T$ & $10 . r \mu$ & $r$. & - إدارة الصف \\
\hline & ضعيفة جدًا & $r V_{.} \cdot \varepsilon$ & $1.0 \mathrm{VV}$ & Ir.IV & $\leqslant 0$ & - الدرض \\
\hline & ضعيفة & $\varepsilon \Lambda_{0} \wedge$ Q & $1.19 \varepsilon$ & Q.V V & $r$. & - العمية المعة \\
\hline & ضعيفة & $\leqslant 1.7 v 0$ & $1.90 r$ & $17.7 \mathrm{~V}$ & $\varepsilon$. & - الإنجليزية فلى اللغة \\
\hline & ضعيفة & $\begin{array}{l}\leq 4 . r \% \\
\sum \Lambda . \vee T 0\end{array}$ & $\begin{array}{l}1.110 \\
r .991\end{array}$ & $\begin{array}{l}1 r .9 . \\
97.0 \leq\end{array}$ & $\begin{array}{l}r . \\
r . .\end{array}$ & - الارجة التقويم العظمى \\
\hline
\end{tabular}

ويتضح من جدول (†) أن قيم متوسطات درجات مجموعة البحث فى كفايات تدريس

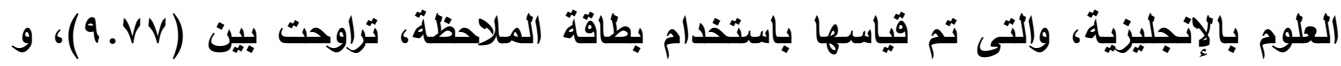

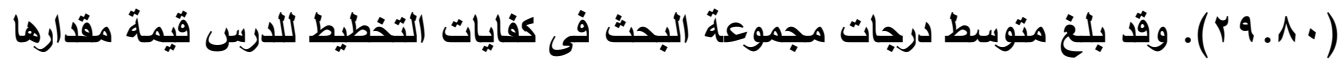

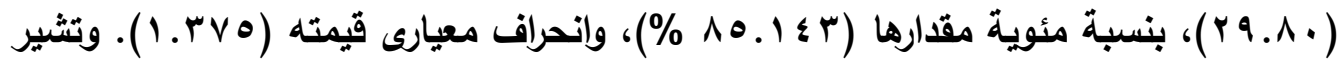
هذه النتيجة إلى توافر كفايات التخطيط لتدريس العلوم باللفة الإنجليزية لاى عينة البحث 
الحالى بدرجة كبيرة قبل تدريبهم. وتتضح هذه النتيجة أيضًا من خطط الاروس التى قاموا بعرضها، وتم فحصها؛ حيث اشتملت على مجموعة من الأهداف الإجرائية مصاغة بطريقة صحيحة، ومرتبطة بموضوع الدروس. ويسؤال مجموعة البحث عن المصادر التى استعانوا

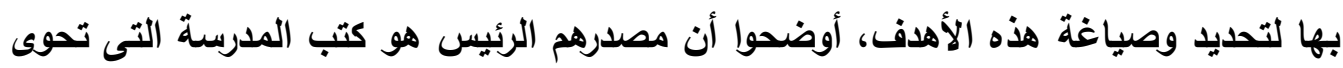
بالفعل الأهداف الإجرائية لكل وحدة دراسية، وكل درس أيضًا، وهو ما يفسر توافر كفايات التخطيط لايهم بلرجة كبيرة. ويوضح جدول (†) أيضًا أن قيمة متوسط درجات مجموعة البحث فى كفايات إدارة الصف

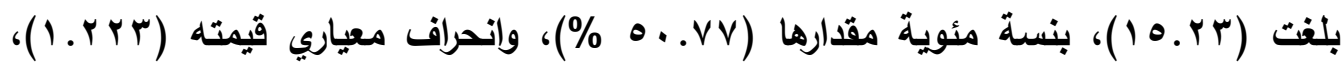
وهى تثير إلى أن توافر الكفايات المطلوية لإدارة الصف لايهم بدرجة ضعيفة. أما أقل درجة

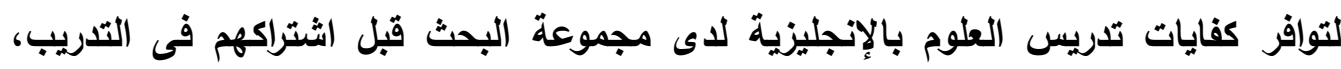

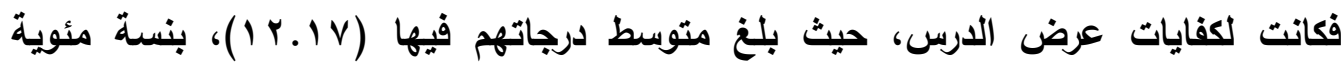

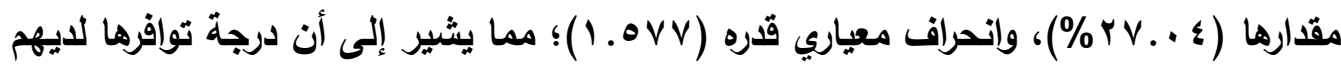

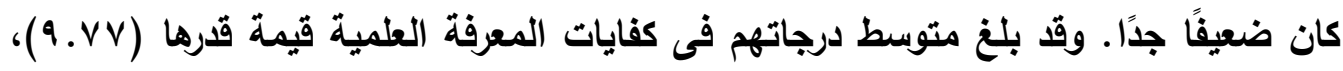

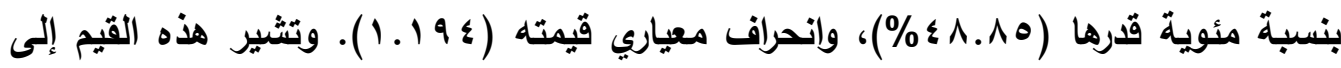
ضعف توافر كفايات المعرفة العلمية لاى مجموعة البحث؛ حيث لم يقوموا بربط موضوعات الاروس التى عرضوها بالمواد الدراسية الأخرى، ولم يستخدموا مصادر متنوعة للمعرفة العلمية المتضمنة بهذه الدروس. ويالرجوع إلى جلول (7)، نجد أيضًا ضعف توافر كفايات استخدام اللغة الإنجليزية فى تدريس العلوم لاى عينة البحث قبل التدريب باستخدام مدخل (CLIL)؛ حيث بلغت قيمة

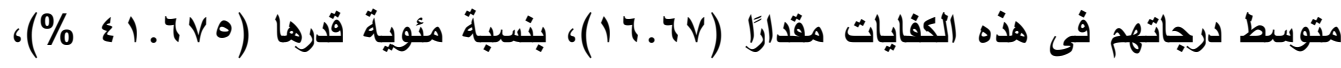

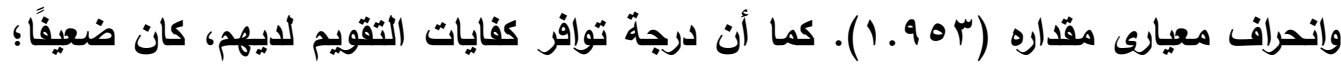

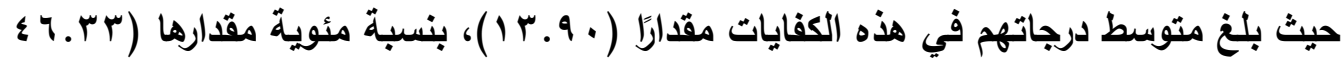
\%)، وانحراف معيارى قيمته (11.1. ). ويتضح ذلك من الأسئلة التى طرحها الطلاب المعلمون أثناء عرض الدروس، حيث كانت فى بعض الأحيان غير دقيقة، وتركز على من ولى مستوى التذكر لبعض المفاهيم المتضمنة بهذه الدروس. أما متوسط الارجة الكلية لمجموعة الاحئ

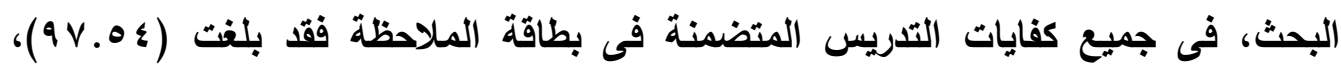




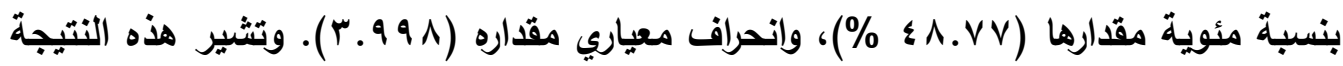

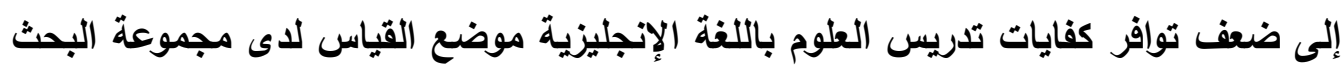
قبل اشتراكهم فى البحث الحالي. وعليه يتم قبول الفرض الأول للبحث الذى ينص لإنى على: "ضعف درجة توافر كفايات تدريس العلوم باللغة الإنجليزية لاى مجموعة البحث قبل تدريبهم

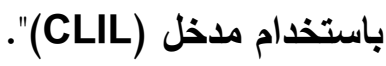

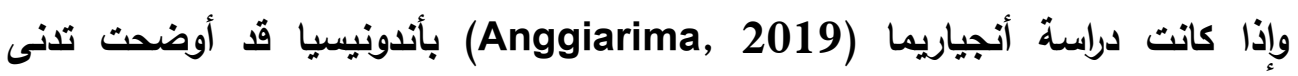
كفايات تدريس العلوم باللغة الإنجليزية لدى معلمى العلوم حديثى التخرج على الرغم من دراستهم المقررات الجامعية باللغة الإنجليزية أثناء مرحلة إعدادهم، فقد يرجع ضعف لإنف توافر كفايات تدريس العلوم لدى الطلاب المعلمين فى مجموعة البحث الحالى، إلى دراستهم

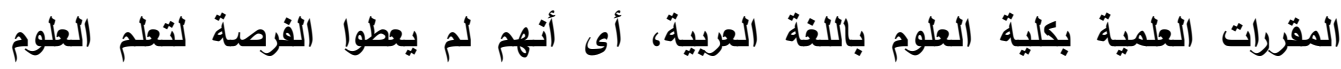
بالإنجليزية، بالإضافة إلى أنهم لم يتم تدريبهم على التدريس بالإنجليزية من قبل، حيث كانت بلته المرة الأولى لهم لعرض درس بالإنجليزية؛ مما نتج عنه ضعف لالده أدائهم التدريسى بالإنجليزية.

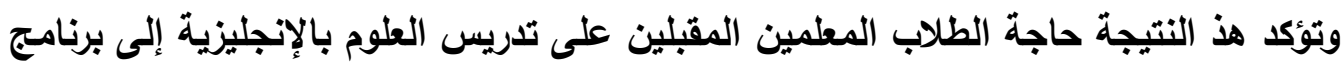
إعداد يتم فيه دمج تعلم كل من المحتوى العلمي، واللغة الإنجليزية فى سياق متكامل، واستخدام استراتيجيات تدريس متنوعة، تتيح لهم تأمل هذا السياق لإدراك كيفية حدوث التعلم، وتسهم فى تنمية كفايات التدريس المطلوية.

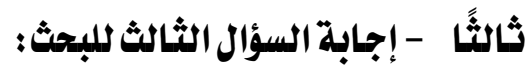
للإجابة عن السؤال الثالث للبحث الأى ينص على: "ما مستوى قلق تدريس العلوم باللغة

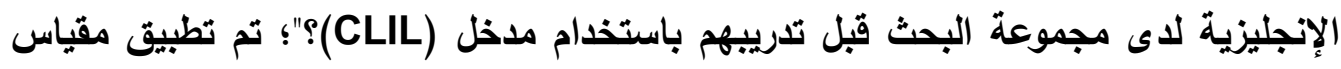
قلق تدريس العلوم باللغة الإنجليزية قبليًا على مجموعة البحث، وتم حساب قيمة كل من المتوسطات الحسابية، والانحرافات المعيارية للارجات الخام لكل بُعد من أبعاد المقياس، لإنه

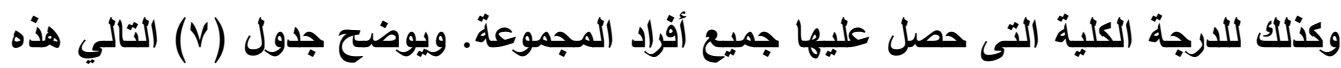




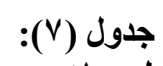

المتوسطات الحسابية والانحرافات المعيارية لارجات مجموعة البحثث فى التطبيق القبلى لمقياس قلق

تاريس العلوم باللغة الإنجليزية لئية

\begin{tabular}{|c|c|c|c|c|c|c|}
\hline أفراد & مستوى القلق & المعياري & $\begin{array}{l}\text { المئوينة } \\
\text { النسبة }\end{array}$ & الحتوسطي & العظمى لكل & أبعاد مقياس قلثق التّريس باللغة \\
\hline \multirow[t]{8}{*}{$r}$. & مرتفع & $r . I V Y$ & 90.90 & $r q . r v$ & 00 & 1- إدارة الصف \\
\hline & مرتفع & $r .09 \wedge$ & $T \cdot . \leqslant Y$ & rr.ru & $\Delta 0$ & r - عرض الدرس \\
\hline & & & & & 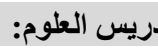 & r- استخدام اللغة الإنجليزية فح \\
\hline & مرتفع & Y.010 & $\vee \wedge . I r$ & 19.04 & ro & الإنجليزية \\
\hline & مرتفع & Y.A. $\varepsilon$ & $7 \varepsilon .$. & $17 .$. & ro & - الإنجليزية أثناء التدريس اللغة \\
\hline & مرتفع & 1.700 & $7 . .70$ & Ir.ir & r. & الإنجليزية القراءة باللغة \\
\hline & متوسط & $r . \varepsilon \cdot r$ & 0 0 ט & $1 \cdot . \wedge \mathrm{V}$ & $r$. & الإنجليزية الكتابة باللغة \\
\hline & مرتفع & $\begin{aligned} 11 . r \leq \\
\Lambda\end{aligned}$ & $7 \varepsilon .10$ & Ir^.•r & r.. & الدرجة العظمى للمقياس \\
\hline
\end{tabular}

يُلاحظ من جدول V) أن قيم متوسطات استجابة مجموعة البحث لمقياس قلق تدريس

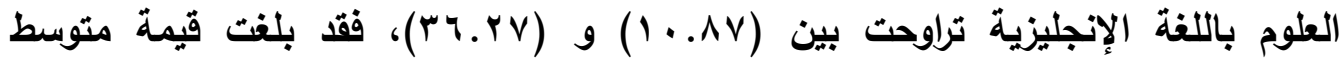

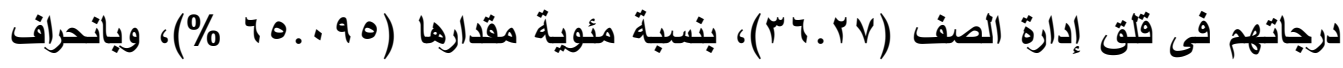

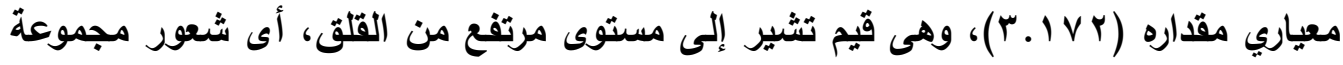
البحث بدرجة عالية من القلق تجاه إدارة الصف عندما يقوموا بتدرس العلوم بالإنجليزية. هذا مهات وقد كان مستوى قلق عرض دروس العلوم باللغة الإنجليزية لاى مجموعة البحث مرتفعًا

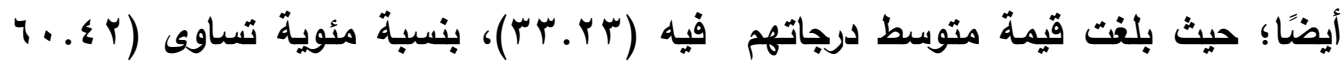

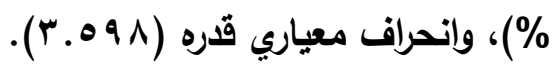

كما بلغت قيمة متوسط درجات مجموعة البحث فى قلث التحدث باللغة الإنجليزية أثناء

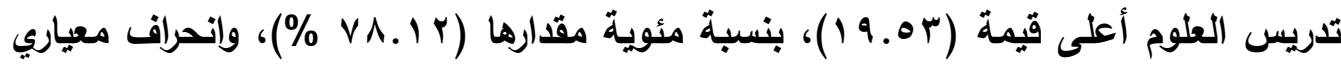

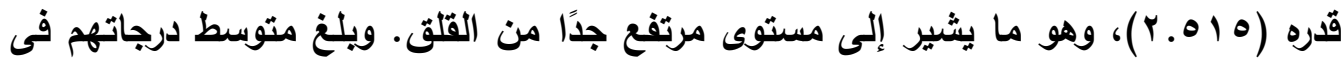
قلق الاستماع إلى اللغة الإنجليزية أثناء تدريس العلوم ( (... 19)، بنسبة مئوية مقدارها

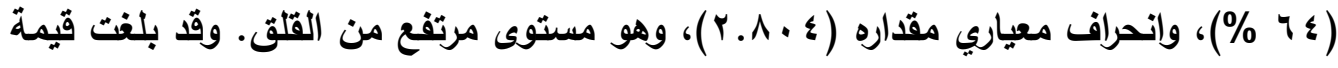

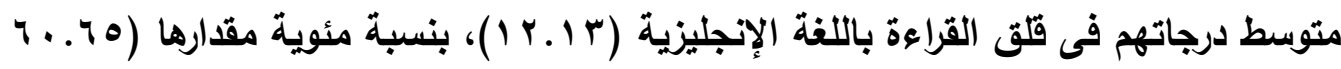
\%)، وانحراف معياري قيمته (100.1.)، وهو ما يشير أيضًا إلى مستوى مرتفع من القلق. 
أما بُعد قلق الكتابة باللغة الإنجليزية أثناء تدريس العلوم، فقد بلغ متوسط درجات مجموعة

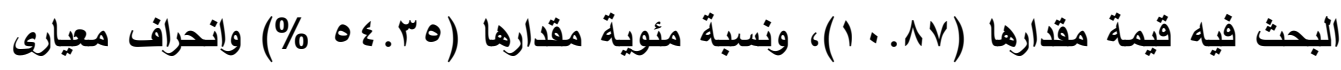

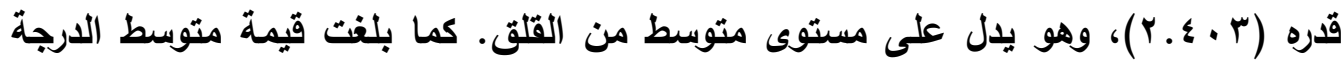

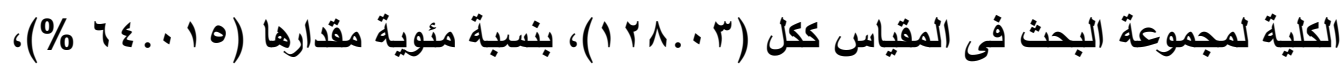

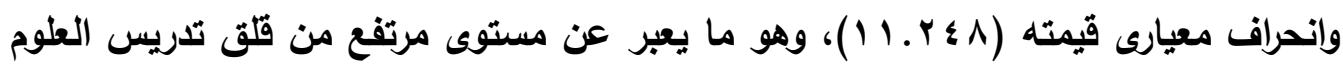

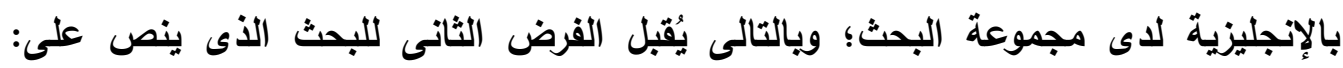

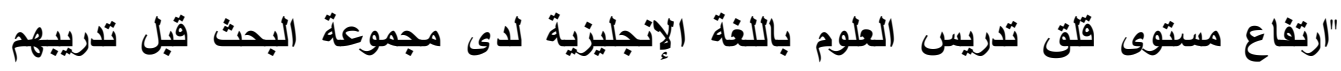

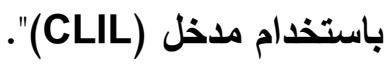
ويالرجوع إلى جدول (V))، نجد أن قلق التحثث بالإنجليزية لاى مجموعة البحث أثناء

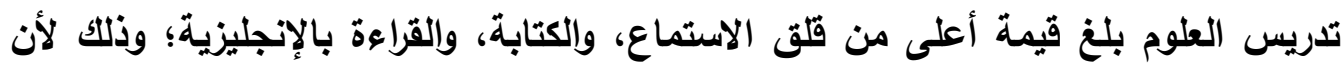

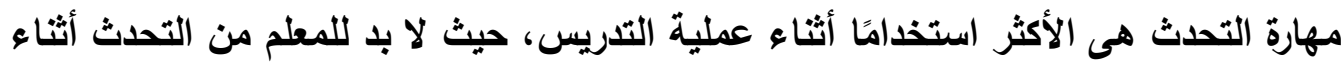
شرح الدرس، ومناقثة التلاميذ، وطرح الأسئلة، وغيرها. هذا وتثير نتائج التطبيق القبلي

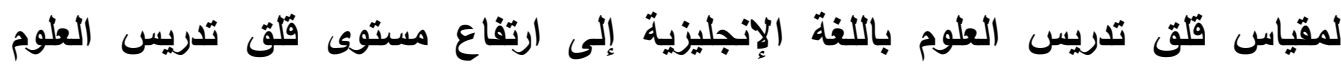

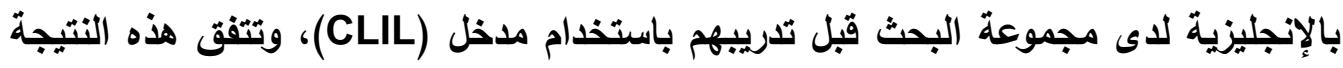

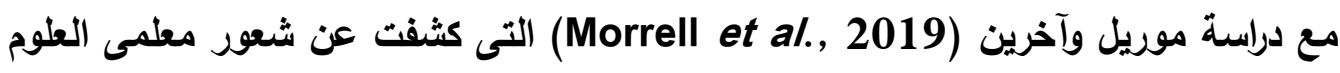

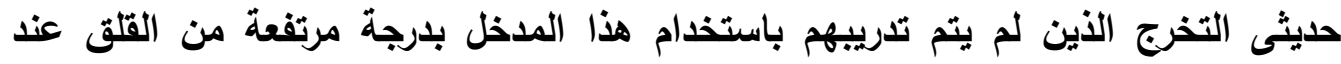
تدريس العلوم بالإنجليزية فى المدارس المتوسطة بإسبانيا.

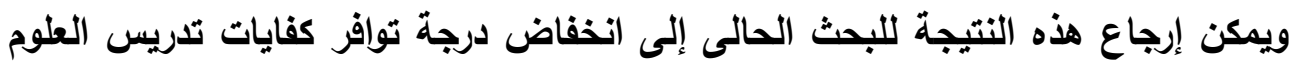

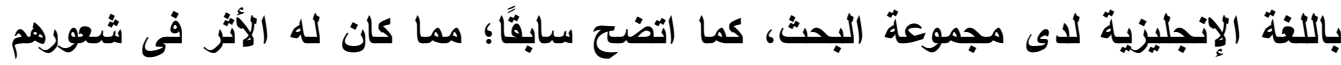
بالرهبة من ممارسة التدريس بالإنجليزية أمام بعضهم، خاصة وأنهم لم يستخدموا اللغة الإنة

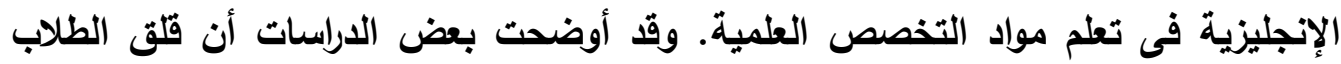
المطلمين من التدريس باستخام اللغة الإنجليزية كلغة أجنبية يرجع إلى تدنى كفايات التدريس لايهم، مثل: الكفايات اللغوية (Zheng and Cheng, 2018; Yasmin et (Lee et al., 2013; Syuhada والكفايات المعرفية والبيداجوجية للمادة al. 2020) .\& Retnawati, 2020) 
رابعًا - إجابة السؤال الرابع للبحث :

للإجابة عن السؤال الرابع للبحث، الذى ينص على: "ما درجة توافر كفايات تدريس العلوم

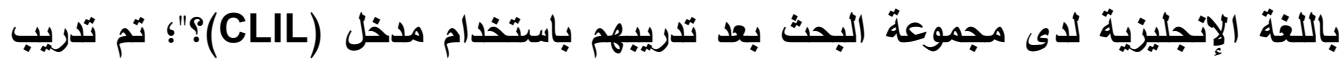
مجموعة البحث على تدريس العلوم بالإنجليزية باستخدام مدخل (CLIL) من خلال عشرة جلسات استغرقت أريعين ساعة، بعدها قام كل طالب على حدة بعرض أحد دروس العلوم على بلى بقية زملائه. كما قامت الباحثة بتسجيل الممارسات التدريسية لهم باستخدام الفيديو، بالإضافة إلى قيامها بدور التلميذة. وتم تحليل هذه الممارسات باستخدام بطاقة الملاحظة المُعدة لهذا الغرض. ويوضح جدول (^) التالي نتائج التطبيق البعدي لبطاقة ملاحظة كفايات تدريس العلوم بالإنجليزية على مجموعة البحث:

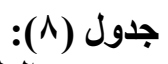

نتائج التطبيق البعدي لبطاقة ملاحظة كفايات تدريس العلوم باللغة الإنجليزية على مجموعة البحث: المتوسطات الحسابية والانحر افات المعيارية الماتية

\begin{tabular}{|c|c|c|c|c|c|c|c|}
\hline أفراد & الكفاية & $\begin{array}{l}\text { المئوية } \\
\text { \% }\end{array}$ & الانحرافياري & الحسابي & الكل كفاية الكلية & أبعادات بطاقة ملاحظة اللغويس الإنجليزية & \\
\hline \multirow[t]{7}{*}{$r}$. & كبيرة جدًا & $90.4 \%$ & .909 & Tr.rr & ro & التخطيط للارس & - \\
\hline & كبيرة & $\Lambda \varepsilon . Y T$ & 1.M. & YO.YV & r. & إدارة الصف & - \\
\hline & كبيرة & $v \cdot .7 v$ & $r .9 \leq 0$ & rI.1 & $\leq 0$ & عرض الدرس & - \\
\hline & كبيرة & $V r .0$ & $1 . \cdot r r$ & $1 \leqslant . V$. & $r$. & المعرفة العلمية & - \\
\hline & كبيرة & $\begin{array}{c}V 0.1 \mathrm{~V} \\
0\end{array}$ & $1 . r \wedge \wedge$ & $r \cdot . \cdot v$ & $\varepsilon$. & 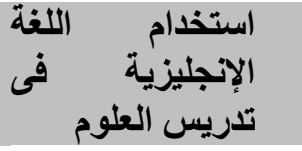 & - \\
\hline & كبيرة & $V \varepsilon$ & $1.7 \leqslant 1$ & r.r.r. & $r$. & التقويم & - \\
\hline & كبيرة & $\begin{array}{c}\vee \wedge .7 \wedge \\
0\end{array}$ & $0 . \vee \wedge \wedge$ & $\begin{array}{c}10 V . r \\
V\end{array}$ & r.. & اللكفايات فى بطاقة العظي & - \\
\hline
\end{tabular}

يُلاحظ من جدول (^) أن قيم متوسطات درجات مجموعة البحث فى كفايات تدريس العلوم

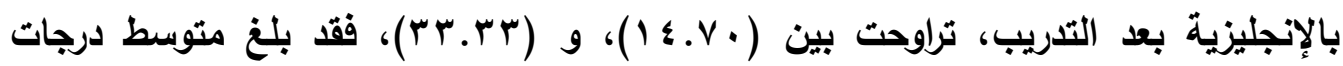

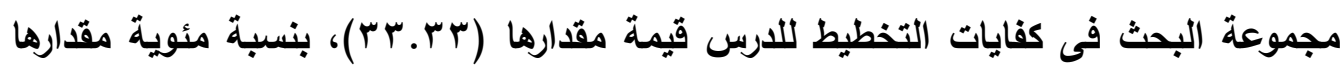

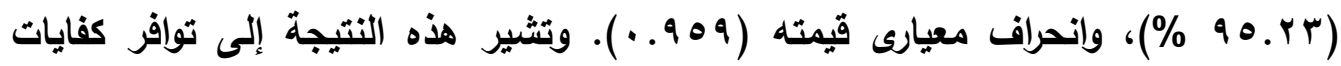

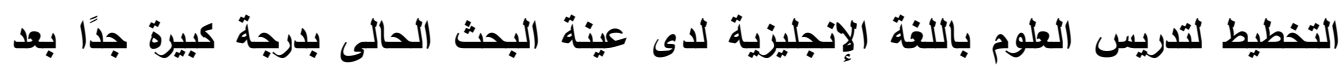
تدريبهم باستخدام مدخل (CLIL). ويلغت قيمة متوسط درجات مجموعة البحث فى كفايات 


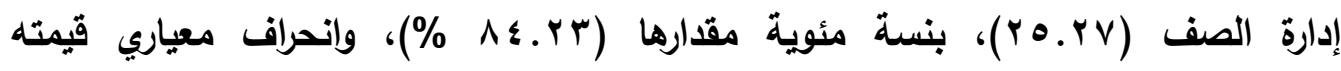

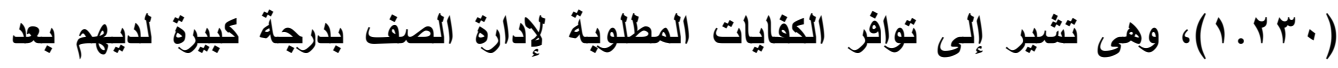

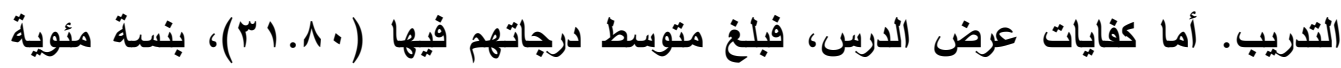

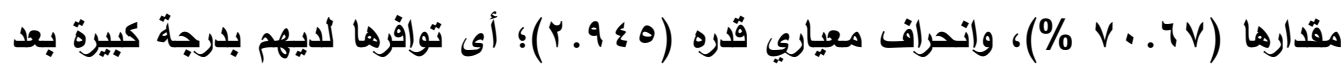

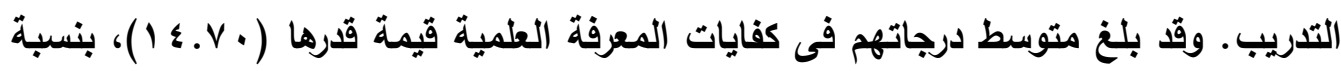

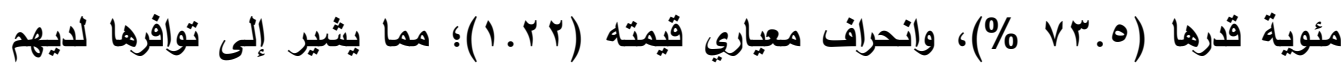
بدرجة كبيرة بعد تدريبهم.

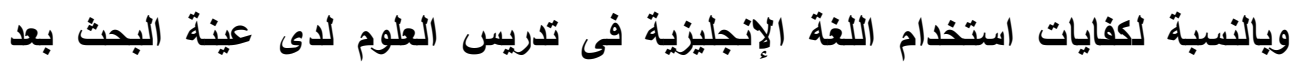
تدريبهم باستخدام مدخل (CLIL)، فيتبين من جدول (^) أن متوسط درجاتهم فيها بلغ قيمة

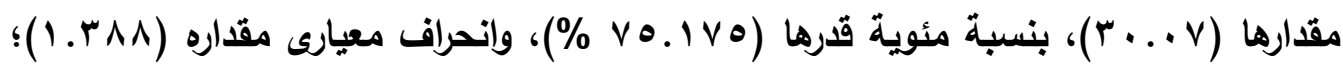
مما يوضح توافرها لايهم بلرجة كبيرة. أما درجة توافر كفايات التقويم لديهم بعد التدريب

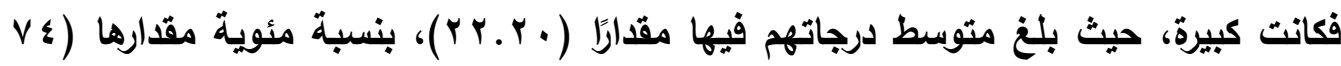

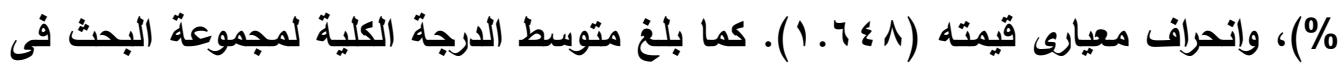

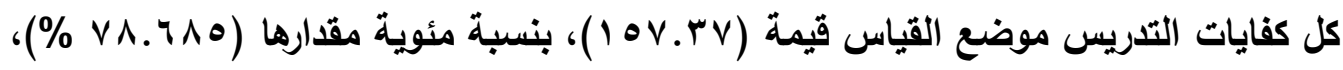

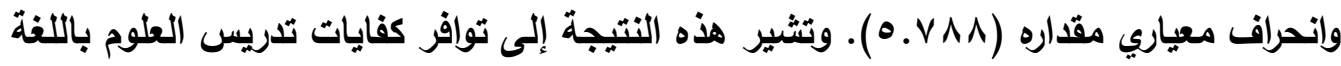
الإنجليزية لاى مجموعة البحث بارجة كبيرة بعد تدريبهم باستخدام مدخل (CLIL). وعليه

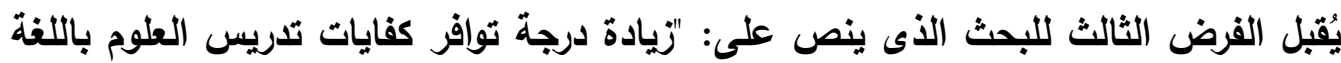
الإنجليزية لاى مجموعة البحث بعد تدريبهم باستخدام مدخل (CLIL)". وتتفق هذه النتيجة للبحث مع نتائج بعض برامج التنمية المهنية القائمة على ملخل (CLIL))، التى أوضحت دور هذا المدخل فى تنمية كفايات التدريس باللغة الإنجليزية لدى كل بله من معلمى العلوم حديثى التخرج فى البرتغال (Piacentini et al., 2019)، ومعلمى العلوم أثناء الخدمة في ليتوانيا (Vilkancienè \& Rozgienè, 2017). ويمكن إرجاع هذه النتيجة للبحث إلى استخدام مدخل (CLIL) فى تدريب الطلاب المعلمين على تدريس العلوم باللفة الإنجليزية؛ حيث تم توفير بيئة تعليمية تضمنت مصادر

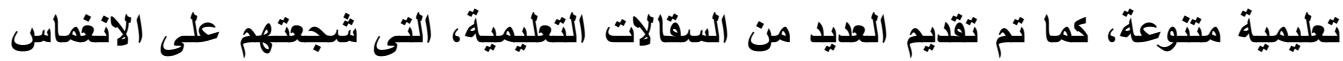
فى التعلم، واستخدام أنشطة تعليمية جماعية، ساعدتهم على تعلم المحتوى العلمي لمقررات 
العلوم مستخدمين اللغة الإنجليزية تحدثًا وكتابةً. مثل هذه البيئة أسهمت فى اكساب مجموعة البحث كفايات تدريس العلوم باللغة الإنجليزية؛ ومكنتهم من توظيف هذه الكفايات فى عرض إضه

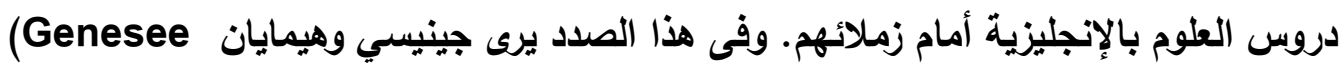
\& Hamayan, 2016) الأجنبية فى الفصول القائمة على مدخل (CLIL)، له تأثير إيجابي يفوق التعلم المنفصل لكليهما؛ حيث يتاح لهم تنمية قدراتهم فى الجانب العلمي، واللغوى معًا بطريقة متكاملة تناسب احتياجاتهم التعليمية؛ مما يجعهم قادرين على توظيف هذه القدرات بنجاح فى مواقف

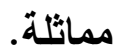

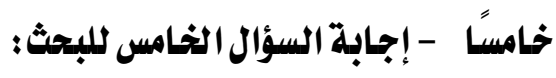
للإجابة عن السؤال الخامس للبحث الأى ينص على: "ما فعالية استخدام مدخل (CLIL)

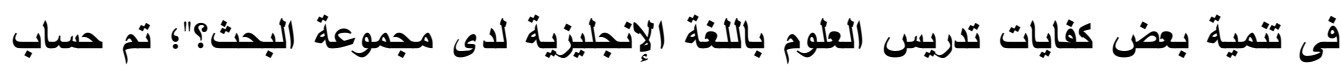
الفروق بين متوسطات درجات مجموعة البحث فى جميع كفايات تدريس العلوم بالإنجليزية المتضمنة فى بطاقة الملاحظة، قبل ويعد تدريبهم على تدريس العلوم باستخدام مدخل (CLIL) 
جدول (9) (9) (9)

الفروق بين متوسطات درجات مجموعة البحث فى كفايات تدريس العلوم بالإنجليزية قبل وبعد التدريب

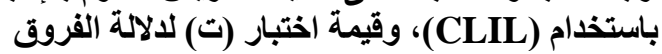

Paired Samples Test

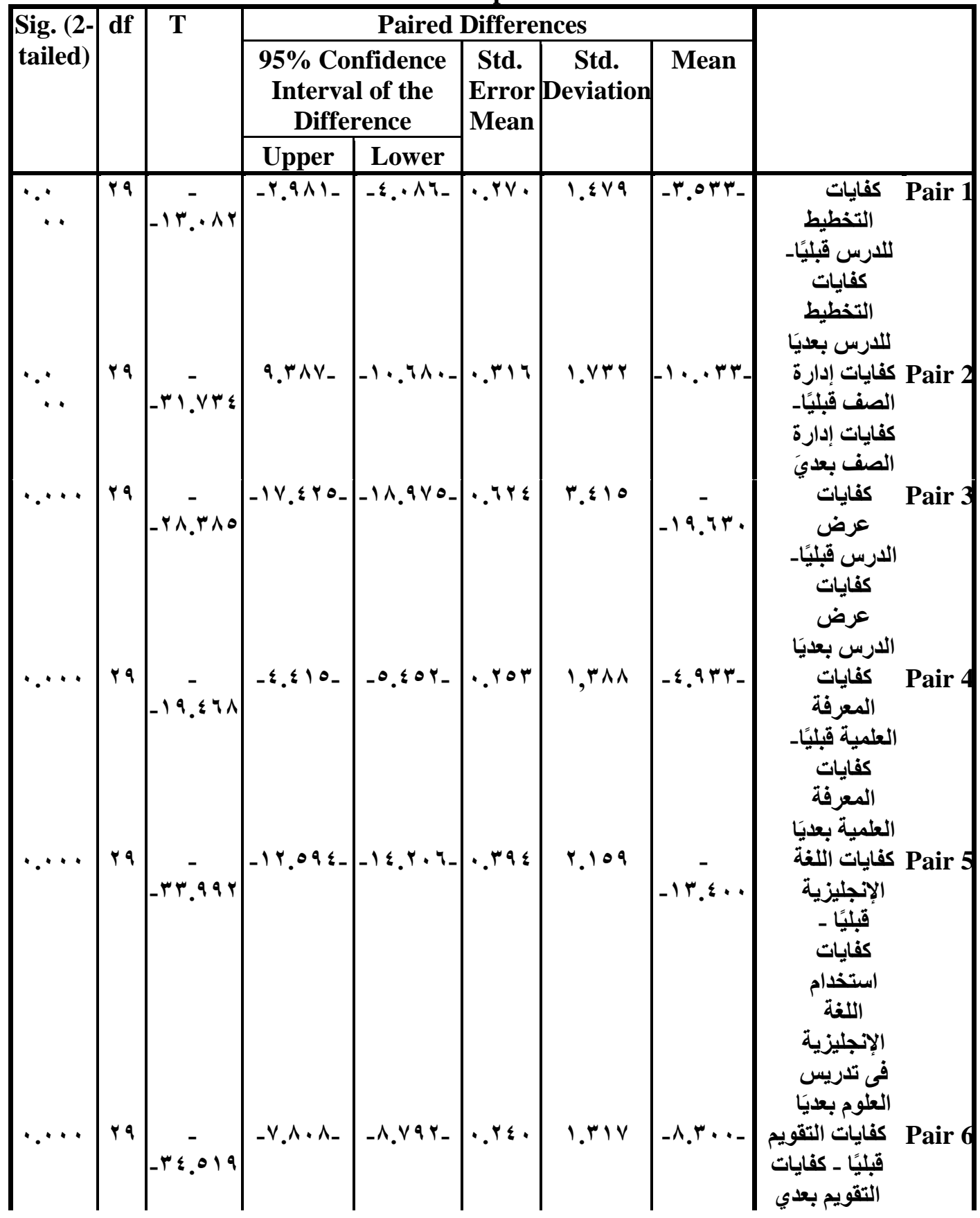


Paired Samples Test

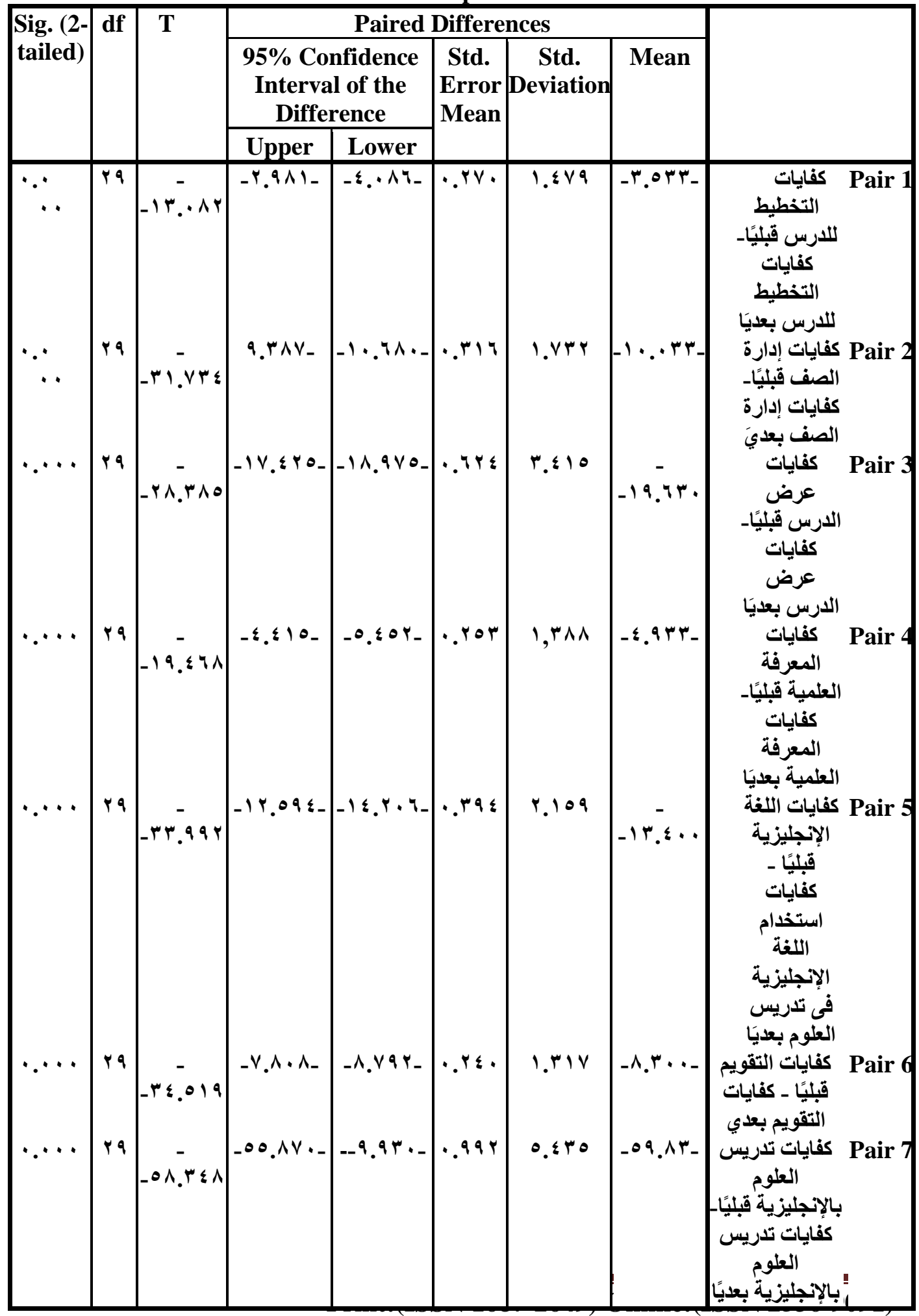


يوضح جدول (9) وجود فرق مقداره (3.533) بين متوسطى درجات مجموعة البحث فى

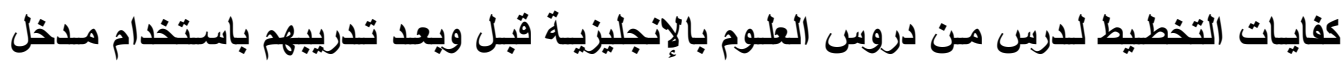

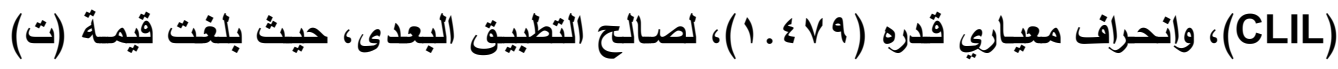

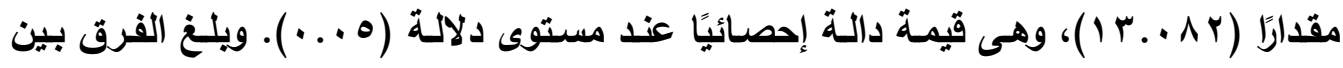
متوسطى درجـاتهم فى كفايـات إدارة الصف عند تـريس العلوم باللغـة الإنجليزيـة قبل ويعد

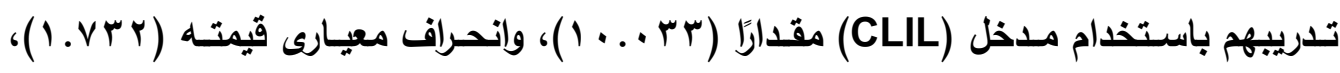

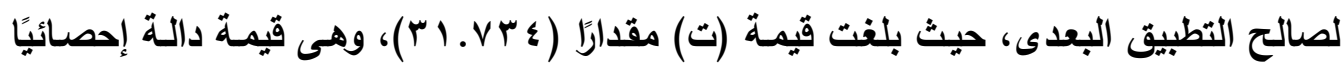
عند مستوى دلالة (ه . . •). كما بلغ الفرق بين متوسطى درجات مجموعة البحث فى كفايات

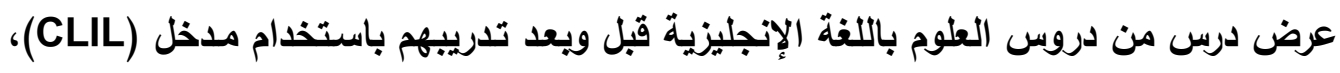

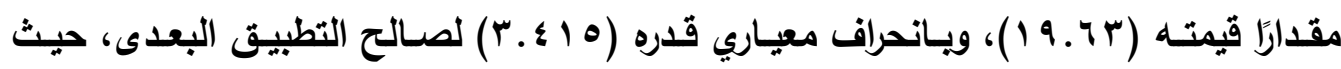

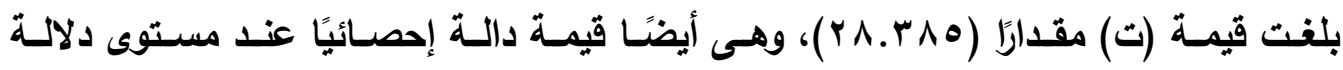
$\cdot(\cdot .0)$ ويتضح من جدول (9) أيضًا أن الفرق بين متوسطى درجات مجموعة البحث فى كفايات المعرفة العلمية فى تدريس العلوم بالإنجليزيـة قبل ويعد تلديبهم باستخدام مدخل (CLIL)،

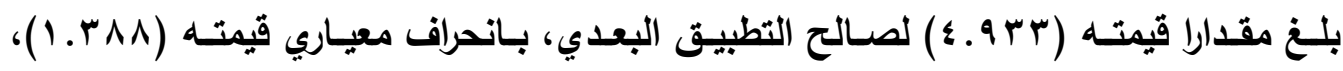

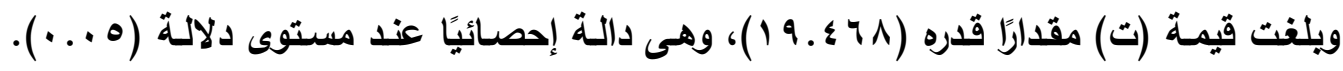
كما بلغ الفرق بين متوسطى درجاتهم فى كفايات استخدام اللغة الإنجليزية فى تدريس العلوم،

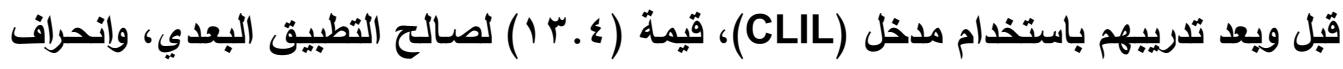

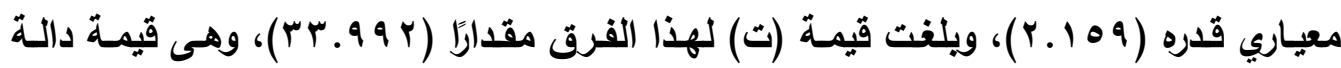
إحصائيًا عند مستوى دلالة (ه . . ). أما الفرق بين متوسطى درجات مجموعة البحث فى كفايات التقويم قبل ويعد تدريبهم باستخدام مدخل (CLIL)، فكان لصـالح التطبيق البعدي،

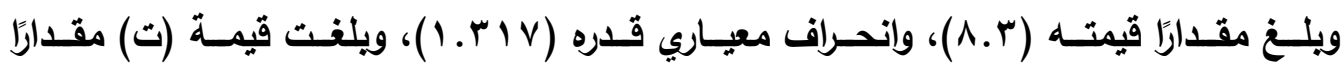

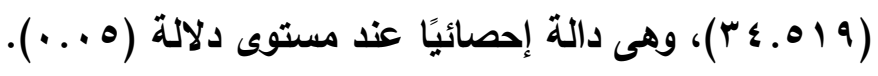
ويبين جـدول (9) أن الفـرق بـين متوسـطى الارجـة الكليـة لمجموعـة البحث قبـل ويعد

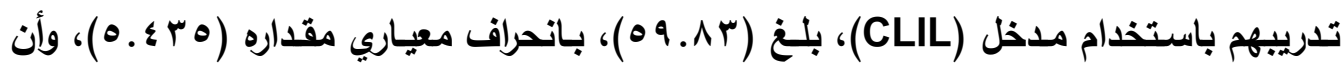

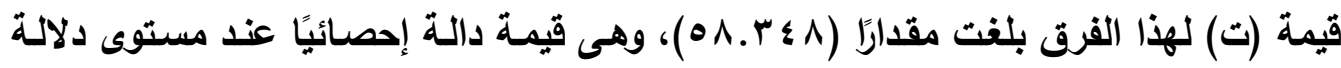




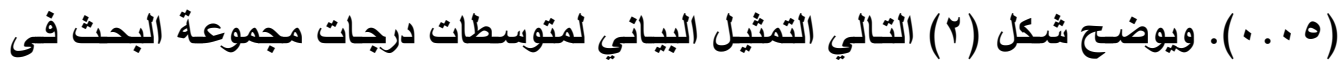
كفايات تدريس العلوم بالإنجليزية قبل ويعد تدريبهم باستخدام مدخل (CLIL):

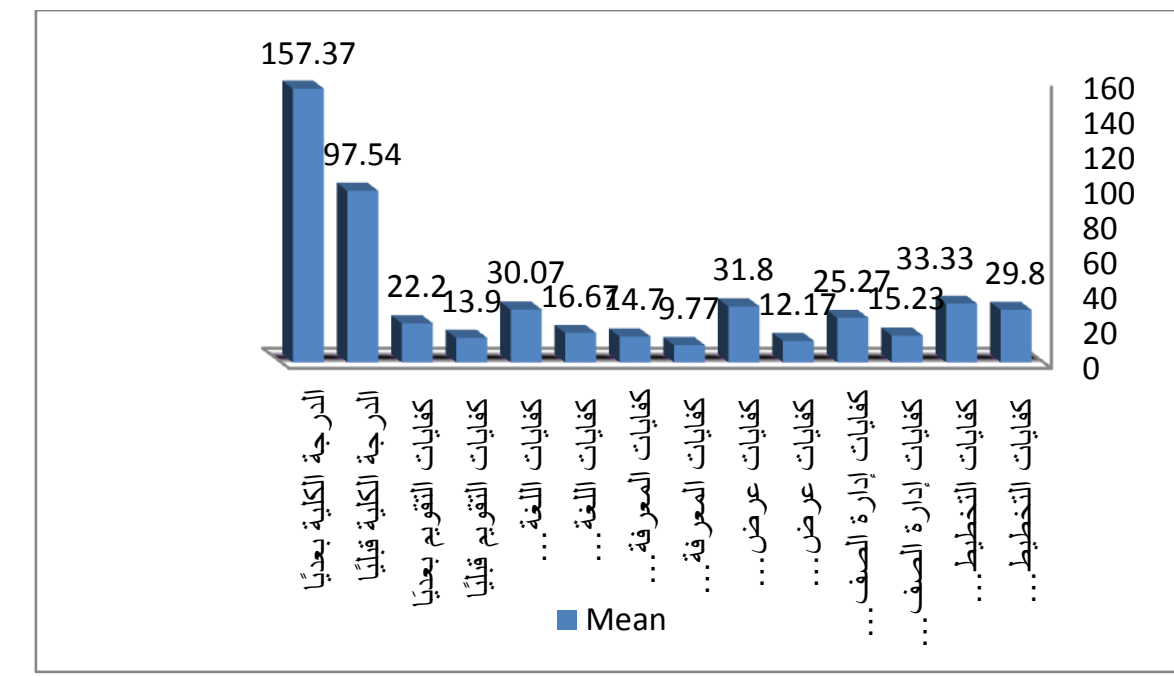

شكل (r): التمثيل البياني لمتوسطات درجات مجموعة البحث فى كفايات تدريس العلوم بالإنجليزية قبل وبعد تدريبهم باستخذام مدخل (CLIL)

وتوضح النتائج السابقة وشكل (r) فعالية مدخل (CLIL) فى تنمية كفايات تدريس العلوم باللغة الإنجليزية لاى مجموعة البحث؛ وعليه يتم قبول الفرض الرابع للبحث، الذى ينص البه

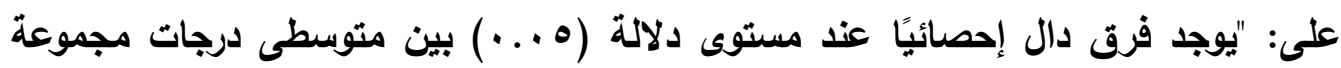
البحث فى القياس القبلى (قبل التدريب باستخدام مدخل (CLIL) والقياس البعدى (بعد ) التدريب باستخدام مدخل (CLIL) لكفايات تدريس العلوم باللغة الإنجليزية لصالح القياس

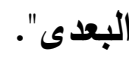

(Aiello et al., 2017; Álvarez- وتتفق هذه النتيجة مـع نتائج بعض الاراسـات Gil, 2021) لمدخل (CLIL) فى تنمية كفايات تدريس العلوم باللغة الإنجليزية لاى الطلاب المعلمين. ويمكن تفسير هذه النتيجة للبحث الحالي بأن تلديب مجموعة البحث على تلدريس العلوم بالإنجليزية باستخدام مدخل (CLIL) قد ساعدهم فى تنمية كفايات التدريس لديهم؛ ويالتالي حسنَ من أدائهم التدريسي، مقارنة بأدائهم قبل التدريب. فقد أوضحت دراسـة (

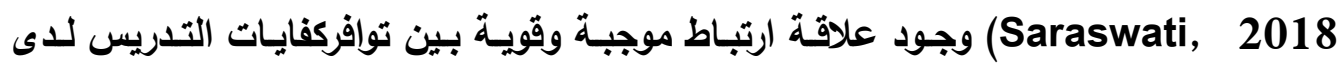


المعلمين، ومستوى أدائهم التدريسى. كما أكدت هذه الدراسة أن كفايات التدريس يتم اكتسابها بالتدريب من خلال برامج محددة قائمة على هذه الكفايات، وهو ما سعى إليه البحث الحالي.

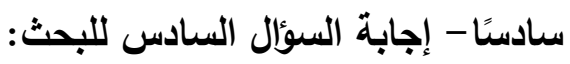

للإجابة عن السؤال السادس للبحث، الذى ينص على: "ما مستوى قلى تدريس العلوم

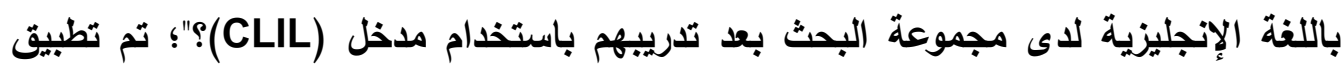

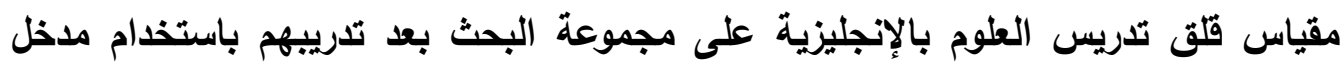
(CLIL)

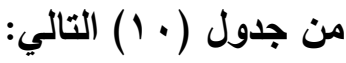

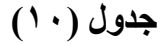

نتائج التطبيق البعدي لمقياس قلق تدريس العلوم بالإنجليزية على مجموعة البحث: المتوسطات الحسابية

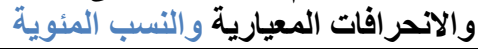

\begin{tabular}{|c|c|c|c|c|c|}
\hline مستوى & $\begin{array}{c}\text { النسبة المئوية } \\
\text { \% }\end{array}$ & المعياري & الحستوسط & الارجة الكلية لكل بعد فى & الإنداديسية مقياس باللغة \\
\hline منخفض & YV.\&. & $r . \cdot r r$ & 10.0 & 00 & - إدارة الصف \\
\hline منخفض & Y.. $\$ 9$ & $1 . \wedge \wedge \wedge$ & $1 \leqslant .0 V$ & 00 & - عرض الدرس \\
\hline \multicolumn{6}{|c|}{ ـ استخدام اللغة الإنجليزية فى تدريس العلوم: } \\
\hline منخفض & YV.・A & $1 . \leqslant 1$ & $7.8 \mathrm{~V}$ & ro & - التحدث الإنجليزية \\
\hline منخفض & rO.VY & $\cdot .9 \times 1$ & $7 . \leqslant \Gamma$ & ro & - الإنجليزية إلى أثناء \\
\hline منخفض & rY.IO & $\cdot . \vee \wedge \wedge$ & $\varepsilon$ & r. & - \\
\hline منخفض & $r 0.10$ &. .999 & 0.4 & $r$. & ـ الكتابة الإنجليزية \\
\hline منخفض & Y..10 & 0.09 & OY.T. & Y.. & للمقياسة \\
\hline
\end{tabular}

ويتضح من جدول (· ل) أن قيم متوسطات درجات مجموعة البحث فى التطبيق البعدي

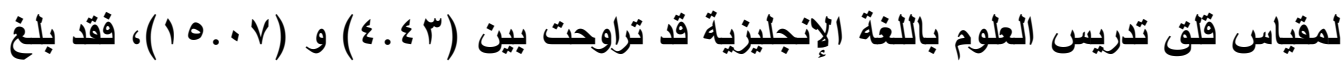
متوسط درجات مجموعة البحث فى قلق إدارة الصف مقدارًا قيمته (V. . . 1 )، بنسبة مئوية

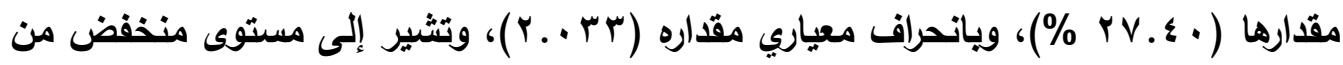
القلق تجاه إدارة الصف أثناء تدريس العلوم بالإنجليزية بعد تدريبهم باستخدام مدخل ) (CLIL) 
منخفضًا؛ حيث بلغ متوسط درجاتهم فيه قيمة مقدارها (OV. ؟ I)، بنسبة مئوية تساوى

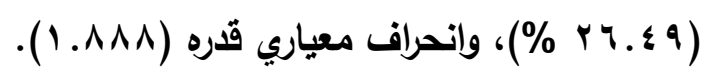

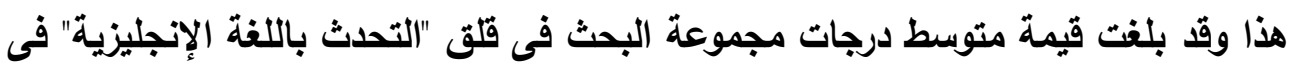

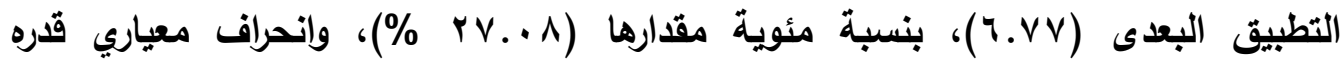

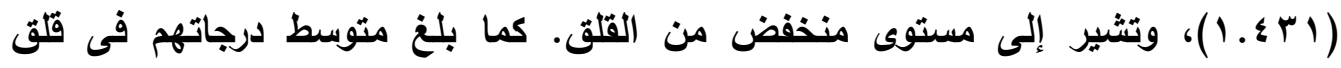

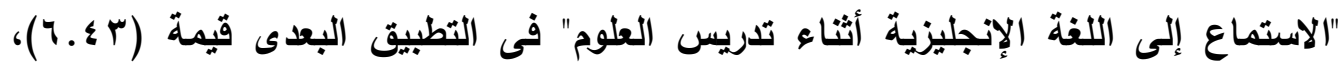

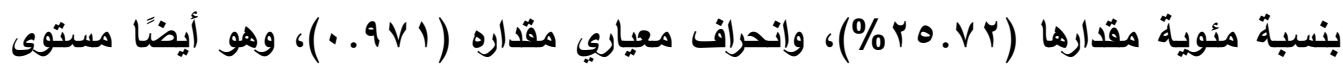

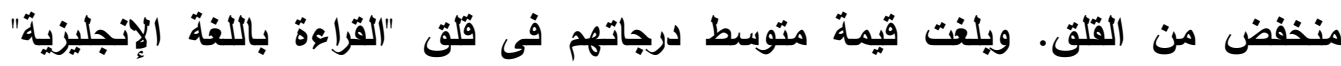

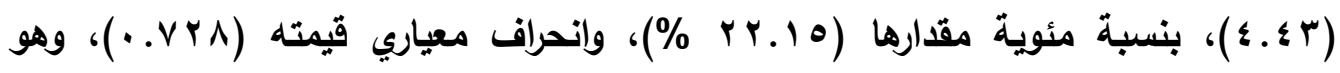
مستوى منخفض من القلق. أما بُعد الكتابة بالإنجليزية فى تدريس العلوم، فقد بلغ متوسط مأه درجات مجموعة البحث فى التطبيق البعدى فيه قيمة مقدارها (r . ـه)، ونسبة مئوية مقدارها

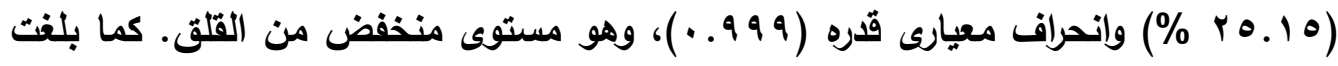

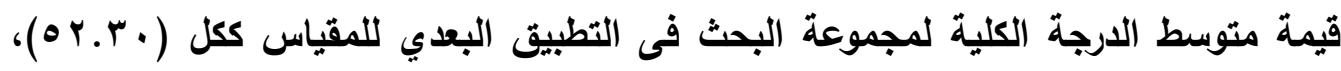

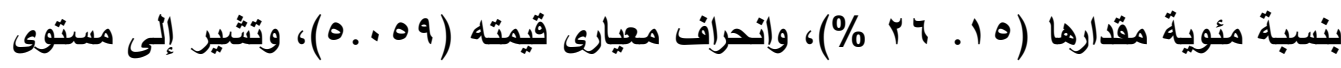
طفيف من القلق. أى أن مستوى قلق تدريس العلوم بالإنجليزية لاى مجموعة البحث بعد تلريبهم باستخدام مدخل (CLIL) قد أصبح منخفضًا. ويالتالي يتم قبول الفرض الخامس

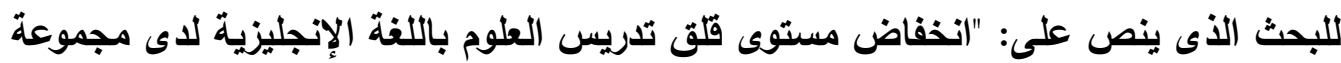

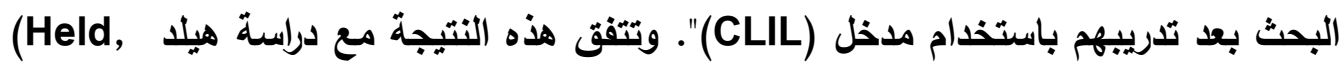
(2017 التى أوضحت أن مدخل (CLIL) يزيد من دافعية المتعلمين نحو استخدام اللغة الأجنبية فى تعلم المواد الدراسية غير اللغوية، كما يخفض لايهم قلق استخدامها فى التعلم. ويمكن تفسير هذه النتيجة للبحث الحالي بأن تدريب مجموعة البحث باستخدام مدخل

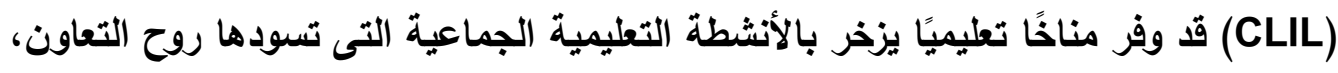
حيث تم تقسيم الطلاب المعلمين إلى مجموعات تراوح عدد كل منها بين خمسة إلى ستة طلاب. وقد تبادل طلاب المجموعات المختلفة أيضًا الأدوات التعليمية، والأفكار والخبرات المرتبطة بكل من المحتوى العلمي، واللغة الإنجليزية. هذا بالإضافة إلى استخدام الألعاب، والألغاز التعليمية، وغيرها من الاستراتيجيات التى زادت من تفاعل مجموعة البحث مع بعضهم 
البعض، وساعدت على وجود الطمأنينة والألفة بينهم، وولات فيهم طاقة إيجابية ودافعية نحو التعلم، بعيدًا عن التوتر والقلق.

وفى هذا الصدد تثير ماثيا سيمونز وآخرون (Simons et al., 2019) أن فصول التعلم القائمة على مدخل (CLIL) توفز بيئة مطمئنة وداعمة للتعلم، حيث تعزز التفاعل والتواصل باللغة الأجنبية بين المتعلمين من خلال العديد من أنثطة التعلم التعاوني بينهم؛ ونها

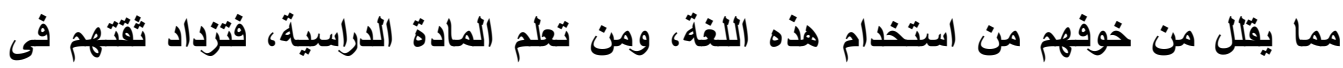
أنفسهم تدريجيًا، وفى قدرتهم على استخدام اللغة فى التعلم، كما تزداد دافعيتهم نحو التعلم، وينخفض قلقهم من إنجاز ما يتعلموه.

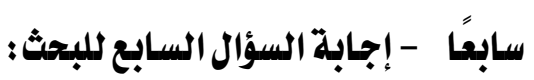
للإجابة عن السؤال السابع للبحث، الذى ينص على: "ما فعالية استخدام مدخل (CLIL)

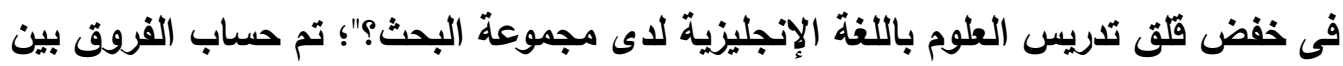

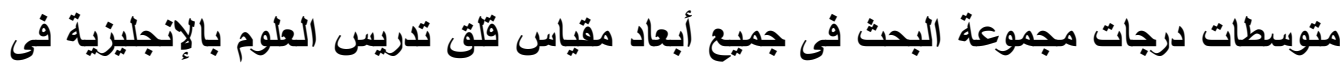
التطبيق القبلي والبعدى، وكذلك حساب قيمة اختبار (ت) لدلالة الفروق، كما فى جدول (11)

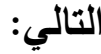




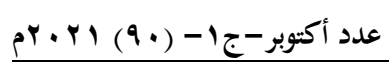

مدى تضمين مقرر لغتي بالمرحلة الابتدائية ...

$$
\text { جدول (11): }
$$

الفروق بين متوسطات درجات مجموعة البحث فى أبعاد قلث تدريس العلوم بالإنجليزية فى التطبيق القبلي والبعدى للمقياس، وقيمة اختبار (ت) لدالة الثة الفروق

\begin{tabular}{|c|c|c|c|c|c|c|c|c|c|}
\hline \multirow{3}{*}{$\begin{array}{l}\text { Sig. (2- } \\
\text { tailed) }\end{array}$} & \multirow[b]{3}{*}{ df } & \multirow[b]{3}{*}{$\mathbf{T}$} & \multicolumn{5}{|c|}{ Paired Differences } & & \\
\hline & & & \multicolumn{2}{|c|}{$\begin{array}{l}95 \% \text { Confidence } \\
\text { Interval of the } \\
\text { Difference } \\
\end{array}$} & \multirow{2}{*}{$\begin{array}{l}\text { Std. } \\
\text { Error } \\
\text { Mean } \\
\end{array}$} & \multirow{2}{*}{$\begin{array}{c}\text { Std. } \\
\text { Deviation }\end{array}$} & \multirow{2}{*}{$\begin{array}{l}\text { Mean } \\
\text { Differe } \\
\text { nce }\end{array}$} & & \\
\hline & & & Upper & Lower & & & & & \\
\hline$\because \cdots$ & rq & $r 0 . \leqslant r \mid$ & $Y 1 . \& Y Y$ & $r \cdot . q \vee \wedge$ & $\because 091$ & T.YV乏 & $r 1 . r \ldots$ & 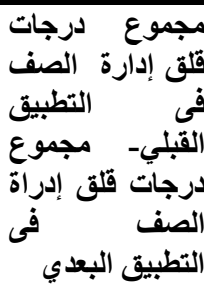 & $\begin{array}{c}\text { Pair } \\
1\end{array}$ \\
\hline$\because \cdots$ & rq & $r 1 . \wedge r v$ & $19.7 \mathrm{Vr}$ & 11.97. & . & r.790 & $11.74 \mathrm{~V}$ & 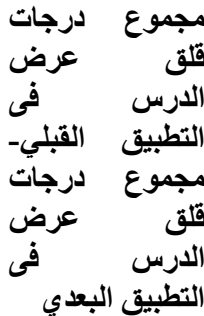 & $\begin{array}{c}\text { Pair } \\
2\end{array}$ \\
\hline$\because \cdots$ & rq & $r r . r r \wedge$ & 17.011 & $M r_{.} \cdot r r$ & צ צד. & 1.990 & I r.VTV & 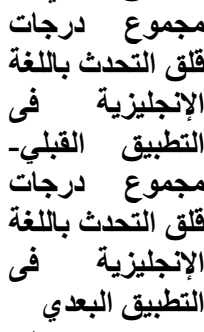 & $\begin{array}{c}\text { Pair } \\
3\end{array}$ \\
\hline$\because \cdots$ & rq & $V . Y \leq V$ & $1 \cdot . \leqslant \leqslant V$ & $\Lambda .714$ & ו ו & r. r०q & $9.0 \mathrm{~V}$ & 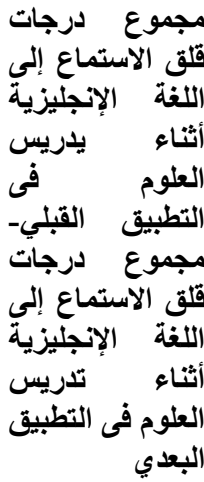 & $\begin{array}{c}\text { Pair } \\
4\end{array}$ \\
\hline
\end{tabular}

Paired Samples Test 


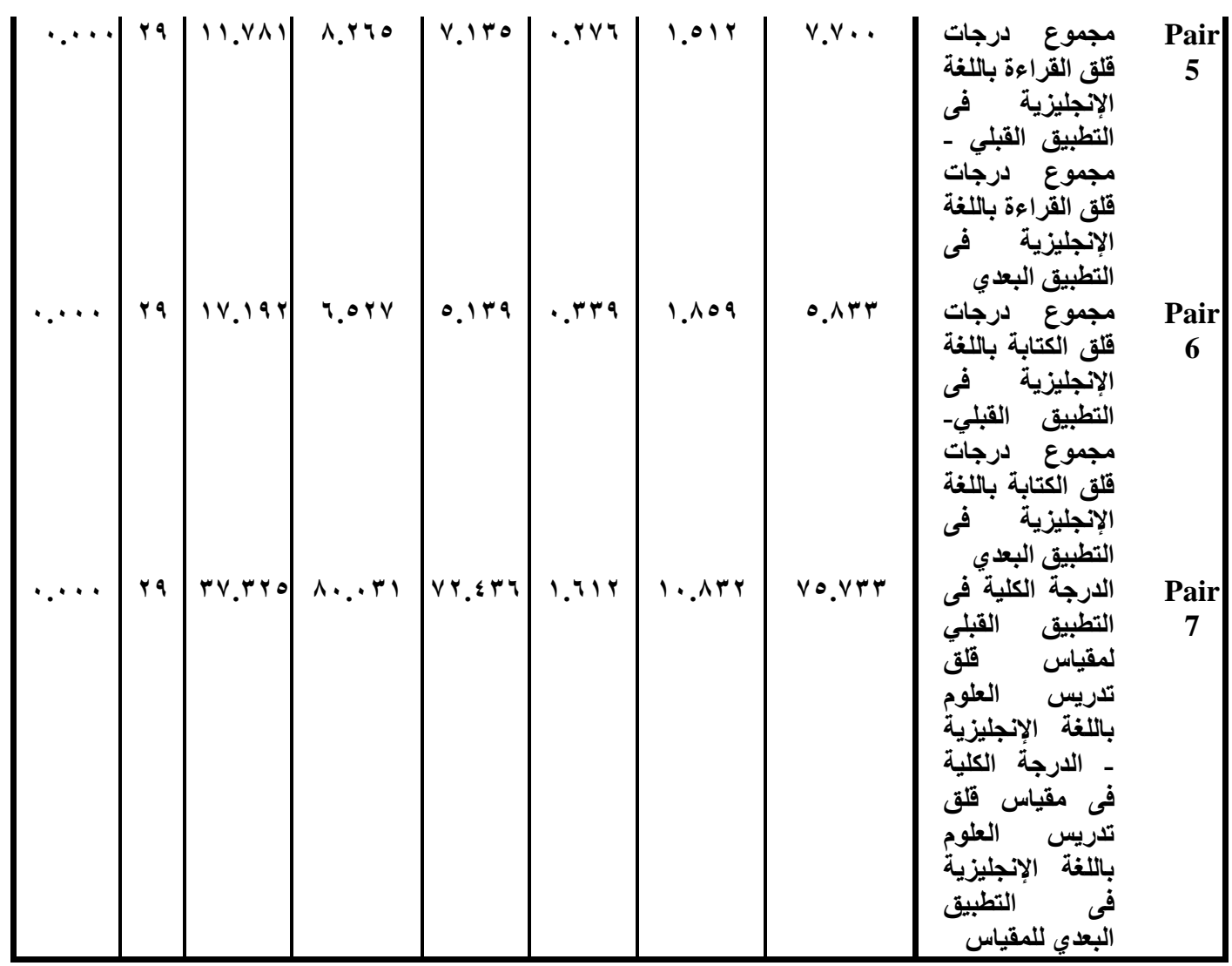

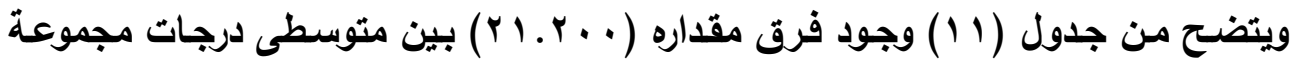
البحث فى قلث إدارة الصف قبل ويعد تدريبهم باستخدام مدخل (CLIL)، وإنحراف معياري قدره

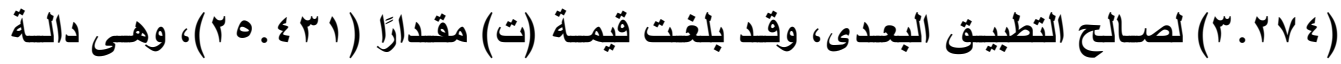
إحصائيًا عند مستوى دلالة (ه . . ). كما بلـغ الفرق بين متوسطى درجات مجموعة البحث فى قلق عرض دروس العلوم باللغة الإنجليزية قبل ويعد تدريبهم باستخدام مدخل (CLIL)،

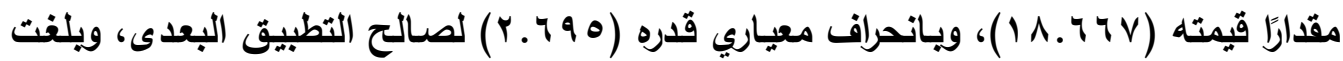

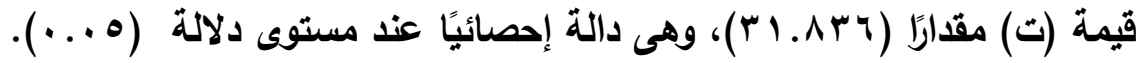
أما الفرق بين متوسطى درجات مجموعة البحث فى قلث التحدث باللغة الإنجليزيـة أثثاء

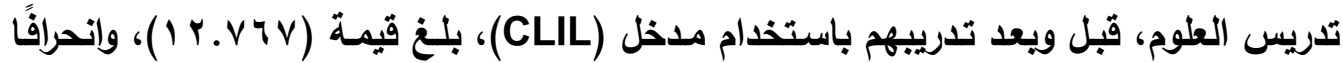

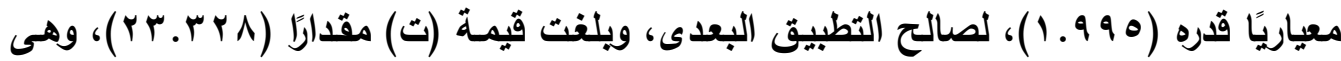

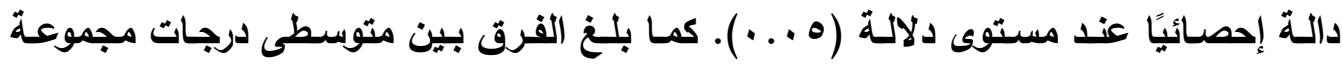

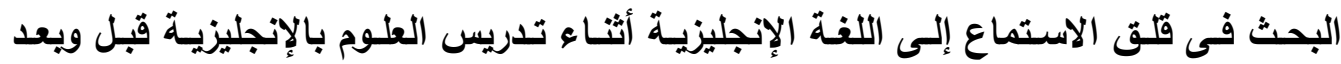




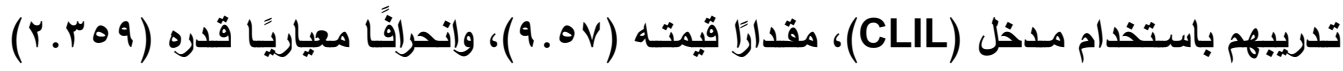

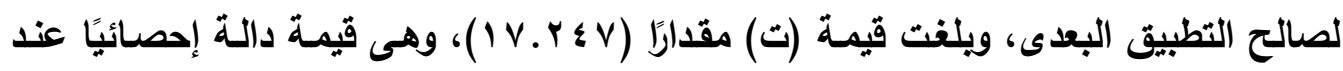
مستوى دلالة (ه . . ). كما بلغ الفرق بين متوسطى درجات مجموعة البحث فى قلق القراءة

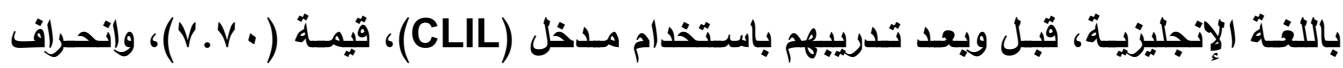

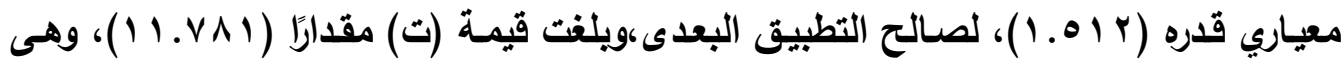

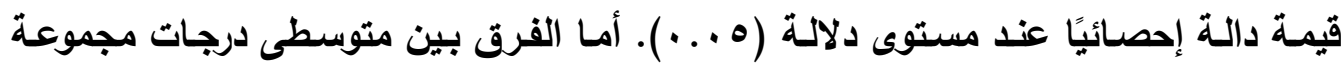
البحث فى قلق الكتابـة باللغـة الإنجليزيـة فى التطبيق القبلى والبعدى لمقياس قلق تلدريس

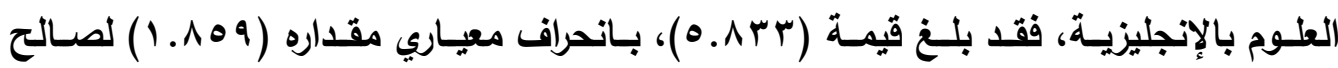

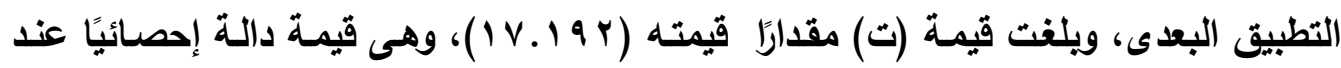
مستوى (0. (*).). كما يوضح جدول (11) وجود فرق مقداره (VO.VMT) بين متوسطى الدرجة الكلية لمجموعة البحث فى التطبيق القبلي، والبعدى لمقياس قلق تدريس العلوم بالإنجليزية،

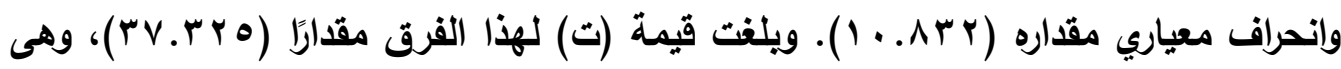
قيمة دالة إحصائيًا عند مستوى دلاية (ه ...). ويوضح شكل (r) التالبي التمثيل البياني لنتائج التطبيق القبلي والبعدى لمقياس قلق تدريس العلوم بالإنجليزية على مجموعة البحث:

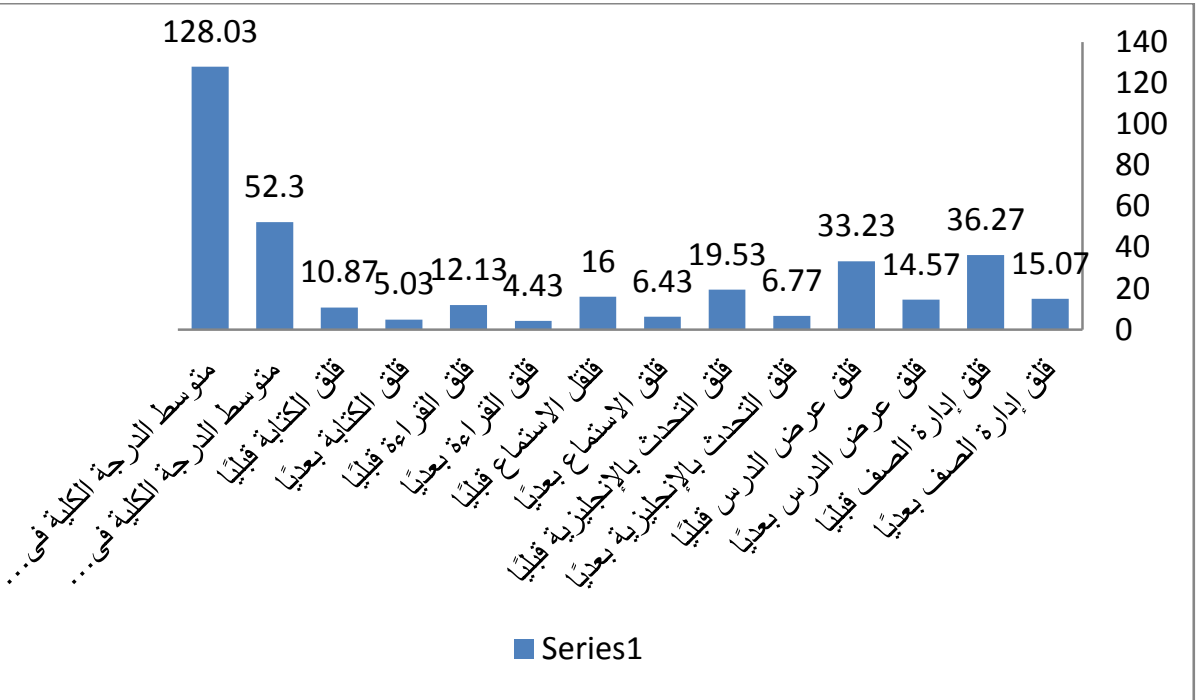

وتثثير هذه النتائج إلى فعالية مدخل (CLIL) فى خفض قلى تدريس العلوم بالإنجليزية

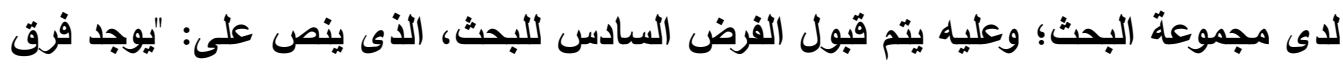


دال إحصائيًا عذد مستوى دلالة (ه ...) بين متوسطى درجات مجموعة البحث فى القياس القبلي (قبل التدريب باستخدام مدخل (CLIL))، والقياس البعدى (بعد التدريب باستخدام مدخل دالئل (CLIL))، لمقياس قلق تدريس العلوم باللغة الإنجليزية لصالح القياس البعدي".

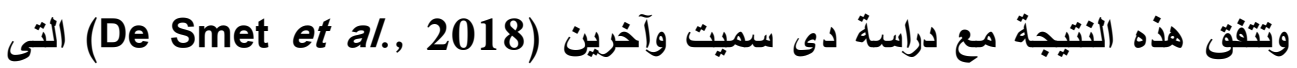
أوضحت فعالية مدخل (CLIL) فى خفض درجة قلق الداراسة باللغة الإنجليزية كلغة أجنبية لاى المتعلمين بمدارس هولندا الابتدائية والثانوية، بالمقارنة بمستوى القلق المرتفع لاى الدى المتعمين الذين لم يدرسوا باستخدام هذا المدخل. وكذلك دراسة سايمونز وآخرين Simons) التى بينت أن توظيف مدخل et al., 2019) اللغوية بمدارس بلجيكا ساعد فى خفض قلق التدريس لاى المعلمين، وكذلك قلق التعلم بالإنجليزية لاى الطلاب، كما أسهم فى تنمية مهارات اللغة الإنجليزية لايهم.

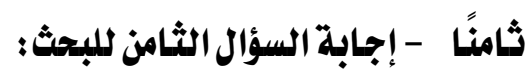
للإجابة عن السؤال الثامن للبحث الذى ينص على: "ما العلاقة بين كفايات تدريس العلوم باللغة الإنجليزية ومستوى قلق التدريس لاى مجموعة البحث؟"؛ تم حساب معامل الارتباط لبيرسون بين متوسطى درجات مجموعة البحث فى كل من كفايات التدريس باللغة الإنجليزية، وقلق التدريس، كما بجدول (r ا ) التالي: 


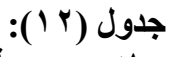

معامل الارتباط لبيرسون بين متوسطى درجات مجموعة البحث فى كل من كفايات التدريس باللغة

$$
\text { الإنجليزية، وقئق التدريس قبل وبعد التدريب في في من }
$$

\begin{tabular}{|c|c|c|c|c|}
\hline 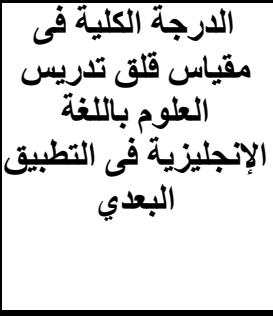 & فلى الارجة التطبية & تالدى كفاياتة الكلية & 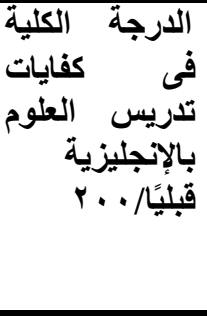 & \\
\hline $\begin{array}{l}\because r \wedge r . \\
.1 r r \\
r .\end{array}$ & $\begin{array}{l}* .497 \\
. . r . \\
r .\end{array}$ & $\begin{array}{l}* . \leqslant 1 \\
. \cdot 1 v \\
r .\end{array}$ & 1 & 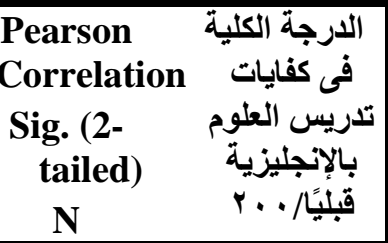 \\
\hline $\begin{array}{l}\because r 4 \leq \\
\because \cdot \leq \Lambda \\
r .\end{array}$ & $\begin{array}{l}* .009 \\
\because \cdots 1 \\
r .\end{array}$ & r. & $\begin{array}{l}\because . \leqslant \mu 1 \\
\because+1 v \\
r .\end{array}$ & 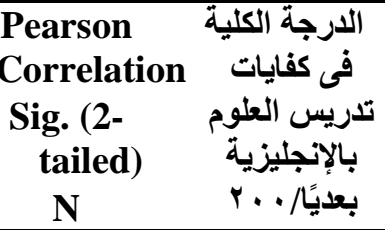 \\
\hline $\begin{array}{l}* .701 \\
\because \cdots \\
r .\end{array}$ & r. & $\begin{array}{c}\because .009 \\
. \cdots 1 \\
r .\end{array}$ & $\begin{array}{l}\because r q 9 \\
\because r r \\
r .\end{array}$ & 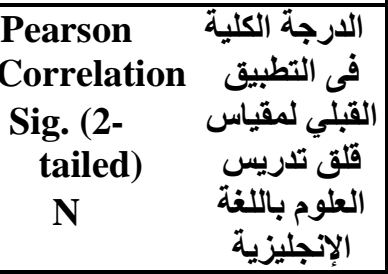 \\
\hline$r$. & $\begin{array}{c}\cdots * .701 \\
\ddots \cdots \\
r .\end{array}$ & $\begin{array}{l}\because . r 4 \leq \\
\ddots .+\leq 1 \\
r .\end{array}$ & $\begin{array}{l}. \text { rAr } \\
. \text { rrt. }\end{array}$ & 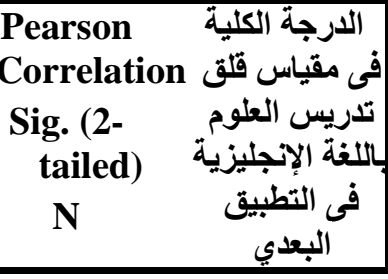 \\
\hline
\end{tabular}

Correlations

*. Correlation is significant at the 0.05 level (2-tailed).

**. Correlation is significant at the 0.01 level (2-tailed).

ويتضح من جدول (r l ) أن قيمتى معامل الارتباط لبيرسون بين متوسطى درجات الطلاب

المعلمين فى كفايات تدريس العلوم باللغة الإنجليزية، وقلق تدريس العلوم بالإنجليزية قبل هبل هلئل

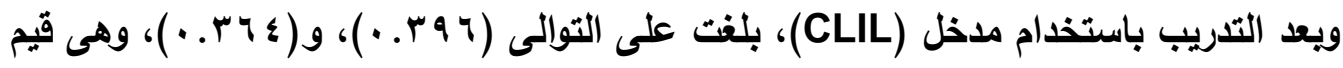

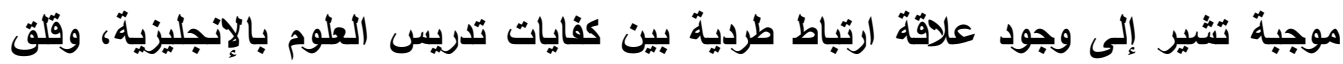


التدريس للى الطلاب المعلمين مجموعة البحث. وعليه يتم رفض الفرض السابع للبحث

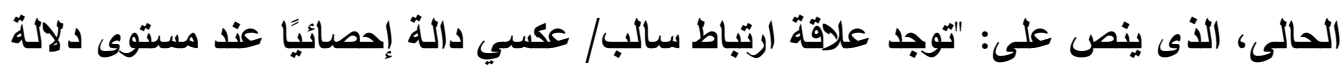
(0 . . ) بين متوسطى درجات مجموعة البحث فى كفايات تدريس العلوم باللغة الإنجليزية

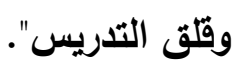

ونظرًا لأن هذه القيمة صغيرة لم تتجاوز النصف درجة، فإنها تعكس علاقة ارتباط ضعيفة.

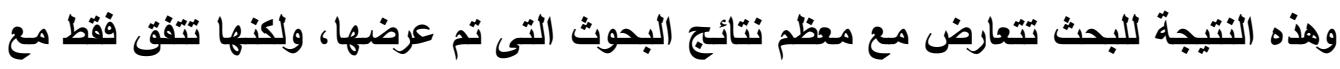

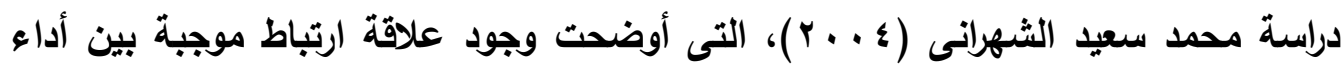

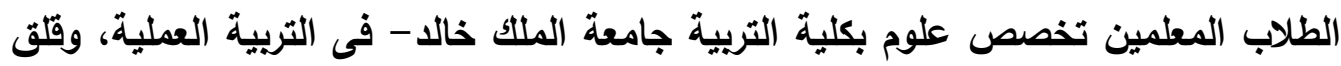
التذريس لايهم. وقد يرجع وجود علاقة ارتباط موجبة وصغيرة القيمة بين كفايات تدريس العلوم باللغة الإنجليزية وقلث التريس لاى مجموعة البحث حتى بعد تدريبه باستخدام

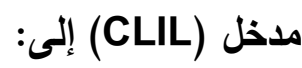
- شعور الطلاب المعلمين بلرجة طفيفة من قلق تدريس العلوم بالانجليزية رغم ارتفاع مستوى

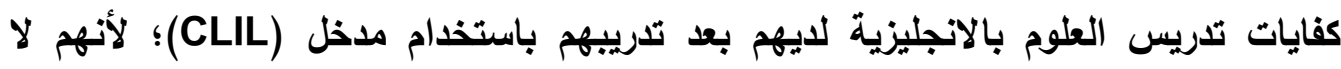
يزالون يهابون إلى حد ما مواجهة المواقف التدريسية فى الواقع، أى داخل الفصول المدرسية بلاية وأمام التلاميذ والمعلمين والموجهين. وهذه الدرجة من القلق مقبولة؛ لأنها لم تتجاوز الحد الطبيعى، ومن الممكن أن تكون دافعًا لهؤلاء الطلاب المعلمين لتنمية مزيد من كفايات تدريس العلوم بالانجليزية لايهم. وفى هذا الصدد يشير هورويتز (Horwitz, 2010) إلى أن القلق فى بعض الأحيان يمكن أن يكون مفتاحًا للأداء الجيد عند استخدام لغة أجنبية. كما

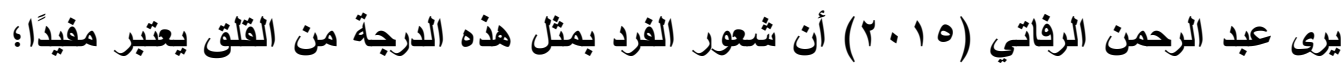
لأنه قلق إيجابي، يدفع صاحبه للإنجاز. وعليه فإن إمتلاك الطلاب المعلمين لكفايات تدريس العلوم بالإنجليزية بعد التدريب من خلال مدخل (CLIL) لا يعنى عدم شعورهم بقلق التدريس، ولكن شعورهم بقر من القلق الإيجابي الأى يدفعهم إلى مزيد من تحسين أدائهم بلهم التدريسي. ـ طبيعة مجموعة البحث، التى تندرج ضمن عينة الصدفة، أو العينة المتاحة ( رافدة الحريري وآخرون، Y V P Y)؛ حيث أعطى الطلاب المعلمون الحرية فى المشاركة فى البحث؛ ويالتالى كاتت لديهم الدافعية والرغبة فى الاثتراك فى التدريب على تدريس العلوم بالإنجليزية من 
خلال مدخل (CLIL). وهذه الدافعية فى حد ذاتها تعكس رغبتهم وحرصهم الثديد على تنمية كفايات تدريس العلوم بالإنجليزية لديهم خثية الوقوع فى أخطاء أثناء التدريس. مثل هؤلاء

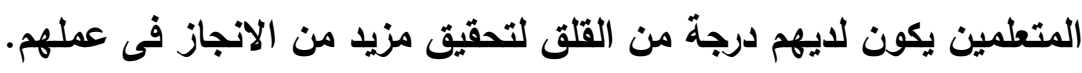

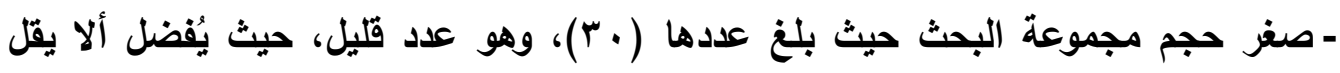
عدد أفراد العينة عن عشرة أضعاف عدد متغيرات الدراسة. وحيث إن البحث الحالي الشتمل على متغيرين إثثين فقط؛ فقد كان من الأفضل ألا يقل عدد مجموعة البحث عن ( • ـ ).

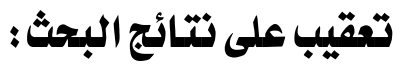
إن لغة المحتوى الأى يقوم المعلم بتدريسه لا تنفصل عن المحتوى نفسه؛ ويالتالي لا بـ الد الدئ

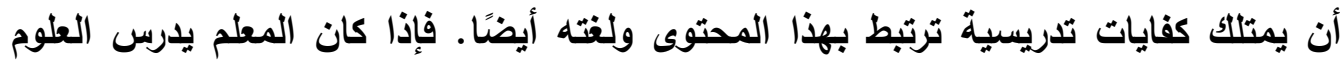

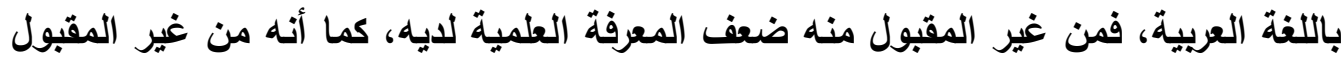
عدم الدقة اللغوية أثناء تناوله المحتوى سواء فى التحلث، أم القراءة، أم الكتابة. فعلى سبيل

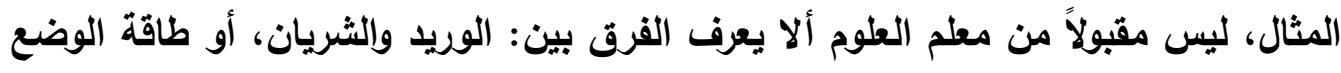

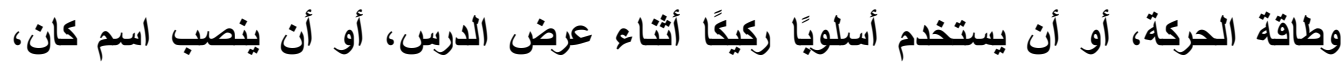

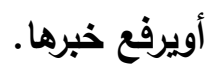

هذا ولم تعد اللغة الإنجليزية لغة التجارة والصناعة، والمعلومات فحسب، بل لغة تمنح

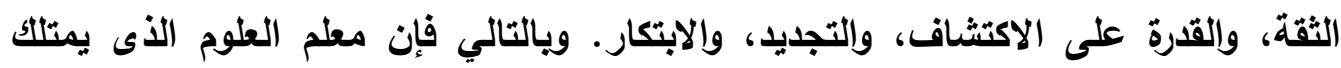

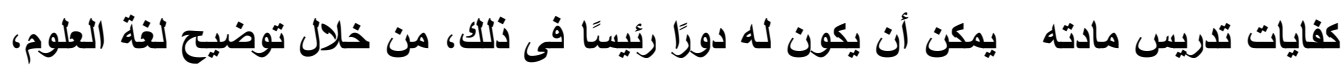

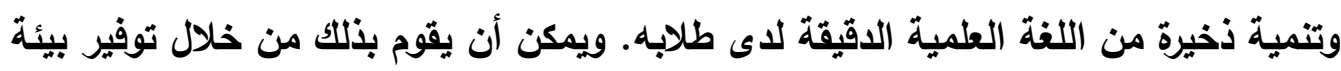

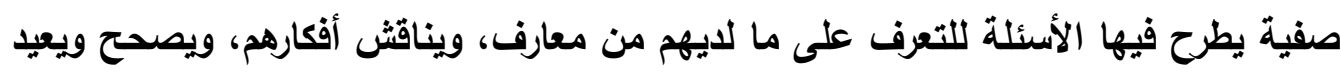

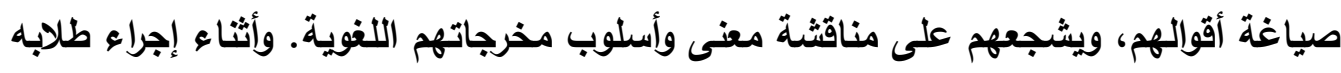
للأنثطة والتجارب العلية المختلفة، يمكن لمعلم العلوم أن يناقش معهم ما توصلوا إليه من

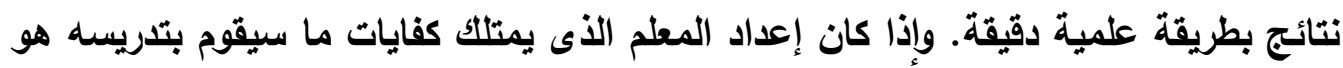

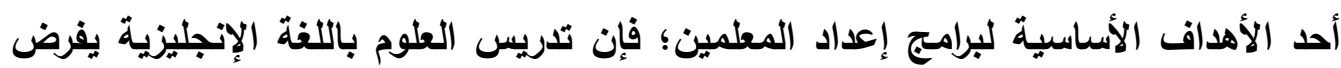

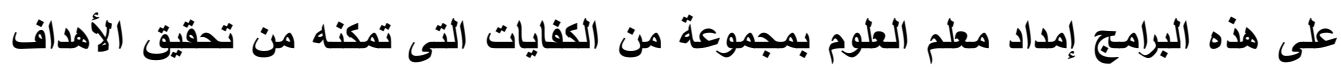
التعليمية التى تسعى إليها المناهج التى سيقوم بتدريسها. 
ومنذ تسعينات القرن الماضى، أصبح مدخل (CLIL) من أهم مداخل إعداد المعلمين لتدريس موادهم غير اللغوية باللغة الإنجليزية، خاصة فى دول أورويا وأمريكا اللاتينية؛ وذلكك لتحفيز وتنمية المحتوى المعرفى للمواد الدراسية لايهم، بالإضافة إلى مهارات تدريس هذابلها Wolff, ) المحتوى باللغة الإنجليزية (Banegas \& Beamud, 2020). وقد قدم وولف بالفي 2020) إطارًا مرجعيًا يتضمن قائمة بالكفايات التدريس المطلوية لإعداد المعلم باستخدام مدخل (CLIL)، تضمنت التأمل الثخصي، وأساسيات مدخل (CLIL)، والوعى بالمحتوى لإني واللغة الإنجليزية، وطرق التدريس والتقييم، والبحث والتتقيم، ومصادر التعلم والبيئة، وإدارة الصف الدراسي، وإدارة مدخل (CLIL). وجميع هذه الكفايات تعكس أيضًا أسس برنامج إعداد

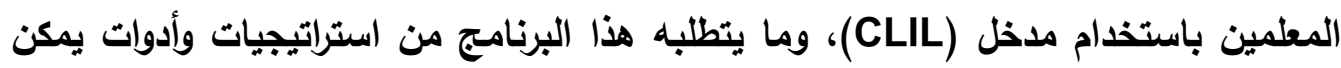
أن تعزز تعلم الطلاب المعلمين كل من المحتوى العلمي، واللفة الإنجليزية معًا.

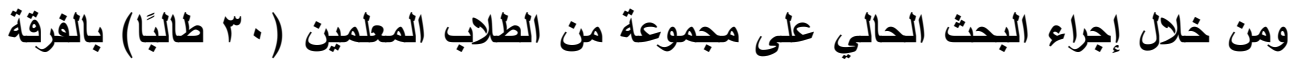
الرابعة بشعبة التعليم الابتدائي تخصص علوم، والملتحقين بدورة تدريس العلوم بالإنجليزية،

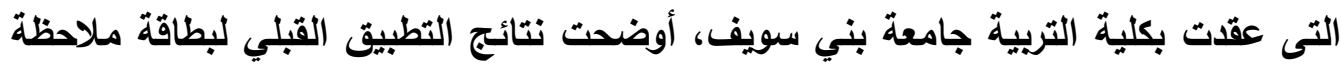
كفايات تدريس العلوم باللغة الإنجليزية، والمتمثلة فى: التخطيط للارس، وإدارة الصف، وعرض الدرس، والمعرفة العلمية، واستخدام اللغة الإنجليزية فى تدريس العلوم، والتتقيم، أوضحت ضعف توافز جميع هذه الكفايات لايهم، ماعدا كفايات التخطيط للارس التى توافرت لايهم بشكل كبيز؛ بسبب اعتمادهم على الكتب المدرسية فى إعداد الدروس التى قاموا بعرضها. كما تبين من التطبيق القبلي لمقياس قلق تدريس العلوم بالإنجليزية على مجموعة

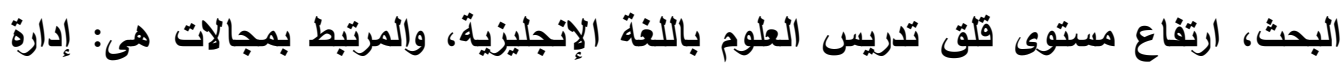
الصف، وعرض الدرس، واستخدام اللغة الإنجليزة فى التدريس. هذا ويقلم البحث الحالي أيضًا مواد تدريبية تمثل نموذجًا "لتوظيف مدخل الإنية التكامل بين

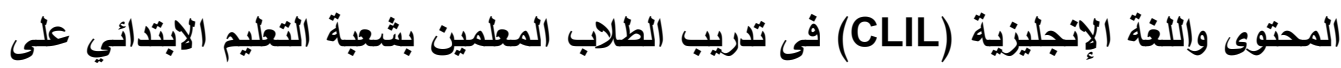

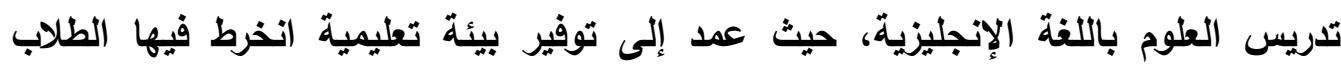

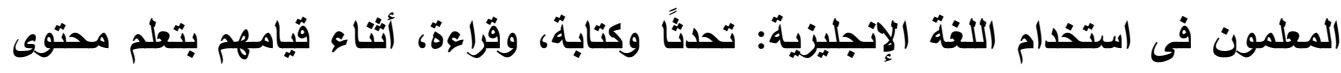

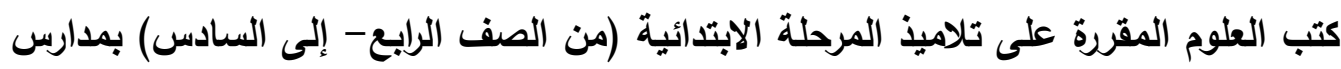


اللغات الرسمية. وقد استخدمت العديد من المحفزات التعليمية فى إطار اجتماعي تعاونى؛ لتحقيق التكامل بين تعلم كل من المحتوى العلمى واللغة الإنجليزية فى ذات الوقت. ويعد تدريب مجموعة البحث باستخدام مدخل (CLIL)، تم تطبيق أداتي البحث على الطلاب المعلمين. وقد أوضحت نتائج التطبيق البعدي لبطاقة ملاحظة كفايات تدريس العلوم بالإنجليزية، فعالية مدخل (CLIL) فى تنمية كفايات التريس المرتبطة بكل من: التخطيط،

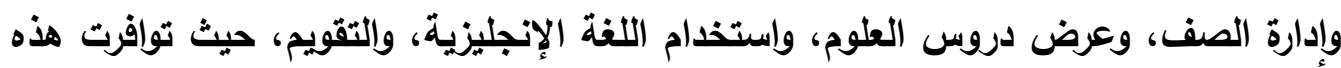

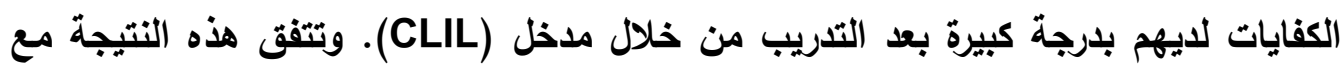

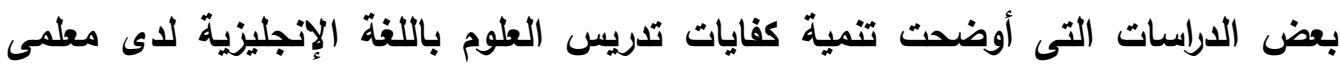

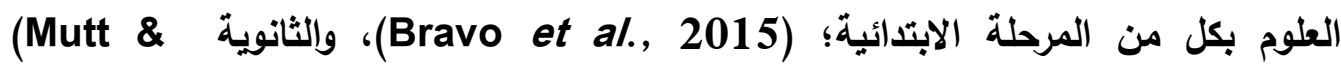
نتيجة تدريبهم على تدريس العلوم باستخدام مدخل التكامل بين محتوى العلوم واللغة الإنجليزية (CLIL). هذا وقد أظهرت نتائج البحث الحالي أيضًا فعالية مدخل (CLIL) فى اختزال قلق تدريس العلوم بالإنجليزية لاى مجموعة البحث، حيث انخفض مستوى قلقهم تجاه إدارة

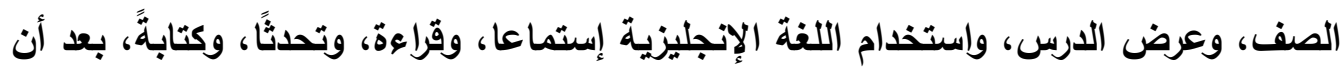
كان مرتفعًا، وهو ما يتفق مع نتائج دراسة كاو (Kao, 2020) فى تايوان، التى بينت تأثير استخدام كل من الموديولات والتدوات القائمة على مدخل (CLIL) فى خفض قلى تدريس

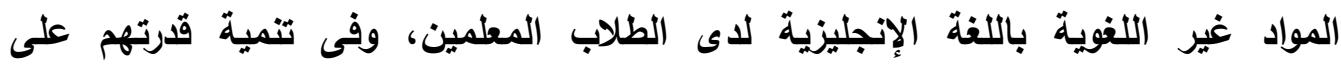
استخدامها فى التدريس. وحيث إن قلق الأداء باستخدام لغة أجنبية مرتبط بشكل أساسي الإبي بالجوانب الاجتماعية والتواصل مع الآخرين (Gkonou et al., 2017, 91)؛ فقا تم توفير بيئة تعليمية تعاونية تعزز التفاعل والتواصل بين أفراد مجموعة البحث الحالي، وبين

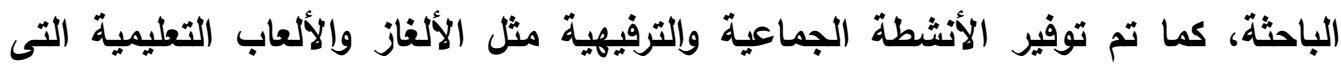

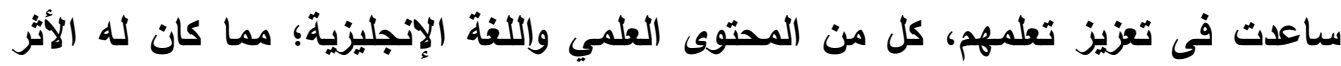
الموجب فى خفض مستوى قلق تدريس العلوم باللغة الإنجليزية لايهر. ويحساب معامل الارتباط لبيرسون بين متوسطى درجات مجموعة البحث فى كفايات تدريس العلوم بالإنجليزية وقلق التدريس لايهم قبل ويعد تدريبهم باستخدام مدخل (CLIL)؛ وجدت علاقة ارتباط موجبة وضعيفة. ونظرًا لصغر قيمة معامل الارتباط لبيرسون بعد تدريب 
مجموعة البحث باستخدام مدخل (CLIL)، حيث لم تبلغ نصف الارجة (ع צب . •)، فلا يمكن الجزم بأنه كلما زاد توافر كفايات تدريس العلوم باللغة الإنجليزية لاى الطلاب المعلمين؛ زاد مستوى قلق التدريس لديهم، لأن ذلك يتطلب مزيدًا من الدراسات التى تثثمل عينات عشوائية ذات حجم كبير. وُيعد إمداد المعلمين الذين سيقومون بتدريس مناهج العلوم باللغة الإنجليزية، بالكفايات

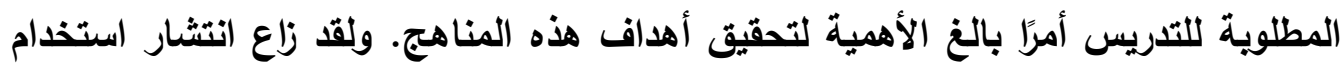
مدخل التعلم القائم على التكامل بين المحتوى واللغة الإنجليزية (CLIL) بشكل كبير داخل

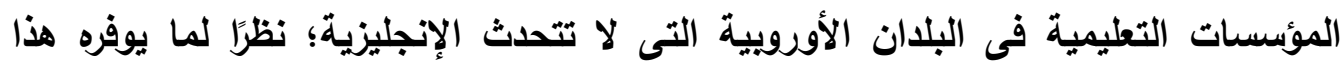

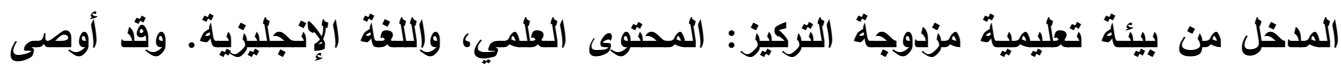
فازكيوس وإليسون (Vázquez \& Ellison, 2018) بأهمية أن يكون مدخل (CLIL)

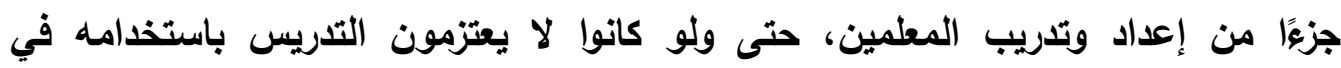
المستقل؛ لما له من دور فى تحسين كفاياتهم اللغوية، والتتأكيا على بعض العض النواحى الاجتماعية والثقافية والقيمية أثناء التدريس. إن تطبيق مدخل (CLIL) يتطلب ما يمكن أن يُسمى بالخليط المتجانس، الأى يكون من الصعب فصل مكوناته. ويعبارة أخرى فإن بيئة التعلم القائم على مدخل (CLIL) لا توجد فيها حدود فاصلة بين تعلم المحتوى العلمي لمادة ليست من اللغويات، واللغة الأجنبية المستخدمة فى صياغة وعرض هذا المحتوى. فعلى سبيل المثال يتطلب تدريب معلمى العلوم على منى

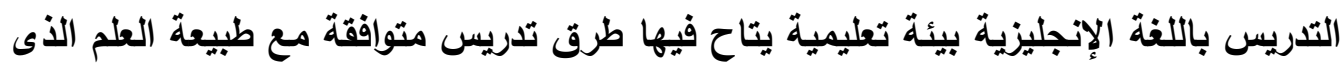

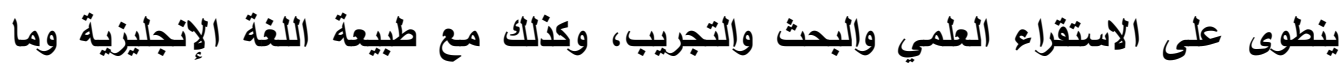

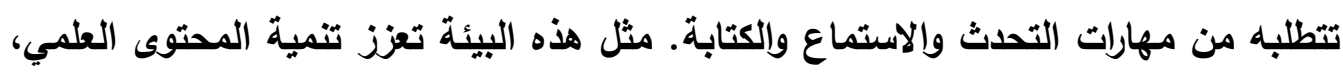
واللغة الإنجليزية لاى المعلمين فى آن واحد.

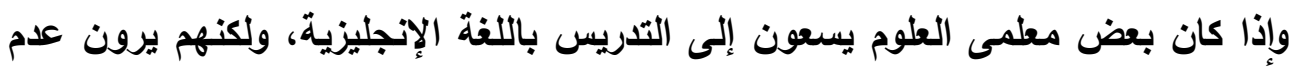
جدوى إتقانهم للإنجليزية، أوعدم أهمية تبنى مدخل (CLIL) فى إعدادهم؛ لأنهم ليسوا

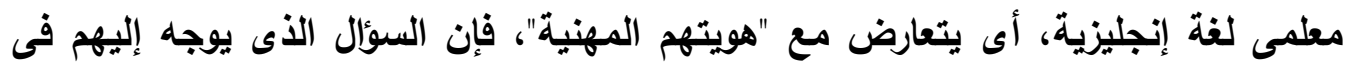

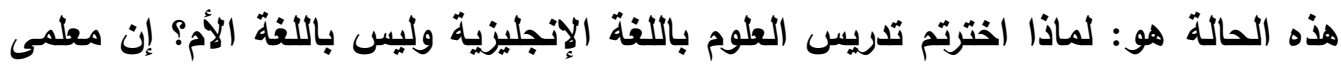
العلوم فى مصر لديهم- حتى هذه اللحظة- حرية الاختيار بين التدريس باللغة العربية، 
والإنجليزية، تبعًا للمدارس التى يرغبون فى العمل بها؛ ويالتالي فعليهم أن يمتلكوا كفايات التدريس باللغة التى سيدرسون بها.

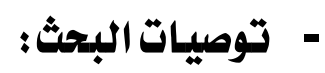
على الرغم من النتائج التى توصل إليها البحث الحالي، فتجدرالإشارة إلى أن مجموعة البحث تضمنت أولئك الذين وافقوا على أن يتدريوا من خلال مدخل (CLIL)؛ ويالتالي فإنه ينبغى التحقق من مدى فعالية مدخل (CLIL) من خلال استخدامه فى تدريب أعداد كبيرة من الطلاب المعلمين، أو توظيفه فى برامج البكالوريوس الخاصة بإعداد معلمى العلوم باللغة الإنجليزية. كما يُوصى ب- الاستفادة من كفايات التدريس الواردة فى هذا البحث كإطار مرجعي يمكن أن يسهم فى تقييم برامج ودورات تدريس العلوم باللغة الإنجليزية المقدمة بكليات التربية فى مصر. - عقد دورات تدريبية لمعلمي العلوم أثناء الخدمة بمدارس اللغات؛ بهدف تدريبهم على لإنى استخدام مدخل (CLIL) فى التدريس. - توزيع جلسات التدريس المصغر المتضمنة فى دورات تدريب معلمى العلوم على التدريس

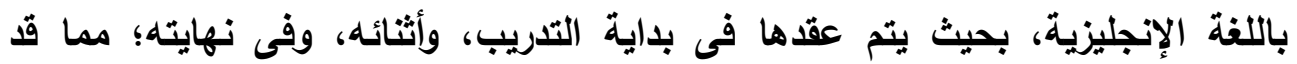
يساعد فى الكثف عن مدى تطور كفايات التدريس لديهم، وتأمل وإدراك المعلمين أنفسهم لهذا التطور.

- استخدام مدخل (CLIL) فى تدريب معلمي الرياضيات على التريس باللغة الإنجليزية. بحوث مقترحة: من خلال ما أسفر عنه البحث الحالي من نتائج، يُوصى بالقيام بالبحوث

التالية:

- فعالية استخدام مدخل (CLIL) فى خفض القلق اللغوى واللدافعية للتدريس بالإنجليزية لاى معلمى العلوم قبل الخدمة. - دراسة مدى تمكن معلمى العلوم أثناء الخدمة بمدارس التعليم الأساسي من تدريس العلوم باللغة الإنجليزية. - دراسة مدى تمكن معلى الكيمياء، والفيزياء، والبيولوجي بالمدارس الثانوية من تدريس تخصصاتهم باللغة الإنجليزية، وعلاقته بالتحصيل العلمى لدى طلابهم. 
- أثر برنامج تدريبي مقترح باستخدام مدخل (CLIL) فى تنمية كفايات تدريس العلوم باللغة

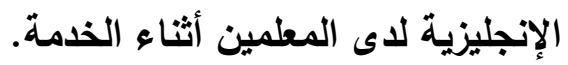

- الكشف عن العلاقة بين كفايات التدريس باللغة الإنجليزية لاى معلى العلوم بمدارس اللغات ودرجة قلق مواصلة دراسة العلوم بالإنجليزية لاى تلاميذ المرحلة الابتدائية والإعدادية. - فعالية تدريس العلوم باستخدام مدخل (CLIL) فى التحصيل وتنمية مهارات اللغة الإنجليزية والاتجاه نحو دراسة العلوم لاى تلاميذ المرحلة الإعدادية. - أثر برنامج تدريبي مقترح باستخدام مدخل (CLIL) فى تنمية كفايات تدريس الرياضيات باللفة الإنجليزية لاى الطلاب المعلمين. 


\section{المراجع}

أولاً : المراجع العربية:

أبو ستة، فريال عبده. (1) (1). فاعلية برنامج تدريبي في تتمية مهارات التدريس الإبداعي وخفض قلق التدريس لدي طلاب كلية التربية في إطار الجودة. دراسات تربوبة ونفسية، كلية التربية، جامعة فئه

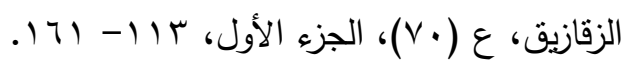

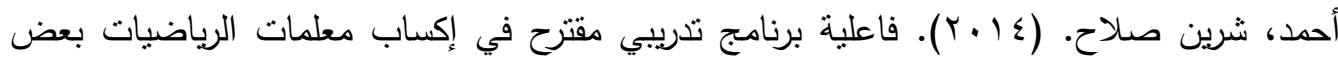

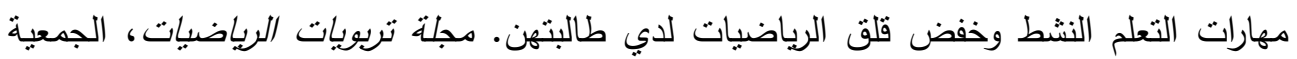

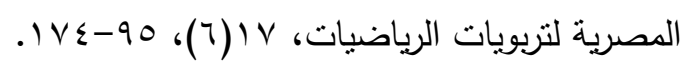

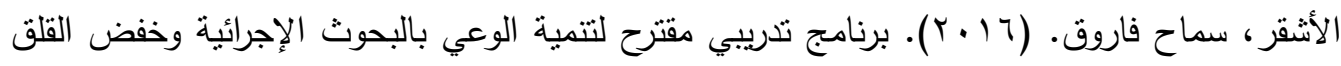

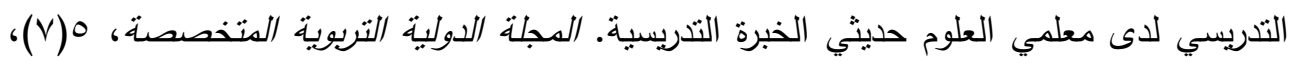
צr-Y

الحريري، رافدة، والوادي، حسن، وعبد الحميد، فاتن. (Y V (Y). أساسيات ومهارات البحث التربوي

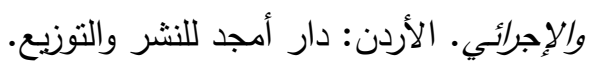
الرفاتي، عبد الرحمن رجب. (10 • r). الذكاء الانفعالي - النظرية والتطبيق في علم النفس الرياضي.

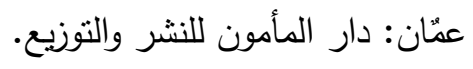

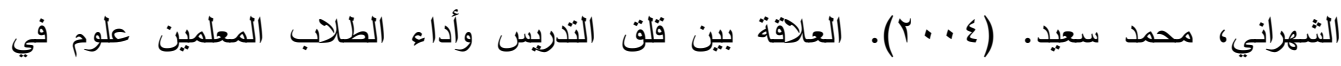

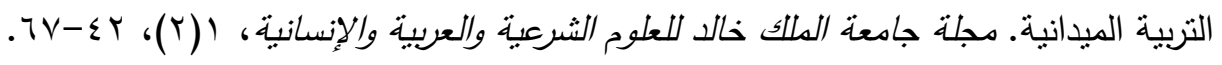

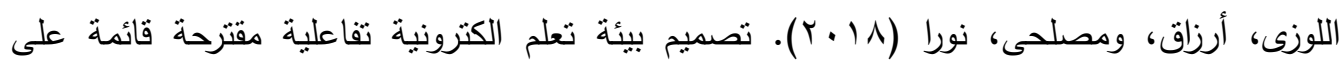
تطبيقات الجيل الثاني للويب وفاعليتها علي التحصيل وتتمية الكفايات المهنية واختزال قلق التدريس لاى الطلاب المعلمين بكلية الاقتصاد المنزلي -جامعة حلوان. المجلة العلدية لكلية التربية النوعية، ولئه

$$
\text { .7r. -00V، ( ( ) ( ) ) }
$$

الهيئة القومية لضمان جودة التعليم والاعتماد. (9 ـ . ب). وثثيقة المستويات الدعيارية لمعلم التعليم قبل الجامعى. جمهورية مصر العربية: وزارة التربية والتعليم.

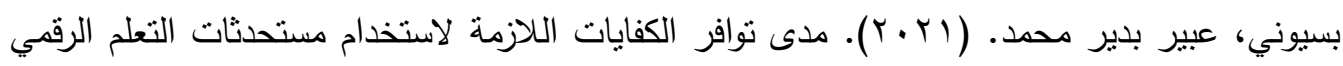

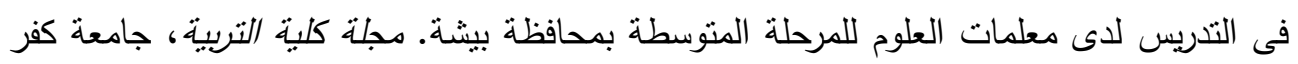

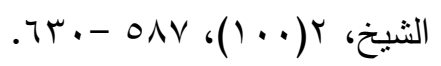




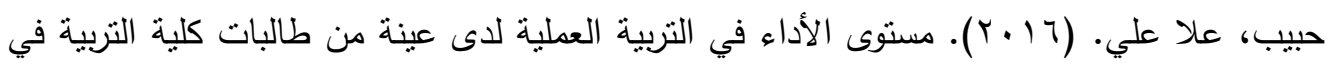

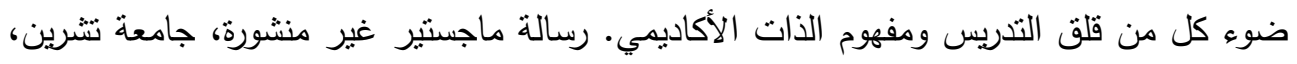

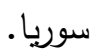

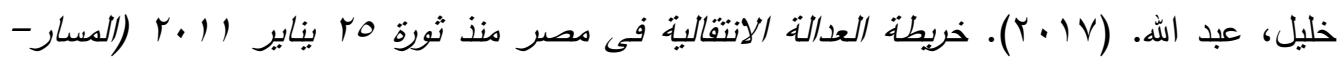
التحديات- السياسات)، القاهرة: دار الكتب المصرية.

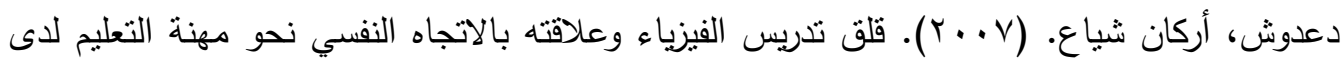
طلبة كليات إعداد المعلمين في غرب ليبيا. رسالة ماجستير غير منشورة، جامعة أم درمان الإسلامية، السودان.

دياب، عانور محمد، الصباطى، وإبراهيم سالم. (10 • ب). الأكسيثيما فى علاقتها بقلق التربية العملية

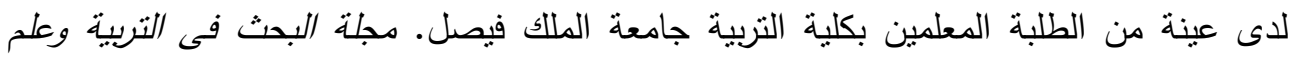

$$
\text { النفس، }
$$

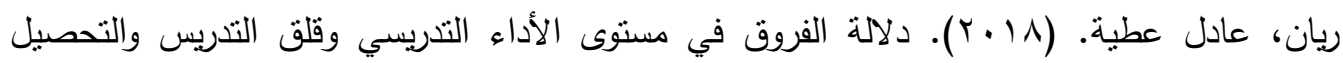

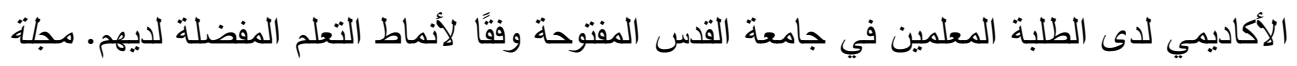

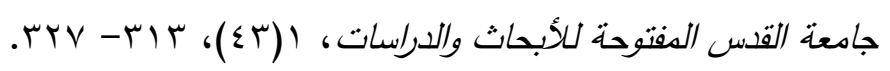

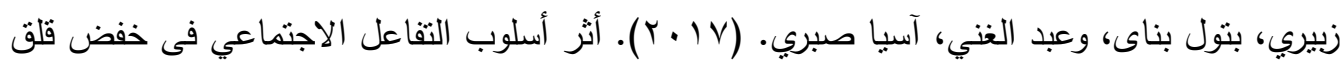

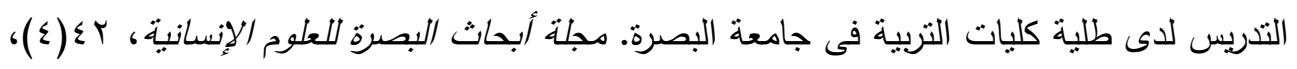

$$
\text { .77- รา }
$$

سنوسي، محمد، و جلون عمر. (Y. V). جودة المعلمبي: دراسة دولية حول كفايات الدعلمين

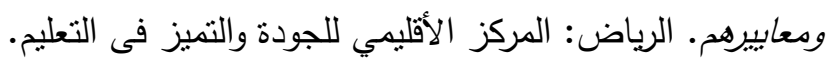

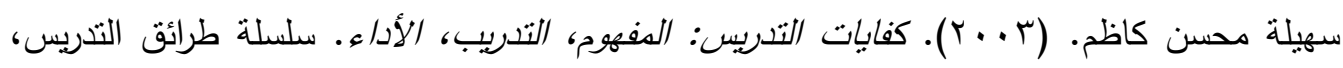
الكتاب الأول، عمان: دار الشرق.

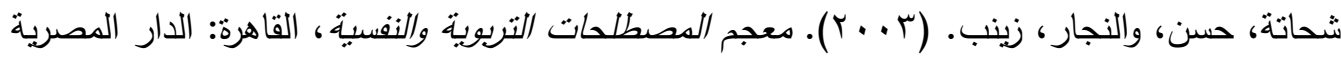
اللبنانية. طاشمان، غازى، والمستريحي، حسين. (19 • (Y). التربية العملية كانت مصدرًا لقلق الطلاب المعلمين.

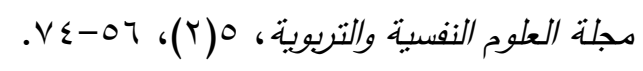

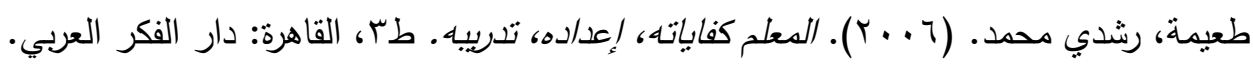


على، مصطفى على خلف. (Y V V V). تأثير التربية العملية في خفض قلق التدريس وتحسين

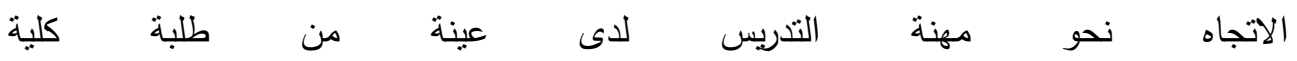

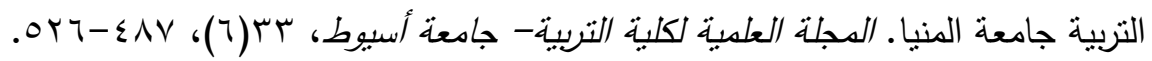

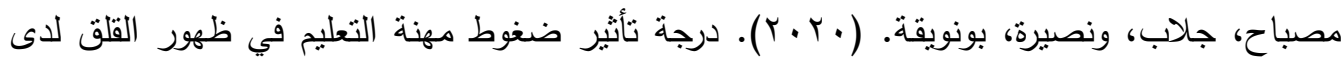

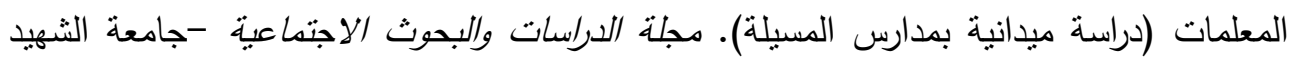

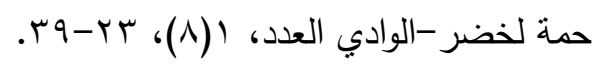
ثانيا : المراجع الأجنبية :

Abdunazarovna, T. M. (2021). Formation of students' communicative competencies based on the integration of foreign languages and natural science. European Scholar Journal, 2(1), 53-55.

Ahmed, S. T. S. \& Pawar, S. V. (2018). Communicative competence in English as a foreign language: Its meaning and the pedagogical considerations for its development. The Creative Launcher, 2(6), 301-312.

Aiello, J. Di Martino, E. and Di Sabato, B. (2017). Preparing teachers in Italy for CLIL: reflections on assessment, language proficiency and willingness to communicate. International Journal of Bilingual Education and Bilingualism, 20:1, 69-8.

Alcaraz-Mármol, G. (2018). Trained and non-trained language teachers on CLIL method-ology: Teachers' facts and opinions about the CLIL approach in the primary education context in Spain. Latin American Journal of Content and Language Integrated Learning, 11(1):39-64.

Alexandra Vraciu, A. \& Tomàs, Y. C. (2018). Focus on Form in ContentBased Instruction: Practical ideas for raising language awareness in primary school arts and crafts CLIL. E-TEALS: An E-journal of Teacher Education and Applied Language Studies, 9, 41-56.

Ali, M. (2015). Effect of Science Anxiety (SA) and Modern Strategies to Combat SA in Grade 4 to 8 Teachers as well as Students. Unpublished M.Ed., Ontario Institute for Studies in Education of the University of Toronto, Canada.

Alrabai, F. (2015). The influence of teachers' anxiety-reducing strategies on learners' foreign language anxiety. Innovation in Language Learning and Teaching, 9(2), 163-190.

Alshammari, K. A. (2015). The influence of management support, computer anxiety and enjoyment on science teachers' perception of the use of digital technologies in Hail primary schools: A survey. Unpublished Ph.D Kulliyyah of Education International Islamic University, Malaysia. 
Álvarez-Gil, F.J. (2021). Essential framework for planning CLIL lessons and teachers' attitudes toward the methodology. In: Carrió-Pastor M.L., Bellés Fortuño B. (eds.). Teaching Language and Content in Multicultural and Multilingual Classrooms, Palgrave Macmillan, Cham.

Amalia, L., \& Saraswati, T. (2018). The impact of competencies toward teacher's performance moderated by the certification in Indonesia. $K n E$ Social Sciences, 3(10), 86-98.

An, J., Macaro, E. \& Childs, A. (2019). Language focused episodes by monolingual teachers in English medium instruction science lessons. Journal of Immersion and Content-Based Language Education, 7(2), 166191.

Anggiarima, P. (2019). Teaching science using English done by primary school teachers in Malang. Journal of Culture, English, Teaching, Literature and Linguistics, 6(1), 51- 57.

Balang, N., Mahamod, Z. \& Buang, N. (2019). Blended Coaching and Coaching Curve Approaches in Enhancing Teaching Competency: A case study. Creative Education, 10(12), 2718-2729.

Banegas, D. L. \& Beamud, M. P. (2020). Content and language integrated learning: A duoethnographic study about clil pre-service teacher education in Argentina and Spain. RELC Journal, 51(1), 1- 14.

Banegas, D. L. (2019). Teacher professional development in language-driven CLIL: A case study. Latin American Journal of Content and Language Integrated Learning, 12(2), 242-64.

Bin Yahaya, M. F., Noor, M. A. B. M., Bin Mokhtar, B. Z., Rawian, R. B. M. \& Othman, M. B. (2009). Teaching of mathematics and science in English: the teachers' voices. English Language Teaching, 2(2), 141-147.

Botes, E., Dewaele, J. \& Greiff, S. (2020). The foreign language classroom anxiety scale and academic achievement: An overview of the prevailing literature and a Meta-Analysis. Journal for the Psychology of Language Learning, 2(1), 26-56.

Bravo, M. A., Mosqueda, E., \& Solís, J. L. (2015). Developing pre-service teacher expertise in integrating science and diversity education. The American Educational Research Association Annual Meeting in Chicago (21-25 April), IL.

Bürgener, L. \& Barth, M. (2018). Sustainability competencies in teacher education: Making teacher education count in everyday school practice. Journal of Cleaner Production, 174(44), 821-826.

Cañado, M. L. P. (2016). Are teachers ready for CLIL? Evidence from a European study. European Journal of Teacher Education, 39(2): 202-21. 
Cañado, M. L. P. (2018). Innovations and challenges in CLIL teacher training. Theory into Practice, 57(3), 1-10.

Charisma, D. \& Nurmalasari, P. (2020). An investigation of student teachers' anxiety related to the teaching practicum. English Language, Literature, and Teaching, 5(1), 15-20.

Chostelidou, D. \& Griva, E. (2014). Measuring the effect of implementing CLIL in higher education: an experimental research project. Social and Behavioral Sciences, 116, 2169 - 2174.

Chow, B. W., Chiu, H. T., \& Wong, S. W. L. (2018). Anxiety in reading and listening English as a foreign language in Chinese undergraduate students, Language Teaching Research, 22(6), 719-738.

Cinganotto, L. (2019). Debate as a teaching strategy for language learning. Lingue e Linguaggi, 30, 1-3.

Coyle, D., Hood, P. \& Marsh, D. (2010). CLIL: Content and Language Integrated Learning, Cambridge: Cambridge University Press.

Cummins, J. (1986). Empowering Minority Students: A Framework for Intervention, Harvard Educational Review, 56(1), 18-36.

Czerniak, C. M. \& Haney, J. J. (1998). The effect of collaborative concept mapping on elementary preservice teachers' anxiety, efficacy, and achievementin physical science. Journal of Science Teacher Education, 9(4), 303-320.

De Diezmas, E. N. M. (2016). The impact of CLIL on the acquisition of L2 competences and skills in primary education. International Journal of English Studies, 16(2), 81-101.

De Smet, A., Mettewie, L., Galand, B., Hiligsmann, P. \& Van Mensel, L. (2018). Classroom anxiety and enjoyment in CLIL and non-CLIL: Does the target language matter? Studies in Second Language Learning and Teaching, Special issue: Emotions in second language acquisition, 8 (1), 47-71.

Dhull, P. \& Verma, G. (2019). Jigsaw teaching technique for teaching science, International Journal of Research and Analytical Reviews, 6(2), 809-815.

Dillon, A. M., \& Gallagher, K. (2019). The experience of co-teaching for emergent Arabic-English literacy. The Qualitative Report, 24(7), 15561576.

Dourda, K., Bratitsis, T., Griva, E. \& Papadopoulou, P. (2014). Content and language integrated learning through an online game in primary school: A case study. The Electronic Journal of e-Learning, 12(3), 243-258.

Ekşi, G. Y. \& Yakışık, B. Y. (2016). To be anxious or not: student teachers in the practicum. Universal Journal of Educational Research, 4(6), 13321339. 
El Fara, R. \& Rashid, T. A. (2013). Suggested strategies for teaching science in Kurdish universities using English as a medium of instruction. International Journal of Applied and Natural Sciences, 2(1), 39-52.

Erasmus+ (2020). CLIL Lesson: Playing a domino - repeat and intensify facts and vocabulary about water as a resource, available on [http://www.4sustainable.eu/files/Water/Activities/CLIL_Domino.pdf], accessed on $15^{\text {th }}$ Dec. 2020.

Eskey, D. E. (1997). 'Syllabus design in content-based instruction'. In: M. A. Snow \& D. A. Brinton (Eds.) The Content-Based Classroom: Perspectives On Integrating Language And Content (pp. 132-141), White Plains, NY: Longman.

Fernández-Batanero, J.-M., Román-Graván, P., Reyes-Rebollo, M.-M. \& Montenegro-Rueda, M. (2021). Impact of educational stress and anxiety: A literature review. International Journal of Environmental Research and Public Health, 18(548), 1-13.

Fernández-Fontecha, A., O’Halloran, K. L., Wignell, P. \& Tan, S. (2020). Scaffolding CLIL in the science classroom via visual thinking: A systemic functional multimodal approach. Linguistics and Education, 55, 1-10.

Fitzpatrick, T., Morris, S., Clark, T., Mitchell, R., Needs, J., Tanguay, E. \& Tovey, B. (2018). Rapid Evidence Assessment: Effective Second language teaching approaches and methods, Cardiff: Welsh Government, Report number 31/2018. Available at: https://gov.wales/statistics-andresearch/assessment-effective-secondlanguage-teaching-approachesmethods/?lang=en.

Garzón-Díaz, E. (2021). From cultural awareness to scientific citizenship: implementing content and language integrated learning projects to connect environmental science and English in a state school in Colombia. International Journal of Bilingual Education and Bilingualism, 24(2), 242-259.

Genesee, F. \& Hamayan, E. (2016). CLIL in Context, Practical Guidance for Educators, UK: Cambridge University Press.

Ger, U., \& Bahar, M. (2018). Learning a language and studying content in an additional language: Student opinions. International Journal of Educational Methodology, 4(1), 29-35.

Gkonou, C., Daubney, M. \& Dewaele, J. (2017). New Insights into Language Anxiety, Bristol: Blue Ridge Summit.

Gougoulakis, P. (2021). Teachers' professional core competencies pedagogy and educational science in Swedish teacher education. Academia, 22, 72-101.

Graham, K. M., Mathews, S. D., \& Eslami, Z. R. (2020). Using children's literature to teach the 4Cs of CLIL: A systematic review of EFL studies. 
Latin American Journal of Content \& Language Integrated Learning, 13(2), 163-189.

Gulzhahan, B.; Zhanat, B.; Balabek, S.; Zinagul, T. and Zhanar, N. (2013).

Pedagogical Basis of Communicative Competence Formation. ProcediaSocial and Behavioral Sciences, 89, 882-885.

Guo, Q, Tao, J. \& Gao, X. (2019). Language teacher education in system. System, 82(1), 132- 39.

Harper, J. (2020). The teaching of intercultural communicative competence in China: How much help do coursebooks provide? Open Journal of Modern Linguistics, 10(6), 647-664.

Held, G. (2017). Foreign language anxiety and motivation in the CLIL classroom. Unpublished M. Ed thesis, Ca' Foscari University of Venice, Spain.

Hernández, A. C. (2017). The professional development of pre-service teachers in an integrated science and language acquisition curriculum with thirdgrade students. In A.W. Oliveira, M.H. Weinburgh (Eds.), Science Teacher Preparation in Content-Based Second Acquisition, ASTE Series in Science Education (59-77), Switzerland: Springer.

Hicks, D. (2017). Content Language Integrated Learning with Diana Hicks, Innovation, Transnational Opportunities and Cooperation around Europe towards In-service Teacher Training, Cambridge Press, UK.

Hodgin, C. M. (2018). Science teaching anxiety: the impact of beliefs on teacher preferences of instructional strategies. Unpublished Ph.D thesis, The University of Texas at Austin, USA.

Horwitz, E. (2010). Foreign and second language anxiety. Language Teaching, 43(2), 154-167.

Huang, Y. (2020). The effects of elementary students' science learning in CLIL. English Language Teaching, 13(2), 1-15.

Hughes, S.P. \& Madrid, D. (2020). The effects of CLIL on content knowledge in monolingual contexts. Language Learning Journal, 48(1), 48-59.

Isidro, X. S. (2018). Innovations and challenges in CLIL implementation in Europe. Theory into Practice, 57(3), 185-195.

Ismail, M. M. Z., Mansor, A. N., Iksan, Z. \& Nor, M. Y. M. (2018). Influence of principals' instructional leadership on science teaching competency. Creative Education, 9(14), 2234-2244.

Jameau, A. \& Henaff, C. (2018). Content and language integrated learning" teaching in science: A didactic analysis of a case study. Review of Science, Mathematics and ICT Education, 12(2), 21-40.

K., R. and Alamelu, C. (2020). A study of factors affecting and causing speaking anxiety. Procedia Computer Science, 172, 1053-1058. 
Kanwal, A, Akhter, N. \& Kanwal, N. (2017). Mixed method approach to explore Student-teachers'anxietyin relation to their teaching practices at school placement. Merit Research Journal of Education and Review, 5(2), 6-15.

Kao, Y. T. (2020). Understanding and addressing the challenges of teaching an online CLIL course: A teacher education study. International Journal of Bilingual Education and Bilingualism, 23(1), 1-20.

Karabassova, L. (2020). Is top-down CLIL justified? A grounded theory exploration of secondary school science teachers' experiences. International Journal of Bilingual Education and Bilingualism, 23(1), 116.

Keavney, G. \& Sinclair, K. E. (1978). Teacher concerns and teacher anxiety: A neglected topic of classroom research. Review of Educational Research, 48(2), 273-290.

Kim, J.; Kim, E. G \& Kweon, S. (2018). Challenges in implementing Englishmedium instruction: Perspectives of humanities and social sciences professors teaching engineering students. English for Specific Purposes, 51, 111-123.

Komorowska, H. (2018). The World of things: material culture in language teaching and teacher education. In: L .Aronin; M. Hornsby and G. Kiliańska-Przybyło (Eds.) The Material Culture of Multilingualism, Educational Linguistics, vol 36. Cham: Springer.

Kralova, Z. and Tirpakova, A. (2019). Nonnative EFL teachers' speaking anxiety: post-communist country context. SAGE Open, 9(2), 1-13.

Kralova, Z., Skorvagova, E., Tirpakova, A. \& Markechova, D. (2017). Teachers' foreign language pronunciation anxiety through psycho-social training. System, 65,49-60.

Kunanbayeva, S. (2017). Professional foreign-language education: goal-setting as basic competent of linguo-didactic competence. Revista, 38(49), 31.

Lee, O., Quinn, H., \& Valdés, G. (2013). Science and language for English language learners in relation to next generation science standards and with implications for common core state standards for English language arts and mathematics. Educational Researcher, 42(4), 223-233.

Lin, A. M. Y. (2016). Language across the Curriculum and CLIL in Englishas-an-additional Language Contexts: Theory and Practice. Dordrecht: Springer.

Lo, Y. (2020). Professional Development of CLIL Teachers. Cham: Springer.

Lo, Y. Y. \& Lin, A. M. Y. (2019). Teaching, learning and scaffolding in CLIL science classrooms. Journal of Immersion and Content-Based Language Education, 7(2), 151-165. 
Lo, Y. Y., Lui, W. \& Wong, M. (2019). Scaffolding for cognitive and linguistic challenges in CLIL science assessments. Journal of Immersion and Content-Based Language Education, 7(2), 289-314.

Lo, Y.Y., Lin, A.M. Y. \& Cheung, T.C.L. (2018). Supporting English-as-aforeign-language (EFL) Learners' science literacy development in CLIL: A genre-based approach. In K.S Tang \& K. Danielsson (Eds.), Global Developments in Literacy Research for Science Education (79-95), Cham: Springer.

Lopes, A. (2020). Linking content and language-integrated learning (CLIL) and task-based language teaching (TBLT) in an effective way: a methodological proposal. ONOMÁZEIN, Journal of Linguistics, Philology and Translation, 6, 5-22.

McDougald, J. (2015). Teachers' attitudes, perceptions and experiences in CLIL: A look at content and language. Colombian Applied Linguistics Journal, 17(1), 25- 41.

Mehisto, P., Marsh, D. \& Frigols, M. J. (2008). Uncovering CLIL, Content and Language Integrated Learning in Bilingual and Multilingual Education, Oxford: Macmillan.

Menon, D. (2020) Influence of the sources of science teaching selfefficacy in preservice elementary teachers' identity development. Journal of Science Teacher Education, 31(4), 460-481.

Merç, A. (2010). Foreign language student teacher anxiety. Unpublished Ph.D. thesis, Anadolu University, Graduate School of Educational Sciences, Turkey.

Merino, J. A., \& Lasagabaster, D. (2018). The effect of content and language integrated learning programmes' intensity on English proficiency: A longitudinal study. International Journal of Applied Linguistics, 28(1), $18-30$.

Molin, F., Cabus, S., Haelermans, C. \& Groot, W. (2019). Toward reducing anxiety and increasing performance in physics education: evidence from a randomized experiment. Research in Science Education, 49(2), 20-38.

Monicka, M. \& Jayachithra, J. (2018). Impact of blended learning in science teaching competency. Journal of Emerging Technologies and Innovative Research, 7(5), 144-146.

Montalto, S.A., Walter; L.; Theodorou, M. and Chrysanthou, M. (2016). The CLIL Guidebook. http://languages.dk/clil4u/\#Guidebook (Accessed on May $2^{\text {nd }} 2020$ ).

Moradkhani, S, Raygan, A. \& Moein, S. (2017). Iranian EFL teachers' reflective practices and self-efficacy: Exploring possible relationships. System, 65, 1-14. 
Morrell P.D., Hood S. \& Mellgren, E. (2019). A first-year middle school science teacher's experiences navigating science content in a Dual Language Immersion Program. Heliyon, 5(10), 1-8.

Mourssi, A. \& Al Kharosi, M. A. S. (2014). The benefits and challenges of implementing content and language integrated learning (CLIL) at the higher college of technology- Sultanate of Oman. International Journal of Language Learning and Applied Linguistics World, 7(4), 272--283.

Muda, N., Ismail, W. R. \& Shahabudin, F. A, (2012). Teaching science and mathematics in English steering mastery in English language amongst sciences students in UKM. Procedia-Social and Behavioral Sciences, 59, 670-677.

Musgrove, M. M. \& Schussler, E. E. (2020). The Ph.D. panic: Examining the relationships among teaching anxiety, teaching self-efficacy, and coping in biology graduate teaching assistants (GTAs). BioRxiv. DOI: https://doi.org/10.1101/2020.02.07.938597.

Navarro-Pablo, M. \& Garcia-Jimenez, E. (2018). Are CLIL students more motivated? An analysis of affective factors and their relation to language attainment. Porta Linguarum: Revista Internacional de Didáctica de Las Lenguas Extranjeras, 29, 71-90.

Ngo, H. Q. T., \& Phan, M. H. (2019). Design of an open platform for multidisciplinary approach in project-based learning of an EPICS class, Electronics, 8(2), 200.

Nikolić, D. (2017). Intelligibility within a Modified CLIL framework. Glottodidactica, An International Journal of Applied Linguistics 44(1), 119-130.

Nitta, R., \& Yamamoto, Y. (2020). Reconceptualizing CLIL from transformative pedagogy perspective: Pilot debate study in English language curriculum. Journal of Foreign Language Education and Research, 1, 47-62.

Novak, E. and Wisdom, S. (2018). Effects of 3D Printing Project-based Learning on preservice elementary teachers' science attitudes, science content knowledge, and anxiety about teaching science. Journal of Science Education and Technology, 27(5), 412 - 432.

Novotná, J., Hadj-Moussová, Z., \& Hofmannová, M. (2001). Teacher training for CLIL-competences of a CLIL teacher. Proceedings SEMT, 1, 122126.

Ohlberger, S., \& Wegner, C. (2019). CLIL modules and their affective impact on students with high English anxiety and low self-efficacy. ApplesJournal of Applied Language Studies, 13(3), 1-15.

Othman, J., Saat, R. M., Senom, F. \& Adli, D. S. H. (2020). Dual language programme: Teachers' beliefs and practices in 
teaching science through English. Journal of Nusantara Studies, 5(1), 255-269.

Otwinowska, A. \& Foryś, M. (2017). They learn the CLIL way, but do they like it? Affectivity and cognition in upper-primary CLIL classes. International Journal of Bilingual Education and Bilingualism, 20(5), 457-480.

Palmer, D. K., Martínez, R. A., Mateus, S. G., \& Henderson, K. (2014). Reframing the debate on language separation: Toward a vision for translanguaging pedagogies in the dual language classroom. The Modern Language Journal, 98(3), 757-772.

Papaja, K. (2013). The role of a teacher in a CLIL classroom, Glottodidactica. An International Journal of Applied Linguistics, 40(1), 147-154.

Papaja, K. (2018). Analyzing types of classroom interaction in CLIL, Glottodidactica. An International Journal of Applied Linguistics, 38(4), 43-52.

Paschalidou, G. (2019). Investigating the impact of content and language integrated learning (CLIL) on EFL oral production: a preliminary research on fluency and quantity. Research Papers in Language Teaching and Learning, 10(1), February, 410-426.

Pawan, F. (2008). Content-area teachers and scaffolded instruction for English language learners, Teaching and Teacher Education, 24(6), 1450-1462.

Pelton, J. A. (2014). Assessing graduate teacher training programs: Can a teaching seminar reduce anxiety and increase confidence? Teaching Sociology, 42(1) 40-49.

Piacentini, V, Simões, A.R, Vieira, R.M. (2019).Teachers' view of language(s) in (CLIL) science education: a case study in Portugal. Problems of Education in the 21st Century, 77(5), 636-649.

Qizi, I., Polatovna, X., Z., Izzatulayevna, A., Z., \& Tursunbayevna, A. A. (2020). Defining communicative competence in teaching a foreign language. Journal of Critical Reviews, 7(5), 278-281.

Rajab, A. (2007). An investigation of the anxiety level of form one and form two science teachers using English as the medium of instruction in the district of Ranau. Unpublished B.Ed. thesis, University of Technology, Malaysian Education Research Repository, Malaysia.

Rajitha, K \& Alamelu, C. (2020). A study of factors affecting and causing speaking anxiety. Procedia Computer Science, 172, 1053-1058.

Ramlawati, A. M. \& Yunus, S. R. (2018). Improving pedagogical competences of prospective science teachers to develop learning materials through jigsaw cooperative model. Journal of Physics: Conference Series, 1028, 012209. 
Rivero, L. R. (2016). Board games as tools to foster a communicative environment in CLIL classrooms, Unpublished M.Ed. thesis, Universidad de Oviedo, Spain.

Rodríguez, R., Blázquez, M., López, B., Castro, M., Cristobal, E. S. \& Martín, S. (2018). Educational games for improving the teaching-learning process of a CLIL subject: Physics and chemistry in secondary education. IEEE Frontiers in Education Conference (FIE) Proceedings, Madrid, Spain, 18.

Rutt, A. A. \& Mumba, F. M. (2020). Developing secondary pre-service science teachers' instructional planning abilities for language- and literacyintegrated science instruction in linguistically diverse classrooms. Journal of Science Teacher Education, 31(8), 841-868.

Samir, A. (2018). Is canceling experimental language schools in Egypt good? [https://www.egypttoday.com/Article/2/49157/Is-canceling-experimentallanguage-schools-in-Egypt-good]. [Accessed on $30^{\text {th }}$ April, 2020].

Sarwer, G. (2019). Secondary school student's academic anxiety and achievement in English. Think India, 22(4), 7289- 7305.

Satılmıs, Y., Yakup, D., Selim, G. \& Aybarsha, I. (2015).Teaching concepts of natural sciences to foreigners through content-based instruction: the adjunct model. English Language Teaching, 8(3), 97-103.

Saviola, F., Pappaianni, E., Monti, A. Grecucci, A., Jovicich, J., and De Pisapia, N. (2020). Trait and state anxiety are mapped differently in the human brain. Scitific Reports, 10(11112), 1-11. [Accessed on Feb. $23^{\text {rd }}$ 2021].

Senler, B. (2016). Pre-service science teachers' self-efficacy: The role of attitude, anxiety and locus of control. Australian Journal of Education, 60(1), 26-41.

Senler, B. (2019). Pre-service science teachers' self-efficacy: The role of attitude, anxiety and locus of control. Australian Journal of Education, 60(1) 26-41.

Sharif, A. M. (2013).Language proficiency and teacher knowledge bases in the teaching of science through English. Unpublished Ph.D. thesis, University of Malaya, Malaysia.

Simons, M., Vanhees C., Smits, T. \& De Putte, K. V. (2019). Remedying foreign language anxiety through CLIL? A mixed-methods study with pupils, teachers and parents. Revista de Lingüística y Lenguas Aplicadas, 14, 153-172.

Smakova, K. \& Paulsrud, B. (2020). Intercultural communicative competence in English language teaching in Kazakhstan. Issues in Educational Research, 30(2), 691-708. 
Soriano, H. A. S. (2017). Student- teachers' characteristics and their anxieties related to practice teaching: basis for practicum enhancement. International Journal of Education and Research, 5(6), 79-92.

Stoddart, T.; Solis, J.; Lyon, E.G.; Tolbert, S. (2017). Preparing pre-service secondary teachers to teach science to English learners: Theory into practice. In In A.W. Oliveira, M.H. Weinburgh (Eds.). Science Teacher Preparation in Content-Based Second Language Acquisition, ASTE Series in Science Education (97-115), Switzerland: Springer.

Su-Bergil, A. (2020). Metacognitive awareness of prospective EFL teachers as predictors for course achievement: Teaching English to young learners. International Online Journal of Education and Teaching, 7(1). 160-175.

Syuhada, N. \& Retnawati, H. (2020). Mathematics teaching anxiety in novice teacher. Journal of Physics: Conf. Ser.1511 012039.

Szyszka, M. (2017). Foreign language anxiety in the context of foreign language oral performance, language and pronunciation learning strategies. In: M. Szyszka (Ed.). Pronunciation Learning Strategies and Language Anxiety, Second Language Learning and Teaching (51-85), Cham: Springer.

Thomas, B. (2006). Composition studies and teaching anxiety: A pilot study of teaching groups and discipline- and program-specific triggers. Uunpublished Ph.D. thesis, Bowling Green University, Kentucky.

Toyama, M. \& Yamazaki, Y. (2021). Classroom interventions and foreign language anxiety: A systematic review with narrative approach, Frontiers in Psychology, 12(614184), 1-15.

Tüfekçi-Can, D. (2018). Foreign language teaching anxiety among pre-service teachers during teaching practicum. International Online Journal of Education and Teaching, 5(3), 579-595.

Turner, M. (2017). The positioning of Japanese in a secondary CLIL science classroom in Australia: Language use and the learning of content. Journal of Immersion and Content-Based Language Education, 7(2), 192-211.

Tytler, R., Prain, V. \& Hannigan, S. (2020). Expanding the languages of science and how they are learnt. Research in Science Education, 1-14.

Valdés-Sánchez, L. \& Espinet, M. (2020). Coteaching in a science-CLIL classroom: changes in discursive interaction as evidence of an English teacher's science-CLIL professional identity development. International Journal of Science Education, 42(14), 2426-2452.

Valeeva, R. A., Baykova O. V. \& Kusainov, A. K. (2016). Foreign language professional communicative competence as a component of the academic science teacher's professional competence. International Journal of Environmental and Science Education, 11(3), 173-183. 
Vázquez, P.V. \& Ellison, M. (2018). Examining teacher roles and competences in Content and Language Integrated Learning (CLIL). Linguarum Arena: Revista de Estudos em Didática de Línguas da Universidade do Porto, 4, $65-78$.

Vilkancienè, L., \& Rozgienè, I. (2017). CLIL teacher competences and attitudes. Sustainable Multilingualism, 11, 196 - 218.

Villalba-Condori, K.O., Adúriz-Bravo, A., Lavonen, J., Wong, L. H. \& Wang, T. H. (2020). Importance of the concept of "competency" in science teacher education: what are the professional competencies for science teachers? In: Villalba-Condori, K., Aduríz-Bravo, A., Lavonen J., Wong L. H. \& Wang T. H. (Eds.) Education and Technology in Sciences. CISETC 2019. Communications in Computer and Information Science (15), vol 1191. Cham: Springer.

Vygotsky, L. (1987). Thought and Language, newly revised, translated, and edited by Alex Kozulin, Cambridge, MA: MIT Press.

Werven, I. M., Coelen, R. J., Jansen, E. P.W.A. \& Hofman, W.H.A. (2021). Global teaching competencies in primary education. Compare, 51(1), 118.

Wolff, D. (2020). The European framework for CLIL teacher education. Synergies Italie, 16, 105-116.

$\mathrm{Xu}$, D. \& Harfitt, G. J. (2019). Teacher language awareness and scaffolded interaction in CLIL science classrooms. Journal of Immersion and Content-Based Language Education, 7(2), 212-232.

Yasmin, T. . ., Nadeem, M. ., Siddique, G. K. ., \& Ali, M. S. Z. . (2020). The effect of teachers' language speaking anxiety on their performance in english. Review of Education, Administration \& LAW, 3(2), 285-291.

Yürük, N. (2020). The predictors of pre-service teachers' anxiety about teaching science. Journal of Baltic Science Education, 10(1), 17-26.

Zheng, Y., Cheng, L. (2018). How does anxiety influence language performance? From the perspectives of foreign language classroom anxiety and cognitive test anxiety. Language Testing in Asia, 8(13),1-19.

Zulkifli, R. M. (2016). Vocational teachers' planning and preparation competencies: What do preservice teachers need to learn? Unpublished Ph.D., The Pennsylvania State University, available from ProQuest Dissertations \& Theses Global. 